\title{
Christliche und muslimische Repräsentationen der Welt. Ein Versuch in transdisziplinärer Mediävistik
}

Kein ernstzunehmender Historiker würde heute noch vom „christlichen Mittelalter“ sprechen. ${ }^{1}$ Denn abgesehen vom schwer messbaren Fortwirken des heidnischen Kosmotheismus auf Lebenspraxis und Denken der Menschen, ${ }^{2}$ hat die Forschung inzwischen herausgearbeitet, wie stark die Juden in ihrer Diaspora und die Muslime von ihren europäischen Randstaaten her das Zeitalter mitbestimmt haben. ${ }^{3}$ Für jeden, der genau hinsah, war schon immer die religiöse Einheit des Mittelalters unter dem Zeichen des Kreuzes eine zu starke Vereinfachung wenn nicht ideologische Täuschung, aber jüngst haben wir gelernt, dass auch Kulturen nie rein vorkommen,

1 Vgl. Borgolte, Michael: „Europa ein christliches Land.“ Religion als Weltstifterin im Mittelalter? In: Zeitschrift für Geschichtswissenschaft 48 (2000), S. 1061-1077. - Der Beitrag wurde, abgesehen vom Öffentlichen Abendvortrag in der Akademie (12.6.2008), am 21.4. auch in meinem Lehrstuhlkolloquium und am 22.5. an der Universität Leipzig gehalten. Selten habe ich so viele Anregungen erhalten wie bei diesen Gelegenheiten; sie lassen sich nicht alle berücksichtigen, ohne eine Monographie über das Thema zu schreiben. Für ihre Hinweise, kritischen Einwände und kreativen Überlegungen, die mich (uns) weiter beschäftigen, danke ich besonders Prof. Dr. Marina Münkler, Prof. Dr. Tanja Michalsky und PD Dr. Jan Rüdiger (alle Humboldt-Universität zu Berlin), Prof. Dr. Enno Bünz, Prof. Dr. Wolfgang Huschner und Prof. Dr. Christian Lübke (alle Universität Leipzig) sowie Prof. Dr. Gudrun Krämer (FU Berlin).

2 Der Begriff „Kosmotheismus“ statt „Polytheismus“ nach Assmann, Jan: Die Mosaische Unterscheidung oder der Preis des Monotheismus. München/Wien 2003, bes. S. 62. Zu Assmann im übrigen kritisch: Borgolte, Michael: Wie Europa seine Vielfalt fand. Über die mittelalterlichen Wurzeln für die Pluralität der Werte. In: Joas, Hans/Wiegandt, Klaus (Hg.), Die kulturellen Werte Europas. Frankfurt am Main 2005, S. 117-163.

3 Vgl. jüngst Borgolte, Michael/Schiel, Juliane: Mediävistik der Zwischenräume - eine Einführung. In: Borgolte, Michael/Schiel, Juliane/Seitz, Annette/Schneidmüller, Bernd (Hg.), Mittelalter im Labor. Die Medävistik testet Wege zu einer transkulturellen Europawissenschaft. (Europa im Mittelalter. Abhandlungen und Beiträge zur historischen Komparatistik, Bd. 10.) Berlin 2008, S. 15-23. 
sondern wegen des ständigen Austauschs des Eigenen mit dem Fremden als hybride Formationen im ständigen Wandel verstanden werden müssen. ${ }^{4}$ Manche beunruhigt, dass mit der einen Kultur des Mittelalters eine sicher geglaubte Identität der Geschichte verlorengegangen ist, andere erkennen in der plurikulturellen Auffassung der Epoche die adäquate Antwort auf Erfahrungen der Gegenwart. ${ }^{5}$ Das Mittelalter als fernen Spiegel unserer eigenen Wirklichkeiten zu nutzen, kann dann bedeuten, es als Zeitalter darzustellen, dem Christentum, Judentum und Islam gemeinsam und auch im Widerstreit ihren Stempel aufgedrückt haben wie kaum etwas anderes. ${ }^{6}$ Versuchsweise konnte auch schon vom „monotheistischen Mittelalter" die Rede sein, um die herrschende religiöse Hinwendung zu dem einen Schöpfergott in drei oder vier Varianten hervorzuheben. ${ }^{7}$ Allerdings führt dieser Ansatz über Europa hinaus. ${ }^{8}$ Denn während sich die drei Religionen auf unserem Kontinent im Mittelalter allgemein durchsetzten, verbreiteten sie sich nach ihren Ursprüngen im östlichen Mittelmeerraum zugleich über die beiden anderen Erdteile. Nur das römische Christentum war seit der Völkerwanderung so gut wie exklusiv europäisch, während schon die griechische Orthodoxie weit nach Asien und sogar nach Afrika hineinreichte. ${ }^{9}$ Im Unterschied zu Europa dominierte im Vorderen Orient der Islam. Vom Atlantik bis zum Indus kann man geradezu von einer monotheistischen Weltzone sprechen, die stets von einem Mit- und Nebeneinander verschiedener Eingottreligionen gekenn-

4 Jüngst Seitz, Annette/Schneidmüller, Bernd: Transkulturelle Mediävistik - ein Schlusswort. In: Mittelalter im Labor (wie Anm. 3), S. 557-566, bes. 564-566.

5 Vgl. zuletzt Groebner, Valentin: Das Mittelalter hört nicht auf. Über historisches Erzählen. München 2008. Dazu Borgolte, Michael, in: Frankfurter Allgemeine vom 12.3.2008, L 20.

6 Borgolte, Michael: Christen, Juden, Muselmanen. Die Erben der Antike und der Aufstieg des Abendlandes 300 bis 1400 n. Chr. (Siedler Geschichte Europas.) München 2006.

7 Vgl. Borgolte, Michael: Der europäische Monotheismus und das Problem kultureller Einheit im Mittelalter. In: Gedenkschrift für Aaron Gurjewitsch (im Druck); zugleich in japanischer Übersetzung im Druck; Ders., Wie Europa seine Vielfalt fand (wie Anm. 2); Ders., Europa im Bann des Mittelalters. Wie Geschichte und Gegenwart unserer Lebenswelt die Perspektiven der Mediävistik verändern. In: Jahrbuch für Europäische Geschichte 6, 2005, S. 117-135; Ders., Die Geburt Europas aus dem Geist der Achsenzeit. In: Csáky, Moritz/Feichtinger, Johannes (Hg.), Europa - geeint durch Werte? Die europäische Wertedebatte auf dem Prüfstand der Geschichte. Bielefeld 2007, S. 45-60; Ders., Auf dem Weg zu einer interkulturellen Mittelalterforschung?, in japanischer Übersetzung im Druck.

8 Vgl. Borgolte, Michael: Über den Tag hinaus. Was nach dem Schwerpunktprogramm kommen könnte (im Druck).

9 Vgl. Hamilton, Bernard: Die christliche Welt des Mittelalters. Der Osten und der Westen. Düsseldorf/Zürich 2004. 
zeichnet war. ${ }^{10}$ Es fragt sich, ob die künftige Mediävistik mit der Formel vom „,monotheistischen Mittelalter" nicht einen Ansatz gewinnen könnte, ihre Epoche über Europa hinaus in der viel beredeten Globalgeschichte zu verankern. ${ }^{11}$

Wie belastbar die These wirklich ist, kann sich allerdings erst nach vielen Untersuchungen über kulturellen Austausch und über religiöse Lebenspraxis im Vergleich erweisen. Recht gut etabliert ist in der Geschichtswissenschaft die Auffassung vom christlich-jüdischen Mittelalter, ${ }^{12}$ vom christlich-muslimischen Mittelalter hat hingegen, sehe ich recht, noch nie jemand gesprochen. Dabei kann es keinen Zweifel geben, dass in der Zeit des sogenannten Mittelalters vor allem Christen und Muslime das Euromediterraneum ${ }^{13}$ zwischen Island und Arabischem Meer geprägt haben. Mit dieser Studie möchte ich testen, welche historischen Einsichten durch einen christlich-

10 Zur Ausbreitung des Islam, bes. im nördlichen Afrika und in Vorderasien, vgl. Krämer, Gudrun: Geschichte des Islam. München 2005, passim; Kettermann, Günter: Atlas zur Geschichte des Islam. Darmstadt 2001, hier bes. S. 26-28, 58-61, 82-84, 86-91; Ruthven, Malise/Nanji, Azim: Historical Atlas of the Islamic World. Oxford 2004, S. 28-33, 40-43, 50f., 76-79, 96f. - Die Abgrenzung der monotheistischen Weltzone durch den Islam einerseits, den Hinduismus und Buddhismus andererseits ist cum grano salis zu nehmen. Mit „Hinduismus“ wird bekanntlich eine Gruppe miteinander verwandter, aber auch verschiedener Religionen bezeichnet; der Sammelbegriff kam erst auf, als die arabischen Muslime 712 n. Chr. ins Industal eindrangen und die „,nicht dem Islam zugehörenden Inder“ so zusammenfassten. Unter den verschiedenen indischen Religionen gibt es neben polytheistischen (z. B. der Vedischen Religion) und vorwiegend dualistischen (Śākismus) Richtungen auch den bis heute sehr bedeutenden monotheistischen Visnuismus: Stietencron, Heinrich von: Art. Hinduismus. In: Theologische Realenzyklopädie, Bd. XV. Berlin/New York 1986, S. 346-355. - Bechert, Heinz: Art. Buddhismus. In: Theologische Realenzyklopädie, Bd. VII. Berlin/New York 1981, S. 317-335.

11 Vgl. jüngst Conrad, Sebastian/Eckert, Andreas/Freitag, Ulrike (Hg.): Globalgeschichte. Theorien, Ansätze, Themen. Frankfurt/New York 2007.

12 Vgl. Cohen, Mark R.: Under Crescent and Cross. The Jews in the Middle Ages. Princeton, N. J. 1994; dt.: Unter Kreuz und Halbmond. Die Juden im Mittelalter. München 2005; Yuval, Israel: Zwei Völker in deinem Leib. Gegenseitige Wahrnehmung von Juden und Christen. (Jüdische Religion, Geschichte und Kultur, Bd. 4.) Göttingen 2007; Haverkamp, Alfred: Juden im Mittelalter. Neue Fragen und Einsichten. In: Informationen für den Geschichts- und Gemeinschaftskundelehrer, Heft 59 (2000), S. 5-23; Ders., Europas Juden im Mittelalter. Zur Einführung. In: Cluse, Christoph (Hg.), Europas Juden im Mittelalter. Beiträge des internationalen Symposiums in Speyer vom 20. bis 25. Oktober 2002. Trier 2004, S. 13-29, hier 13, 19f.. Ähnlich ebd. Abulafia, Anna Sapir: Christen und Juden im hohen Mittelalter. Christliche Judenbilder. S. 33-44, hier 33.

13 Zum „Euromediterraneum“ im oben gemeinten Sinn s. Rüdiger, Jan: Prolog. In: Mittelalter im Labor (wie Anm. 3), S. 305-314, hier 311 u. ö. 
muslimischen Vergleich möglich sind und welche neuen Forschungsfragen sich so erschließen. ${ }^{14}$

Mich interessiert, welche Repräsentationen der Welt Christen und Muslime des Mittelalters im Bild der Karte gefunden haben. ${ }^{15}$ Für eine solche Untersuchung ist die Forschungslage ausgesprochen günstig. Durch die Wiederentdeckung des Raumes in den Kulturwissenschaften ${ }^{16}$ sind Kartographie und Geographie jetzt zu stark beachteten, international gepflegten Forschungsfeldern geworden. Dem Nichtfachmann wird die Breite der Überlieferung durch eine mehrbändige „History of Cartography“ von etwa 1990 erschlossen, ${ }^{17}$ wichtige jüngere Arbeiten erscheinen seit 2001 vor

14 Ähnliche Studien bereits von Borgolte, Michael: Von der Geschichte des Stiftungsrechts zur Geschichte der Stiftungen. In: Hans Liermann, Handbuch des Stiftungsrechts. Unveränderter Nachdruck der ersten Auflage 1963, hrsg. v. Axel Frhr. von Campenhausen/ Christoph Mecking, Tübingen 2002, S. 13*-69*; Ders., Kulturelle Einheit und religiöse Differenz. Zur Verbreitung der Polygynie im mittelalterlichen Europa. In: Zeitschrift für Historische Forschung 31 (2004), S. 1-36; Ders., Universität und Intellektueller - Erfindungen des Mittelalters unter dem Einfluß des Islam? In: Jahrbuch für Universitätsgeschichte 11, 2008, S. 91-109; Ders., Christen und Juden im Disput. Mittelalterliche Religionsgespräche im ,spatial turn“. In: Historische Zeitschrift 286 (2008), S. 359-402.

15 Zur neueren Erforschung von „Repräsentation“, besonders unter dem Aspekt der Kartographie, vgl. jüngst Michalsky, Tanja: Medien der Beschreibung. Zum Verhältnis von Kartographie, Topographie und Landschaftsmalerei in der Frühen Neuzeit. In: Glauser, Jürg/Kiening, Christian (Hg.), Text - Bild - Karte. Kartographien der Vormoderne. Freiburg 2007, S. 319-349; Baumgärtner, Ingrid: Die Welt im kartographischen Blick. Zur Veränderbarkeit mittelalterlicher Weltkarten am Beispiel der Beatustradition vom 10. bis 13. Jahrhundert. In: Ehbrecht, Wilfried/Lampen, Angelika/Post, Franz-Joseph/Siekmann, Mechthild (Hg.), Der weite Blick des Historikers. Einsichten in Kultur-, Landes- und Stadtgeschichte. Peter Johanek zum 65. Geburtstag. Köln/Weimar/Wien 2002, S. 527-549. S. a. die Reihe „Terrarum Orbis“ mit dem signifikanten Untertitel (wie unten Anm. 18).

16 Guter Überblick zum ,spatial turn“ jetzt bei Bachmann-Medick, Doris: Cultural Turns. Neuorientierungen in den Kulturwissenschaften. Reinbek bei Hamburg 2006, S. 284-328. Ferner jüngst: Dünne, Jörg/Günzel, Stephan: (Hg.): Raumtheorie. Grundlagentexte aus Philosophie und Kulturwissenschaften. Frankfurt am Main 2006; Schroer, Markus: Räume, Orte, Grenzen. Auf dem Weg zu einer Soziologie des Raums. Frankfurt am Main 2006; Ott, Michaela/Uhl, Elke (Hg.): Denken des Raums in Zeiten der Globalisierung. (Kultur und Technik, Bd. 1.) Münster 2005. Vgl. auch: Gebhardt, Hans/Reuber, Paul/ Wolkersdorfer, Günter (Hg.): Kulturgeographie. Aktuelle Ansätze und Entwicklungen. Heidelberg/Bonn 2003; Schneider, Ute: Die Macht der Karten. Eine Geschichte der Kartographie vom Mittelalter bis heute. Darmstadt ${ }^{2} 2006$.

17 Für das Folgende vgl. die Bände von Harley, J. B./Woodward, David (Eds.): The History of Cartography. Vol. One: Cartography in Prehistoric, Ancient, and Medieval Europe and the Mediterranean. Chicago/London 1987, und Dens. (Eds.): The History of Cartography. 
allem in der monumentalen Reihe „Terrarum Orbis. Histoire des répresentations de l'espace: textes, images“, die Brepols in Belgien verlegt. ${ }^{18}$ Auch die „Karten der christlichen und islamischen Welt“ des Mittelalters sind kürzlich zum ersten Mal miteinander verglichen worden. Die englischen Autorinnen Evelyn Edson und Emilie Savage-Smith sowie die deutsche Mediävistin Anna-Dorothee von den Brincken stellten dabei eindrucksvoll die grundsätzliche christlich-muslimische Übereinstimmung im Kosmos-Denken bis zur kopernikanischen Revolution unter Beweis. ${ }^{19}$ Ihren komparativ-interkulturellen Ansatz haben sie allerdings nicht eingehend begründet und systematisch auf Konvergenzen und Differenzen hin entfaltet. Letztlich bleibt unklar, in welchem Maße die Religionen selbst tatsächlich die Repräsentation der Welt in der Karte bestimmt haben und was das Ergebnis für unsere Auffassung der mittelalterlichen Geschichte bedeuten würde. ${ }^{20}$

Vol. Two, Book One: Cartography in the Traditional Islamic and South Asian Societies. Chicago/London 1992. In der deutschen Mediävistik hat sich in den letzten Jahrzehnten besonders Anna-Dorothee von den Brincken große Verdienste um die historische Kartographie erworben, vgl. zu Beginn: Dies., Mappa mundi und Chronographia. Studien zur imago mundi des abendländischen Mittelalters. In: Deutsches Archiv für Erforschung des Mittelalters 24, 1968, S. 118-186, und jetzt die in gewisser Weise abschließenden Werke: Dies., Fines Terrae. Die Enden der Erde und der vierte Kontinent auf mittelalterlichen Weltkarten. (Monumenta Germaniae Historica. Schriften, Bd. 36.) Hannover 1992; Dies., Studien zur Universalkartographie des Mittelalters, hrsg. v. Thomas Szabó. (Veröffentlichungen des Max-Planck-Instituts für Geschichte, Bd. 229.) Göttingen 2008, S. 683-703.

18 Terrarum Orbis. Histoire des représentations de l'espace: textes, images. History of the Representations of Space in Text and Image. Collection dirigée par General Editor of the Series Patrick Gautier Dalché. Vol. 1: Westrem, Scott D.: The Hereford Map. A Transcription and Translation of the Legends with Commentary. Turnhout 2001; Vol. 2: Bouloux, Nathalie: Culture et savoirs géographiques en Italie au XIV siècle. Turnhout 2002; Vol. 3: Marcotte. Didier (Ed.) : Humanisme et culture géographique à l'époque du Concile de Constance autour de Guillaume Fillastre. Actes du Colloque de l'Université de Reims, 18-19 novembre 1999. Turnhout 2002; Vol. 4: Chekin, Leonid S.: Northern Eurasia in Medieval Cartography. Inventory, Text, Translation, and Commentary. Turnhout 2006; Vol. 5: Falchetta, Piero: Fra Mauro's Map of the World. Turnhout 2006; Vol. 6: Couto, Dejanirah/Bacqué-Grammont, Jean Louis/Taleghani, Mahmoud: Atlas Historique du Golfe Persique (XVI ${ }^{\mathrm{e}}-\mathrm{XVIII}{ }^{\mathrm{e}}$ siècles). Turnhout 2006; Vol. 7: Hoogvliet, Margriet : Pictura et scriptura. Textes, images et herméneutique des mappae mundi (XIII $-\mathrm{XVI}^{\mathrm{e}}$ siècles). Leiden 2007.

19 Edson, Evelyn/Savage-Smith, Emilie/Von den Brincken, Anna-Dorothee: Der mittelalterliche Kosmos. Karten der christlichen und islamischen Welt. Darmstadt 2005.

20 Dazu Borgolte, Michael: Als man sich noch zutraute, das Weltganze zu würdigen. Kosmisch: Bildzeugnisse für alle Aspekte von Himmel und Erde in der christlichen und muslimischen Kultur des Mittelalters. In: Frankfurter Allgemeine vom 16.9.2005, S. 51. 
Wo, wie hier, die Fachleute verschiedener Disziplinen gemeinsam zum selben Thema geforscht haben, bestehen zwar gute Aussichten, über die abweichenden Befunde der Anderen ins Staunen zu geraten, doch wird man dadurch noch nicht klüger. Das könnte erst durch eine Horizontverschmelzung oder eine Integration des Fremden ins eigene Geschichtsbild gelingen; solange Forscherin und Forscher aber nicht den Mut haben, selbst beides zusammenzudenken, erweisen sich die Grenzen der Fächer als abträglich für die Wissenschaft. Natürlich gibt es gute Gründe, nur dort urteilen zu wollen, wo man über die Quellensprachen verfügt, dem Standard der theoretischen Diskurse und methodologischen Anforderungen gerecht wird und die Forschungslage beherrscht. In diesem Sinne ist der Experte durch niemanden zu ersetzen. Unentbehrlich für die Fortentwicklung unserer Wissenschaften ist aber auch der Generalist, der die Schulung in seinem Spezialfach dazu nutzen kann, sich kritisch die Ergebnisse anderer Disziplinen anzueignen, neue Fragen an beide Seiten zu formulieren und überkommene Geschichtsauffassungen für die Bedürfnisse einer anderen Zeit zu erneuern. Wer als einzelner Historiker den interkulturellen Vergleich wagt, befindet sich fast stets in dem Dilemma asymetrischer Fähigkeiten und bleibt für seine Ergebnisse immer auf eine korrigierende Gegenlektüre durch die Nachbarn angewiesen. Trotzdem ist historische Komparatistik besonders dann kreativ, wenn sie in einer Hand liegt.

Die Überlieferung von Karten reicht im westlichen Europa ebenso wie in islamisch geprägten Gesellschaften ins achte Jahrhundert nach Christus zurück; ältere Produkte sind hier wie dort zu erschließen. ${ }^{21}$ In situ erhalten blieb zuerst die um 711 datierte Himmelskarte im Gewölbe des Palastes von Quşayr 'Amra in der syrischen Wüste, ${ }^{22}$

21 So soll der Gouverneur des Kalifats in den Jahren 702 und 707 christlicher Zeitrechnung Karten der Provinz Daylam südlich des Kaspischen Meeres und der Stadt Buchara in Transoxanien zu militärischen Zwecken haben anfertigen lassen: Tibbetts, Gerald R.: The Beginnings of a Cartographic Tradition. In: The History of Cartography II.1 (wie Anm. 17), S. 90-107, hier 90.

22 Savage-Smith, Emilie: Celestial Mapping. In: The History of Cartography II.1 (wie Anm. 17), S. 12-70, hier 12-18. Vielleicht hat hierbei das indische Konzept der Erdkuppel Pate gestanden, vgl. Tibbetts, The Beginnings of a Cartographic Tradition (wie Anm. 21), S. 93. - Die ältesten erhaltenen kosmographischen Diagramme in Handschriften der arabischen Welt werden an die Wende zum 11. Jahrhundert datiert, ein Himmelssphären-Diagramm soll aber schon von 873/909 n. Chr. stammen: Karamustafa, Ahmet T.: Cosmographical Diagrams. In: The History of Cartography II.1 (wie Anm. 17), S. 71-89, hier 75. Eigentliche Karten datieren erst aus dem 11. Jahrhundert. Dabei handelt es sich um Regionalkarten zum Werk des al-Khwārazmī in einem Manuskript von $1037 \mathrm{n}$. Chr. (Tibbetts, The Beginnings, S. 105f.), bevor ein halbes Jahrhundert später die Karten der 
bevor gegen Ende des Saeculums die Zeugnisse der lateinischen Welt einsetzen. ${ }^{23}$ Die allermeisten Karten des Mittelalters sind in Codices überliefert. Neben der Schriftkundigkeit setzten sie die Fähigkeit zur Dechiffrierung graphischer Symbole und der Interpretation von Bild und Text im Zusammenhang voraus. ${ }^{24}$ Karten wandten sich also primär an ein gelehrtes Publikum, ihr Weltbild ist eines von und für Eliten. Aller-

Balkhī-Schule einsetzen: Tibbetts, Gerald R.: The Balkhī School of Geographers. In: The History of Cartography II.1 (wie Anm. 17), S. 108-136.

23 Vgl. Harvey, P. D. A.: Medieval Maps: An Introduction. In: The History of Cartography I (wie Anm. 17), S. 283-285; Woodward, David: Medieval Mappaemundi. In: ebd., S. 286370, passim, bes. 359f.; Von den Brincken, Fines Terrae (wie Anm. 17), S. 49, 52 . Die Karte aus Albi (Bibliothèque municipale, 29, fol. 57v) wird in die zweite Hälfte des 8. Jahrhunderts n. Chr. datiert durch Chekin, Northern Eurasia in Medieval Cartography (wie Anm. 18), S. 93-95 ad VII.1 mit Abb. 394, um 730 durch Woodward, Medieval Mappaemundi, S. 360, ins 9. Jahrhundert durch Von den Brincken, Fines Terrae, S. 33 mit Abb. 1. - Das St. Galler Palimpsest (St. Gallen, Stiftsbibliothek, Ms. 237, pag. 1), das gewöhnlich im 8. Jahrhundert eingeordnet wird, befindet sich in einer Handschrift aus zwei Teilen, deren Hände jetzt um 830 datiert werden: Gautier Dalché, Patrick: De la glose à la contemplation. Place et fonction de la carte dans les manuscrits du haut Moyen Age. In: Testo e immagine nell'alto medioevo. Tomo Secondo. (Settimane di studio del centro italiano di studi sull'alto medioevo, T. 41.) Spoleto 1994, S. 693-764, hier 727f.; Chekin, Northern Eurasia in Medieval Cartography, S. 75 ad IV.1.1; Abbildung mit Umzeichnung am besten bei Arentzen, Jörg: Imago Mundi Cartographia. Studien zur Bildlichkeit mittelalterlicher Welt- und Ökumenekarten unter besonderer Berücksichtigung des Zusammenwirkens von Text und Bild. (Münstersche Mittelalter-Schriften, Bd. 53.) München 1984, Tafeln 15/15a. - Nach Chekin, Northern Eurasia in Medieval Cartography, S. 59 ad III.1.1 mit Abb. 362 ist die T-O-Karte aus Madrid, Biblioteca Nacional, Vitr. 14.3, fol. 117v vielleicht älter als die St. Galler Karte. - Zur vatikanischen „Isidorkarte“ (Ms. Vat. Lat. 6018, fol. 64v/65r), die meist um 775 datiert wird, s. Von den Brincken, Fines Terrae, S. 49f. mit Abb. 16; Chekin, Northern Eurasia in Medieval Cartography, S. 126-128 ad X.1 (,probably between 762 and 777“"); Brigitte Englisch, Ordo orbis terrae. Die Weltsicht in den Mappae mundi des frühen und hohen Mittelalters. (Orbis mediaevalis. Vorstellungswelten des Mittelalters, Bd. 3.) Berlin 2002, S. 126ff., $568 \mathrm{ff}$.

24 Hoogvliet, Pictura et Scriptura (wie Anm. 18); Glauser/Kiening (Hg.), Text - Bild Karte (wie Anm. 15); Ruberg, Uwe: Mappae Mundi des Mittelalters im Zusammenwirken von Text und Bild. Mit einem Beitrag zur Verbindung von Antikem und Christlichem in der principium- und finis-Thematik auf der Ebstorfkarte. In: Meier, Christel/Ruberg, Uwe (Hg.), Text und Bild. Aspekte des Zusammenwirkens zweier Künste in Mittelalter und früher Neuzeit. Wiesbaden 1980, S. 550-592; Edson, Evelyn: Mapping Time and Space. How Medieval Mapmakers viewed their World. London 1997; Kliege, Herma: Weltbild und Darstellungspraxis hochmittelalterlicher Weltkarten. Münster 1991; Simek, Rudolf: Erde und Kosmos im Mittelalter. Das Weltbild vor Kolumbus. München 1992. 
dings hatten sie auch didaktische Zwecke und dienten der politischen Propaganda. In Westeuropa wirkte lange die Erinnerung an eine „Weltkarte“ nach, die Kaiser Augustus in einer Säulenhalle aufstellen ließ, um die Bürger Roms zur grenzüberschreitenden Handelstätigkeit und zur Gründung von Kolonien zu animieren. ${ }^{25}$ Zur Repräsentation ihrer Herrschaft haben auch sonst bedeutende Regenten monumentale Weltkarten anfertigen lassen, so der Perserkönig Ardaschir I. und der abbasidische Kalif al-Ma'mūn, ${ }^{26}$ der graecophone Papst Zacharias ${ }^{27}$ und sein jüngerer Zeitgenosse Karl der Große, ${ }^{28}$ der nordafrikanische Fatimide al-'Aziz, der Normanne Roger II.

25 Dilke, O. A. W.: Maps in the Service of the State: Roman Cartography to the End of the Augustan Era. In: The History of Cartography I (wie Anm. 17), S. 201-211, hier 207-209; Edson/Savage-Smith/Von den Brincken, Der mittelalterliche Kosmos (wie Anm. 19), S. 44. Vgl. Dicuili Liber de Mensura Orbis Terrae. Ed. J. J. Tierney. (Scriptores Latini Hiberniae, Vol. VI.) Dublin 1967, S. 44 lib. I.2. - Zur Mensuratio Orbis, die Kaiser Theodosius II. 435 in Auftrag gegeben hatte und die am Hof Karls des Großen bekannt war, neben Tierney, S. 22-24, s. Traube, Ludwig: Zur Chorographie des Augustus. In: Ders., Kleine Schriften. Hrsg. v. Samuel Brandt. (Traube, Ludwig: Vorlesungen und Abhandlungen. Hrsg. v. Franz Boll. Bd. 3.) München 1920, S. 17-20; Dilke, O. A. W.: Cartography in the Byzantine Empire. In: The History of Cartography I (wie Anm. 17), S. 258-275, hier 259.

$26 \mathrm{Zu}$ beiden s. Tibbetts, The Beginnings of a Cartographic Tradition (wie Anm.-21), S. 95 mit Anm. 22.

27 Le Liber Pontificalis. Texte, Introduction et commentaire par Louis Duchesne. Tome premier, Paris 1955, S. 432. Kenntnisse der Kosmographie lässt der Papst aufscheinen, als er sich im Mai 748 in einem Brief an Bischof Bonifatius mit der Antipodenlehre auseinandersetzt, die offenbar Virgil (von Salzburg) vertreten hatte (Die Briefe des heiligen Bonifatius und Lullus, hrsg. v. Michael Tangl. [Monumenta Germaniae Historica, Epistolae Selectae, T. I.] Berlin 1916, S. 178f. Nr. 80). Zur Laterankarte zuletzt Englisch, Ordo orbis terrae (wie Anm. 23), S. 78f.; Kupfer, Marcia: Medieval world maps: embedded images, interpretive frames. In: Word \& Image 10 (1994), S. 262-288, hier 267; Ruberg, Mappae Mundi (wie Anm. 24), S. 561f.; Von den Brincken, Mappa mundi und Chronographia (wie Anm. 17), S. 128f., ND in: Dies., Studien zur Universalkartographie des Mittelalters (wie Anm. 17), S. 17-81, hier 27. Zur Auseinandersetzung mit Virgil: Flint, Valerie I. J.: Monsters and the Antipodes in the Early Middle Ages and Enlightenment. In: Viator 15 (1984), S. 64-80; Woodward, Medieval Mappaemundi (wie Anm. 23), S. 319, sowie Schieffer, Theodor: Winfrid-Bonifatius und die christliche Grundlegung Europas. Freiburg 1954, S. 248 (präzise), und Prinz, Friedrich: Art. Virgil. In: Lexikon des Mittelalters, Bd. VIII. 8. München 1997, Sp. 1711f., hier 1711 (ungenau). Allgemein zu Zacharias jetzt Delogu, Paolo: Art. Zaccaria, santo. In: Enciclopedia dei Papi. T. I. Ed. Massimo Bray. Rom 2000, S. 656-660.

28 Einhardi Vita Karoli Magni, Ed. Georg Waitz (Monumenta Germaniae Historica, Scriptores rerum Germanicarum.) Hannover 1911, S. 40f. cap. 33.- Thegan, Die Taten Kaiser 
von Sizilien ${ }^{29}$ oder der englische König Heinrich III. ${ }^{30}$ Zur Unterrichtung der Schüler sollte im gallischen Autun schon um 264 eine Karte erneuert werden, damit „die Jungen und Mädchen (!) auf den Kolonnaden alle Länder und Meere" sowie die Flussläufe betrachten könnten. ${ }^{31}$ Den Zöglingen des Klosters Reichenau wurde um 821 die Karte der Welt (mappa mundi) auf einem Rotulus präsentiert, ${ }^{32}$ und Theodulf, der westgotische Gelehrte in der Umgebung des großen Karl, wollte durch die

Ludwigs, in: Thegan, Die Taten Kaiser Ludwigs (Gesta Hludowici imperatoris). Astronomus, Das Leben Kaiser Ludwigs. (Vita Hludowici imperatoris.), hrsg. und übers. v. Ernst Tremp. (Monumenta Germaniae Historica, Scriptores rerum Germanicarum, Bd. 64.) Hannover 1995, S. 188-191 cap. 8. - Annales Bertiniani, rec. Georg Waitz. [Monumenta Germaniae Historica, Scriptores rerum Germanicarum.] Hannover 1883, S. 27 ad a. 842). Nach der letztgenannten Quelle handelte es sich um eine Kombination von Welt- und Himmelskarte, so auch Kupfer, Medieval world maps (wie Anm. 27), S. 268 (mit Zitaten der älteren Literatur mit z. T. abweichenden Deutungen, S. 283, Anm. 51f.).

29 Zu al-'Aziz (r. 975-996) s. Tibbetts, The Beginnings of a Cartographic Tradition (wie Anm. 21), S. 95 mit Anm. 22. Zu Roger II. (gest. 1154) und al-Idrīīi: Houben, Hubert: Roger II. von Sizilien. Herrscher zwischen Orient und Okzident. Darmstadt 1997, S. 108113; Ahmad, S. Maqbul: Cartography of al-Sharīf al-Idrīsī. In: The History of Cartography II.1 (wie Anm. 17), S. 156-174; Edson/Savage-Smith/Von den Brincken, Der mittelalterliche Kosmos (wie Anm. 19), S. 93, 98-100, 102 f.

30 Zu Heinrichs III. (gest. 1272) Karte ,in seiner Schatzkammer“ s. Von den Brincken, Anna-Dorothee: Die Klimatenkarte in der Chronik des Johann von Wallingford - ein Werk des Matthaeis Parisiensis? In: Westfalen 51, 1973, S. 47-56, hier 53, ND in: Dies., Studien zur Universalkartographie (wie Anm. 17), S. 137-148, hier 144; Kupfer, Marcia: The Lost Mappamundi at Chalivoy-Milon. In: Speculum 66 (1991), S. 540-571, hier 555, Anm. 26.

31 Dilke, Maps in the Service of the State: Roman Cartography (wie Anm. 25), S. 209.

32 Lehmann, Paul (Hg.): Mittelalterliche Bibliothekskataloge Deutschlands und der Schweiz, Bd. 1: Die Bistümer Konstanz und Chur. München 1918 , S. 240-252, mit dem Zitat des Eintrags S. 248, 5-6: mappa mundi in rotulis II bzw. in der Murbacher Überlieferung in rotulo I; vgl. Lieb, Hans: Zur Herkunft der Tabula Peutingeriana. In: Maurer, Helmut (Hg.), Die Abtei Reichenau. Neue Beiträge zur Geschichte und Kultur des Inselklosters. Sigmaringen 1974, S. 31-33, hier 32; Gautier Dalché, Patrick: La „Descriptio Mappae Mundi“ de Hugues de Saint-Victor. Texte inédit avec introduction et commentaire. Paris 1988, S. 92f., der (93f.) in diesem Zusammenhang die These entwickelt, die Mappae mundi seien überhaupt eine Erfindung der karolingischen Renaissance und als Wandkarten im Schulgebrauch verwendet worden; Kupfer, Medieval world maps (wie Anm. 27), S. 264. - Bereits Cassiodor (gest. um 580) hatte die Mönche seines Klosters Vivarium angehalten, sich zum Verständnis der heiligen Schriften auch mit Geographie zu beschäftigen und Karten zu studieren: Ruberg, Mappae Mundi (wie Anm. 24), S. 550. 
Einzeichnung einer Karte auf dem Tisch seines Speisezimmers den Gästen auch geistige Nahrung bieten. ${ }^{33}$ In einem christologischen Kontext wurden wenig später die Adepten der Abtei Saint-Riquier (Picardie) mit einer Weltkarte konfrontiert, ${ }^{34}$ während die Königstochter Adela von Blois um $1100 \mathrm{ihr}$ Schlafzimmer mit einem Sternenhimmel und einem Fußbodenmosaik der Weltkarte schmückte. ${ }^{35}$ In der Forschung wird vermutet, dass es noch viel mehr Einzelkarten im Überformat gegeben

33 Theodulfi Carmina, in: Poetae Latini Aevi Carolini, Tomus I, rec. Ernestus Dümmler. (Monumenta Germaniae Historica, Poetarum Latinorum Medii Aevi Tomus I.) Berlin 1881, S. 547f., hier bes. 548 v. 49-53. In der Deutung (Tisch) folge ich Brunhölzl, Franz: Geschichte der lateinischen Literatur des Mittelalters, Bd. I: Von Cassiodor bis zum Ausklang der karolingischen Erneuerung. München 1975, S. 297; ob aber auch ein Wandgemälde gemeint sein könnte, zweifelt Schaller, Dieter: Philologische Untersuchungen zu den Gedichten des Theodulph von Orléans. In: Deutsches Archiv für Erforschung des Mittelalters 18, 1962, S. 13-91, hier 82-84, vgl. Von den Brincken, Fines Terrae (wie Anm. 17), S. 58f. Die hier angeschlossene (und auch anderswo vertretene) These, dass die Kopie der Karte in einer Handschrift aus Kloster Ripoll von 1055 erhalten sei (Biblioteca Apostolica Vaticana, Reg. Lat. 123, fol. 143v/144r, s. Von den Brincken, Abb. 18), wird neuerdings in Zweifel gezogen durch Englisch, Ordo orbis terrae (wie Anm. 23), S. 224 239, hier 238.

34 Carmina Centulensia, in: Poetae Latini Aevi Carolini, Tomus III, rec. Ludovicus Traube. (Monumenta Germaniae Historica, Poetarum Latinorum Medii Aevi Tomus III.) Berlin 1886/1896, ND München 1978, S. 265-368, hier 297. Der Dichter Micon lebte um 825853 (ebd., 272) bzw. um 840 (Ruberg, Mappae Mundi [wie Anm. 24], S. 553). Kupfer, Medieval world maps (wie Anm. 27), S. 265, meint, dass es sich um eine Wandkarte gehandelt habe (vgl. oben Anm. 32) und die wiederholten Hinweise auf Christi Leiden (u. a. Carmina Centulensia 296f.) stark dafür sprächen, dass die Karte selbst kreuzförmig gegliedert gewesen sei, also den T-O-Typ repräsentiert habe.

35 Das Gedicht, in dem Balderich, Prior und Abt von Bourgueil (1089-1107, gest. 1130), die gesamte Ausstattung des Schlafgemachs schildert, von der die Wandteppiche mit Szenen der biblischen Geschichte, der trojanischen Sage, der griechischen und römischen Mythologie sowie der Eroberung Englands durch Adelas Vater, König Wilhelm I., berühmt sind (Analogie zum Bildteppich von Bayeux), jetzt in: Baudri de Bourgueil, Poèmes, Tome 2. Texte établi, traduit et commenté par Jean-Yves Tilliette. Paris 2002, S. 1-43 Nr. 134, hier 19-31 vv. 583-948, vgl. S. 180-197; vgl. Kubitschek, Wilhelm: Eine römische Straßenkarte. In: Jahreshefte des Österreichischen Archäologischen Instituts in Wien 5, 1902, S. 20-96, hier 95f.; vgl. Von den Brincken, Mappa mundi und Chronographia (wie Anm. 17), S. 129, ND S. 27. Zum Dichter mit weiterführender Literatur: Vernet, André: Art. Balderich v. Bourgeuil. In: Lexikon des Mittelalters, Bd. I.7. Zürich/München 1980, Sp. 1364f.; zu Adela: Werner, Karl Ferdinand: Art. Adela v. England. In: Lexikon des Mittelalters, Bd. I.1. Zürich/München 1977, Sp. 142. 
habe, ${ }^{36}$ obgleich der erhebliche finanzielle und technische Aufwand gegen eine zu weite Verbreitung des Typs spricht. ${ }^{37}$ In Lateineuropa ist nur ein Exemplar im ganzen erhalten: Die um 1300 datierte Weltkarte der Kathedrale von Hereford an der englisch-walisischen Grenze; sie bildet einen Kreis in einem Pentagon von 159 mal 134 Zentimetern. ${ }^{38}$ Vermutlich zur gleichen Zeit wurde die nur kopial erhaltene, noch monumentalere Weltkarte des Klosters Ebstorf in Niedersachsen angefertigt, die in Höhe und Breite je dreieinhalb Meter maß. ${ }^{39}$

Christliche und muslimische Geographen und Kartographen des Mittelalters schöpften aus der Überlieferung der Antike; sie machten von dieser jedoch einen unterschiedlichen Gebrauch, der von der jeweiligen Religion beeinflusst war. Durch ihre frühe Expansion nach Norden und Osten kamen die islamisierten Araber rasch mit persischer, indischer, chinesischer, syrischer und griechischer Wissenschaft in Berührung. ${ }^{40}$ Um die systematische Übersetzung griechischer (und anderer) Naturwissenschaft und Philosophie zu fördern, richtete Kalif al-Ma 'mūn in Bagdad ein „Haus der Wissenschaft" ein. Dabei konnten die Araber die Schriften des Gelehrten Ptolemaios aus Alexandria über Astronomie, Geographie und Astrologie rezipieren. ${ }^{41}$ Hellenisierte muslimische Wissenschaftler und Philosophen übernahmen die Auffassung eines geozentrischen Universums mit einer meist auf neun begrenzten Anzahl von himmlischen Sphären und einer selbst kugelförmigen, aber nur teilweise bewohnbaren Erde. ${ }^{42}$ Nach ptolemaischem Vorbild wurde in geographischen Diagrammen der bekannte beziehungsweise besiedelte Teil der Erde in sieben Klimazonen ein-

36 Gautier Dalché und Kupfer (je wie Anm. 32); Kupfer, The Lost Mappamundi (wie Anm. 30).

37 Vgl. Kugler, Hartmut (Hg.), Die Ebstorfer Weltkarte. Kommentierte Neuausgabe in zwei Bänden. Bd. II: Untersuchungen und Kommentar. Berlin 2007, S. $25 f$.

38 S. u. Anm. 117. - Zu den Fragmenten aus Cornwall und Vercelli, die in diesen Zusammenhang gehören, s. u. Anm. 116.

39 S. u. Anm. 118.

40 Hierzu und zum Folgenden vgl. Borgolte, Christen, Juden, Muselmanen (wie Anm. 6), S. 544ff.; Hughes, Aaron: Art. Science, Islam and. In: Martin, Richard C. (Ed.), Encyclopedia of Islam and the Muslim World. New York u. a. 2004, S. 611-614, bes. 612f.

41 Karamustafa, Ahmet T.: Introduction to Islamic Maps. In: The History of Cartography II.1 (wie Anm. 17), S. 3-11, hier 4; Savage-Smith, Celestial Mapping (wie Anm. 22), S. 43; Karamustafa, Cosmographical Diagrams (wie Anm. 22), S. 73, 76: Tibbetts, The Beginnings of a Cartographic Tradition (wie Anm. 21), S. 94f., 102 u. ö.; Edson/Savage-Smith/ Von den Brincken, Der mittelalterliche Kosmos (wie Anm. 19), S. 21, 28f., 90f.; Pinto, Karen C.: Cartography and Geography. In: Martin (Ed.), Encyclopedia of Islam and the Muslim World (wie Anm. 40), S. 128-132.

42 Karamustafa, Cosmographical Diagrams (wie Anm. 22), S. 73. 


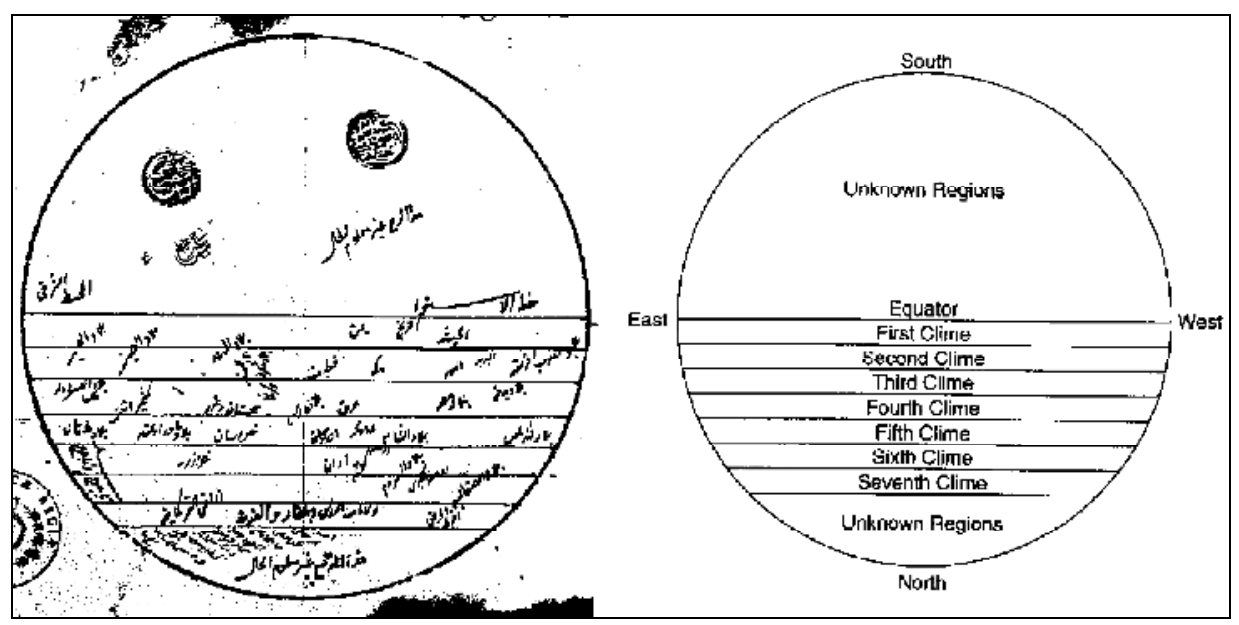

Abbildung 1

Klimata-Karte von 967 n. Chr. (?). Paris, Bibliothèque Nationale, MS Arabe 2214 (Repro nach Harley, J. B./Woodward, David (Eds.): The History of Cartography. Vol. 2, 1: Cartography in the Traditional Islamic and South Asian Societies. Chicago/London 1992, S. 78, Fig. 3.6)

geteilt, die vierte von ihnen oft hervorgehoben, weil sich dort Arabien, das Zentrum der muslimischen Welt, befand (Abb. 1). ${ }^{43}$ Ein anderes, weniger erfolgreiches Weltmodell übernahmen die Muslime von den Persern. Hier stand Iran im Mittelpunkt einer Reihe von sieben Kreisen (,Kishvars“), die Arabien und seine Nachbarn, aber auch China, Indien sowie die Länder der Türken und der Slawen bezeichneten (Abb. 2). ${ }^{44}$ Auch die Gog und Magog wurden repräsentiert, die die Überlieferung der Bibel als Feinde des Gottesvolkes Israel von Norden her sowie als einbrechende Heidenvölker der Endzeit kennt. ${ }^{45}$ Sie werden auch im Koran erwähnt, aber mit Alexander dem Großen in Verbindung gebracht. Nach Sure 18, 94-97 soll der „Zweigehörnte" die unheilstiftenden Gog und Magog durch eine Mauer mit Eisen bis zum Ende der Zeiten ferngehalten haben. ${ }^{46}$

43 Ebd., S. 76.

44 Ebd., S. 77/80. - S. unten Anm. 176.

45 Hossfeld, Frank-Lothar: Art. Gog u. Magog. In: Lexikon für Theologie und Kirche, Bd. 4. Freiburg/Basel/Rom/Wien ${ }^{3} 1995$, Sp. 818f., unter Bezug auf Ez 38f. und Off 20, 8f.

46 Nagel, Tilman: Der Koran. Einführungen - Texte - Erläuterungen. München ${ }^{4} 2002$, S. 65 mit S. 68; vgl. Edson/Savage-Smith/Von den Brincken, Der mittelalterliche Kosmos (wie Anm. 19), S. 48f.; Von den Brincken, Anna-Dorothee: Gog und Magog. In: Heissig. Walther/Müller. Claudius C. (Hg.), Die Mongolen. Innsbruck/Frankfurt am Main 1989, S. 27-29; Lewinstein, Keith: Art. Gog and Magog, In: McAuliffe, Jane Dammen (Ed.), Encyclopedia of the Qur'ān, Vol. 2. Leiden/Boston 2002, S. 331-333. 


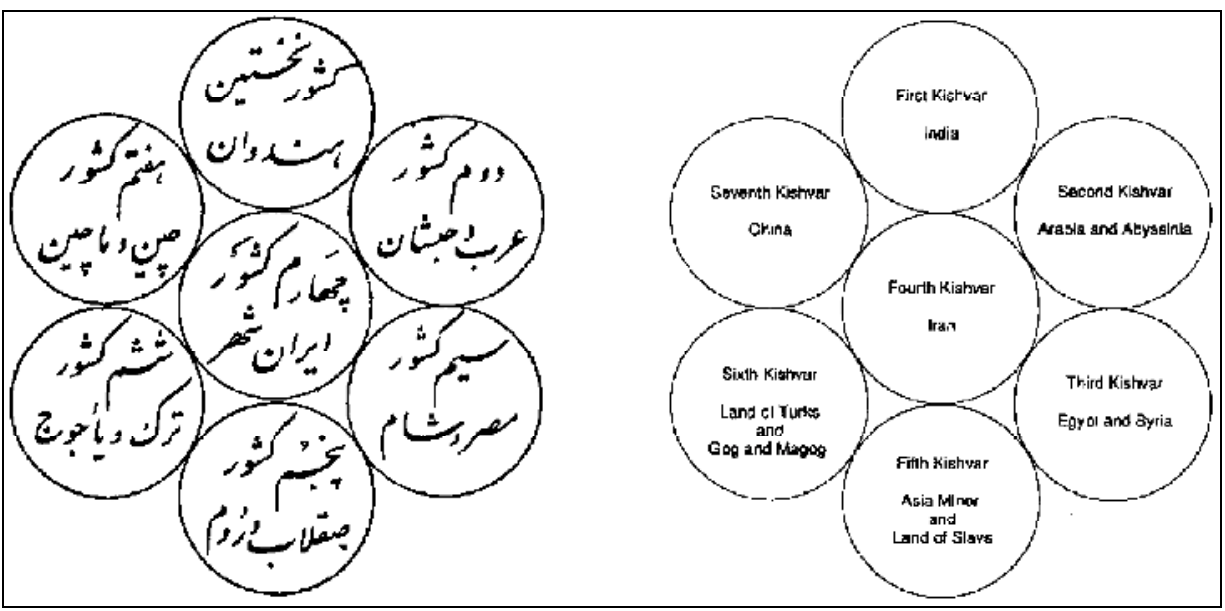

Abbildung 2

Karte der sieben Kishvars nach al-Bīrūnī (gest. 1048 n. Chr.) (Repro nach Harley, J. B./Woodward, David (Eds.): The History of Cartography. Vol. 2, 1: Cartography in the Traditional Islamic and South Asian Societies. Chicago/London 1992, S. 80, Fig. 3.10, Abb. ohne Hs.-nachweis )

Die Karte, die al-Ma'mūn anfertigen ließ, ist nicht erhalten; nach der ältesten Beschreibung soll der Kalif eine Reihe von Gelehrten beauftragt haben, „die Welt zu repräsentieren mit ihren Sphären und Sternen, mit dem Land und den Meeren, den bewohnten und unbewohnten Regionen, den Ansiedlungen der Völker, den Städten und so weiter." ${ }^{47}$ Nichts weist hier und bei den frühen erhaltenen Zeugnissen der Kartographie auf eine religiöse Sinngebung hin. ${ }^{48}$ Andererseits konnten sich die Muslime die Lehren des Alexandriners für astronomische Berechnungen und Himmelskarten nutzbar machen, wenn sie für ihre Rituale den Mondkalender erstellen oder die vorgeschriebenen Gebetszeiten ermitteln wollten. ${ }^{49}$ Die Himmelskarten selbst dokumentierten allerdings nichts als „,wissenschaftliche“ Leistungen ${ }^{50}$; sollte doch

47 Tibbetts, The Beginnings of a Cartographic Tradition (wie Anm. 21), S. 95, mit Zitat des al-Mas'ūdī (gest. 956). Pinto, Cartography and Geography (wie Anm. 41), S. 130, schätzt diese Überlieferung skeptisch ein.

48 Vgl. die generalisierende Aussage von Hughes, Science, Islam (wie Anm. 40), S. 612: „The term Arabic science might be better than Islamic science, because there was nothing particular religious about science (...)."

49 Savage-Smith, Celestial Mapping (wie Anm. 22), S. 12, vgl. ebd. 43, sowie Karamustafa, Cosmographical Diagrams (wie Anm. 22), S. 72.

50 Vgl. zusammenfassend Karamustafa, Cosmographical Diagrams (wie Anm. 22), S. 88f. Vgl. auch Dallal, Ahmad S.: Art. Astronomy. In: Martin (Ed.), Encyclopedia of Islam and the Muslim World (wie Anm. 41), S. 86-88, hier 87; Ders., Art. Astrology. In: ebd., S. 86. 
einmal der Kosmos mit Paradies, Erde und Hölle dargestellt werden, lösten sich die Künstler fast ganz von den Konventionen des Diagramms und der Karte. ${ }^{51}$

Bald nach al-Ma'mūns Tod wurden im Kalifat die freien, rationalistischen Wissenschaften erheblich eingeschränkt. Die „Traditionalisten“ siegten über die „Philosophen“; privilegiert waren seit Mitte des neunten Jahrhunderts die sogenannten ,islamischen Wissenschaften“, die der Kenntnis und dem Verständnis des Korans sowie des Rechts dienten. Die „fremden Wissenschaften“, die auf den Lehren der heidnischen Griechen beruhten, waren zwar nicht verboten, gediehen jedoch nur noch außerhalb der anerkannten Schulen. ${ }^{52}$ Bei allem Misstrauen, das die Koran- und Hadith-Gelehrten den externen Intellektuellen entgegenbrachten, behauptete sich so eine eigene wissenschaftliche Tradition ohne religiöse Überformung.

Von weitreichender Wirkung war die sogenannte Schule des Iraners al-Balkhī (gest. 934), der vor allem in Bagdad beziehungsweise im Irak forschte und lehrte. ${ }^{53}$ In seinem geographischen Werk bemühte er sich „,vor allem um die Repräsentation der Welt durch Karten“. ${ }^{54}$ Zwar ist nichts davon erhalten geblieben, dafür sind aber die Werke seiner Schüler und Enkelschüler seit dem späten elften Jahrhundert überkommen. ${ }^{55}$ Es handelte sich geradezu um einen Satz von über zwanzig Bildern, die auch dazu dienten, die Pilgerwege und Poststationen für die Verwaltung zu veranschaulichen. Die Zeichnungen sind auf bestimmte Regionen beschränkt, die zusammengenommen das ,islamische Reich“ in seiner Ausdehnung während des zehnten Jahrhunderts erfassen. Anderes, wie Andalusien, das kein Teil des abbasidischen Kalifats war, blieb unberücksichtigt. ${ }^{56}$ Man hat vom „Islam-Atlas“ der Balkhī-Schule gesprochen, da der von Ptolemaios herrührende Anspruch aufgegeben war, die ganze bekannte Welt aufzuzeichnen; doch wird damit eher eine politische als eine religiöse Dimension akzentuiert. Eine Ausnahme von der rein saecularen Zwecksetzung machen nur die Pilgerstraßen nach Mekka und Medina (Abb. 3). ${ }^{57} \mathrm{Zu}$ den Kartenwerken der Schule fügte sich stets eine Weltkarte. In der Regel bildet der Ozean einen Kreis um die bewohnte Welt; als Meeresbuchten schieben sich von Osten der Indische

51 Beispiele sind aus osmanischer Zeit nachgewiesen bei Karamustafa, Cosmographical Diagrams (wie Anm. 22), S. 88f. mit Fig. 3.18, sowie im selben Band, Plate 3 („,Topographie“ des Jüngsten Gerichts bzw. Kosmos aus dem „Buch des Gnosis“ des Mystiker Ibrāhīm Haķkıı, gest. 1780), vgl. ebd., S. 85.

52 Neben der Anm. 40 zit. Lit. vgl. Borgolte, Universität und Intellektueller (wie Anm. 14).

53 Hierzu und zum Folgenden: Tibbetts, The Balkhī School of Geographers (wie Anm. 22).

54 Ebd., S. 112, Zitat von al-Muqaddasī (gest. ca. 1000).

55 Ebd., S. 108.

56 Ebd., S. 114.

57 Ebd., S. 118. 


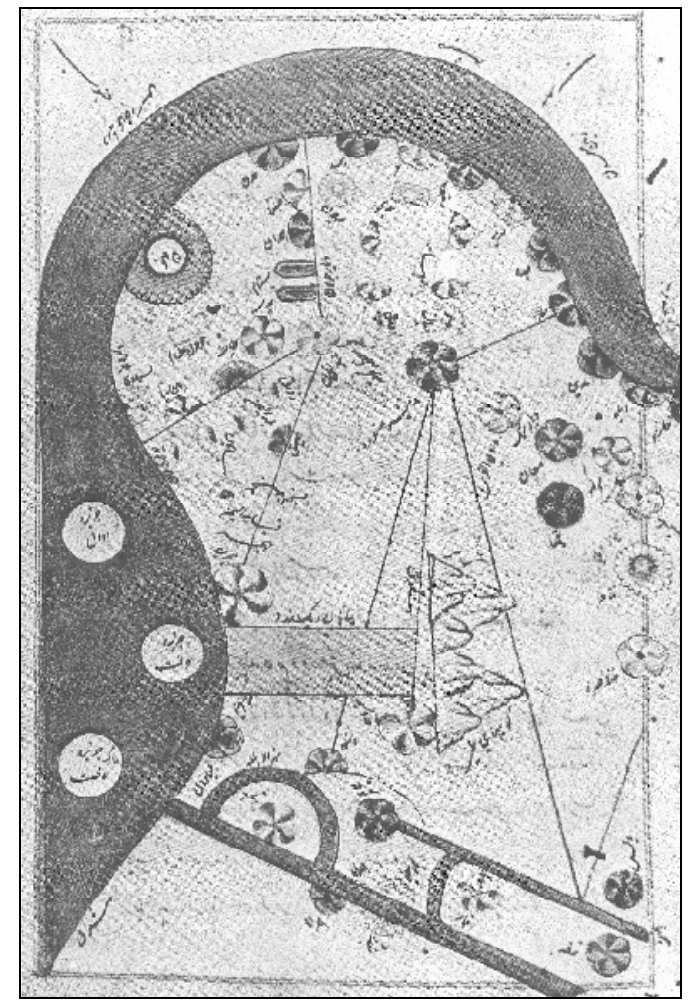

Abbildung 3

Arabienkarte der Balkhï-Schule in der Version des al-Işţakhrī (ca. 930/933 n. Chr.). Leningrader Handschrift MS. C-610, fol. 13a (Repro nach Harley, J. B./Woodward, David (Eds.): The History of Cartography. Vol. 2, 1: Cartography in the Traditional Islamic and South Asian Societies. Chicago/London 1992, S. 118, Fig. 5.8)

Ozean und von Westen das Mittelmeer zwischen die südliche und nördliche Hälfte der Ökumene vor (Abb. 4). ${ }^{58}$

Für die Karten der Balkhî-Schule war die mathematische Lehre des Ptolemaios nicht maßgeblich. ${ }^{59}$ Als jedoch der Normannenkönig Roger II. um 1138 den vielgereisten Maghrebiner al-Sharīf al-Idrīsī mit einer Beschreibung der Welt und der Herstellung einer Erdkarte beauftragte, begnügte er sich nicht mit dem Niveau einer Kartographie ohne rationale Forschung und aktuelle Beobachtung. ${ }^{60}$ Er konsultierte neben der einschlägigen arabischen Literatur die Werke des Ptolemaios und des christlichen Gelehrten Orosius und befragte auf der „Suche nach der Wahrheit“" zahlreiche Gelehrte.

58 Ebd., S. 120-123; Edson/Savage-Smith/Von den Brincken, Der mittelalterliche Kosmos (wie Anm. 19), S. 95-101.

59 Maqbul Ahmad, Cartography of al-Sharīf al-Idrīsī (wie Anm. 29), S. 157.

60 Hierzu und zum Folgenden die Anm. 29 zit. Lit. - Nach Maqbul Ahmad, Cartography of al-Sharīf al-Idrīsī (wie Anm. 29), S. 156, stammte al-Idrīsī aus Ceuta im heutigen Marokko, doch sei dieser nach Houben, Roger II. (wie Anm. 29), S. 108, „möglicherweise auf Sizilien, vielleicht in Mazara“, aufgewachsen. 


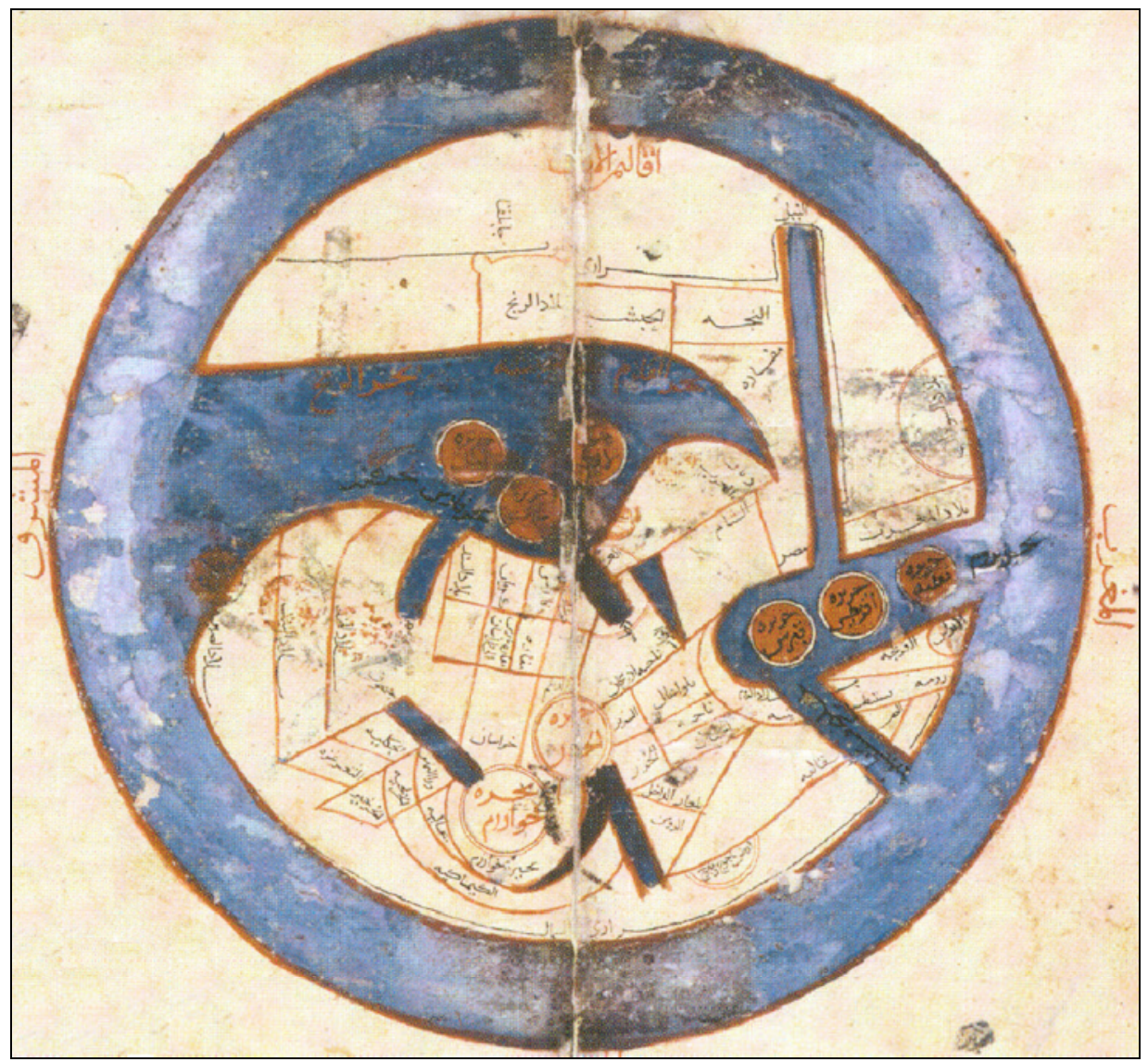

Abbildung 4

Weltkarte der Balkhī-Schule vom Jahr 1297 n. Chr., Oxford, Bodleian Library, MS Ouseley 373, fols. 3b-4a (Repro nach Edson, Evelyn/Savage-Smith, Emilie/Von den Brincken, Anna-Dorothee: Der mittelalterliche Kosmos. Karten der christlichen und islamischen Welt. Darmstadt 2005, S. 96, Abb. 68)

Nach fünfzehn Jahren der Recherche, so berichtet al-Idrīsī, wollte Roger ,erforschen, was die erwähnten Personen über die Längen- und Breitengrade der Itinerare einhellig berichtet hatten. Man brachte ihm die Karte, und er begann, diese Stück für Stück mit Hilfe eines Eisenzirkels nachzuprüfen und bezog sich dabei auf die erwähnten alten Werke. ${ }^{\text {“61 }}$ Der christliche Herrscher ließ in eine Silberplatte die sieben Klimata mit geologischen Formationen und menschlichen Siedlungen eingravieren. Außerdem gab er bei al-Idrīsī ein geographisches Kompendium mit der Beschreibung der Welt in Auftrag, das dieser nach Rogers Tod 1154 vollendete. Eingeteilt in

61 Zitiert nach Houben, Roger II. (wie Anm. 29), S. 109 


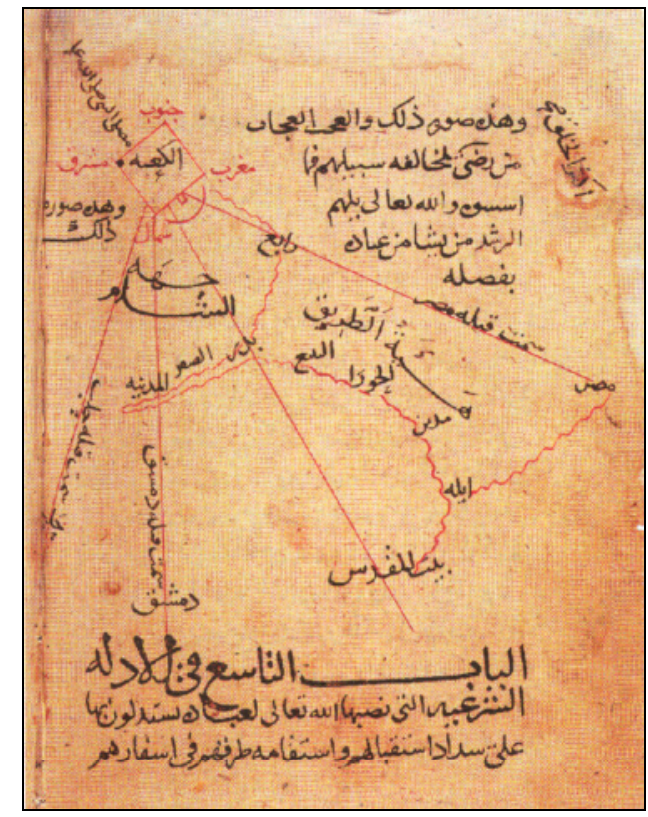

\section{Abbildung 5}

Qibla-Diagramm für [Aleppo], Damaskus, Jerusalem, Kairo von 1196 n. Chr., Oxford, Bodleian Library, MS Marsh 592, fol. 88b (Repro nach Edson, Evelyn/Savage-Smith, Emilie/Von den Brincken, Anna-Dorothee: Der mittelalterliche Kosmos. Karten der christlichen und islamischen Welt. Darmstadt 2005, S. 16, Abb. 9)

die Klimazonen mit jeweils zehn Abschnitten reichen die gut überlieferten Regionalkarten vom ersten Meridian der „Glücklichen Inseln“ (al-Khālidāt) im Westen bis Korea im Osten, sie überschreiten also die Grenzen des Islams und des Christentums gleichermaßen. ${ }^{62}$ Mindestens einigen der Manuskripte ist auch eine Weltkarte nach Art der Balkhī-Schule beigefügt.

Weltkarten und Diagramme aus dem islamischen „Mittelalter“ konnten also zwar in einem religiösen Bedingungsgefüge entstanden sein, repräsentierten selbst aber keine religiöse Weltsicht. Nur wo Karten die Wege nach Mekka (und Medina) zeigen, scheint überhaupt ein religiöser Zweck auf. Bekanntlich verlangt der Koran unter den fünf „Säulen“ des Islam die Pilgerfahrt nach dem „ersten Gotteshaus“ in Mekka: „Die Menschen sind Gott gegenüber verpflichtet, die Wallfahrt nach dem Haus zu machen - soweit sie eine Möglichkeit finden“" (Sure 3, 97). ${ }^{63}$ Zumindest für den Nahen Osten selbst wurden dafür eigene Diagramme erstellt (Abb. 5). ${ }^{64}$ Nach der Ka'ba in Mekka muss sich der Muslim aber auch beim täglichen Gebet ausrichten,

62 Maqbul Ahmad, Cartography of al-Sharīf al-Idrīsī (wie Anm. 29), S. 162f.

63 Vgl. Halm, Heinz: Der Islam. Geschichte und Gegenwart. München ${ }^{4} 2002$, S. 70.

64 Vgl. Edson/Savage-Smith/Von den Brincken, Der mittelalterliche Kosmos (wie Anm. 19), S. 16 Abb. 9f.: Qibla-Diagramm von 1196 aus London, Bodleian Library, MS Marsh 592, fol. $88 \mathrm{v}$, mit Umzeichnung. 
wie es Sure 2, 144 vorschreibt. ${ }^{65}$ Um dieses Gebot erfüllen zu können, war es nötig, von jedem denkbaren Platz aus die qibla, also die Gebetsrichtung nach Mekka, zu ermitteln. ${ }^{66}$ Abgesehen von der Berechnung des Kalenders und der Gebetszeiten ist dies auch der wichtigste Grund für die traditionelle Pflege der Astronomie und Mathematik. Zur Ermittlung der qibla wurden Instrumente entwickelt ${ }^{67}$ und die Berechnungen der Richtungen nach Mekka in Listen zusammengestellt. Die Moscheen sollten in aller Welt nach der Ka'ba orientiert sein; die qibla-Wand mit der Nische (mihrāb) war oft parallel zu einer der vier Seiten des Heiligtums selbst erbaut. ${ }^{68}$ Die „Sakralgeographie" des Islam behauptete einen eigenen Platz neben der mathematischen, auf Ptolemaios zurückgehenden Geographie und Kartographie ${ }^{69}$ und brachte für ihre Zwecke auch qibla-Karten hervor. ${ }^{70}$ Das älteste Schema geht auf das „Buch der Wege und Provinzen“ eines Postmeisters aus dem neunten Jahrhundert zurück. Es schloss sogar schon das geographische Verhältnis von Tibet, China und Manşūra zur Ka'ba mit ein (Abb. 6). ${ }^{71}$ In späteren Jahrhunderten entstanden Diagramme mit zwölf bis zu 72 Kreissektoren, die die Orientierung auf das muslimische Heiligtum aus jeder Richtung der Welt dokumentieren sollten (Abb. 7). ${ }^{72}$ Die qibla-Karten sind

65 Halm, Der Islam (wie Anm. 63), S. 61f.

66 Hierzu und zum Folgenden: King, David A./Lorch, Richard P.: Qibla Charts, Qibla Maps, and Related Instruments. In: The History of Cartography II.1 (wie Anm. 10), S. 189208; King, David A.: Makka: As the Centre of the World. In: Encyclopedia of Islam, Vol. 6. Leiden ${ }^{2} 1991$, S. 180-187.

67 Vgl. jetzt: King, David A.: World-Maps for Finding the Direction and Distance to Mecca. Innovation and Tradition in Islamic Science. (Islamic Philosophy, Theology and Science. Texts and Studies, Vol. XXXVI.) London/Leiden/Boston/Köln 1999. Noch nicht erschienen ist das mehrfach angekündigte Werk desselben Autors: The Sacred Geography of Islam. S. auch unten Anm. 70.

68 King, Makka (wie Anm. 66), S. 186; vgl. Halm, Der Islam (wie Anm. 63), S. $63 \mathrm{f}$.

69 King, Makka (wie Anm. 66), S. 181, 186.

70 Neben der Anm. 66 zit. Lit. vgl. Edson/Savage-Smith/Von den Brincken, Der mittelalterliche Kosmos (wie Anm. 19), S. 93. - Eine Edition der qibla-Karten mit Übersetzung der In- und Beischriften wäre sehr erwünscht. Vgl. King, David A.: The Sacred Geography of Islam. In: Koetsier, T./Bergmans, L. (Eds.), Mathematics and the Divine: A Historical Study. Amsterdam u. a. 2005, S. 161-178, hier $165 f$.

71 King, Makka (wie Anm. 66), S. 183 (mit Fig. 2); Ders./Lorch, Qibla Charts (wie Anm. 66), S. 196 mit Fig. 9.1.

72 Vgl. Ders./Lorch, Qibla Charts (wie Anm. 66), S. 194-197. - The History of Cartography II.1 (wie Anm. 17), Plate 13 = King, World-Maps for Finding the Direction and Distance to Mecca (wie Anm. 67), S. 55: Seeatlas des Tunesiers al-Sharafī von 1551, qibla-Diagramm mit 40 mihrābs (Paris, Bibliothèque Nationale, Arab. 2278, fol. 2v). Vgl. King, World-Maps for Finding the Direction and Distance to Mecca, S. 55: Oxford Bodleian Library, MS Marsh 294, fol. 2v, sowie 103: Abbildung einer modernen qibla-Karte. 

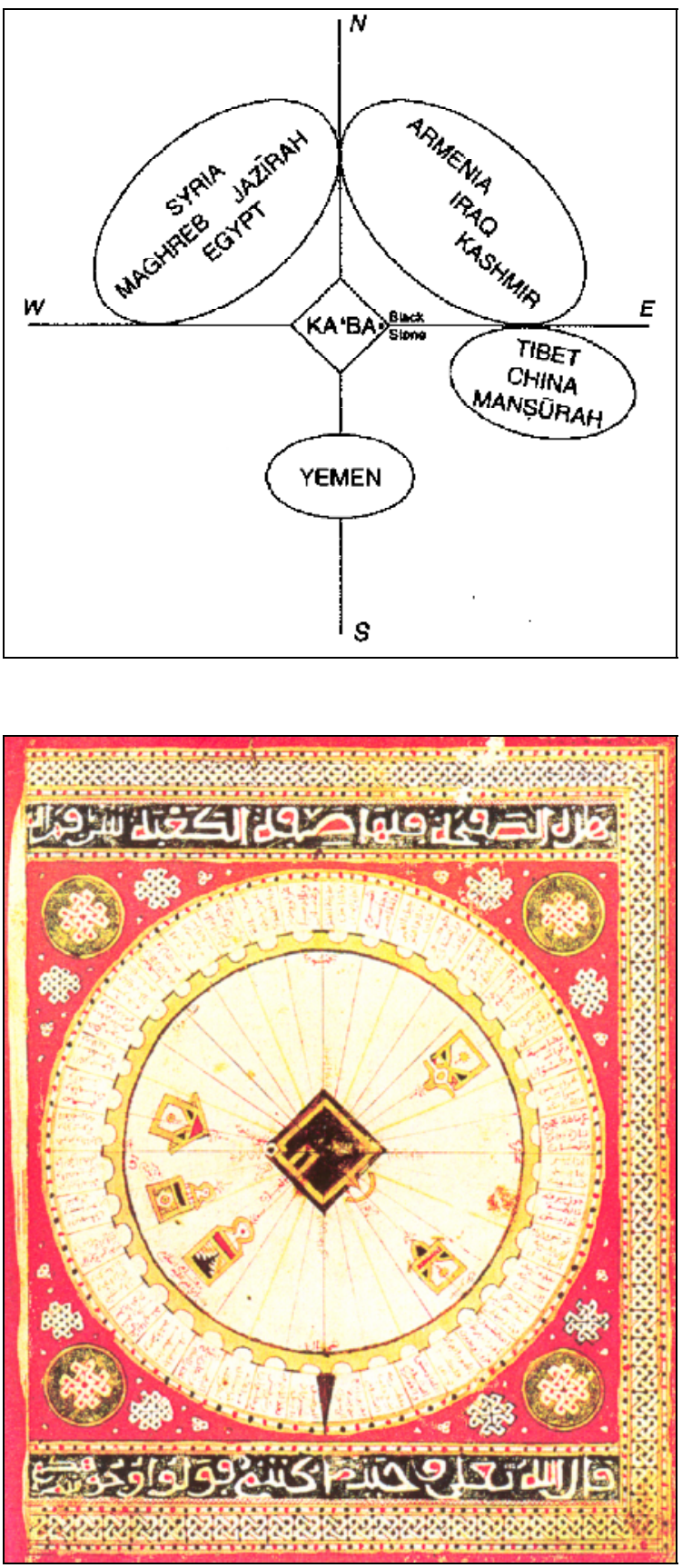

Abbildung 6

Schema der muslimischen Sakralgeographie nach Ibn Khurradbeh, 9. Jh. n. Chr. (Repro nach Harley, J. B./ Woodward, David (Eds.): The History of Cartography. Vol. 2, 1: Cartography in the Traditional Islamic and South Asian Societies. Chicago/London 1992, S. 190, Fig. 9.1)

Abbildung 7

Seeatlas des Tunesiers al-Sharafi von 1551 n. Chr., Qibla-Diagramm mit 40 mihrābs, Paris, Bibliothèque Nationale, Arab. 2278, fol. 2v (Repro nach King, David A.: World-Maps for Finding the Direction and Distance to Mecca. Innovation and Tradition in Islamic Science. (Islamic Philosophy, Theology and Science. Texts and Studies, Vol. XXXVI.) London/Leiden/ Boston/Köln 1999, S. 55) 
der einzige Typ religiöser Weltrepräsentation in der Kartographie der Muslime. Sie hierarchisieren die Welt und fokussieren die Blicke der Menschen auf ein einziges Zentrum.

Ein ganz anderer Befund zeigt sich im Bereich des Christentums. Zum einen fehlen die Himmelskarten hier weitgehend, ${ }^{73}$ Ptolemaios und die Geographie der Griechen blieben im lateinischen Mittelalter nahezu unbekannt. ${ }^{74}$ Bis zum Zeitalter der Portolane ${ }^{75}$ traten ferner die regionalen Karten - wieder im Gegensatz zu den Ländern des Islam - sehr stark hinter den Weltkarten zurück. ${ }^{76}$ Und drittens sind diese von Anfang an religiös geprägt, wenn auch von Zeit zu Zeit und von Ort zu Ort in verschiedener Weise und in verschiedenem Maße. ${ }^{77}$ Die radikalsten Lösungen fand der Kaufmann Kosmas Indikopleustes aus Alexandrien schon in der Mitte des sechsten Jahrhunderts. ${ }^{78}$ Als Nestorianer wollte er die wahre christliche Lehre verbreiten

73 Harvey, Medieval Maps (wie Anm. 23), S. 283.

74 Dilke, O. A. W.: The Culmination of Greek Cartography in Ptolemy. In: The History of Cartography I (wie Anm. 17), S. 177-200, hier 177. Zur Ptolemaios-Rezeption in Byzanz s. Dilke, Cartography in the Byzantine Empire (wie Anm. 25), S. 258, 266-274.

75 Auf diesen am Ende des dreizehnten Jahrhunderts aufkommenden Kartentyp, ,der für die Praxis bestimmt ist und nicht primär Weltbild sein will“, gehe ich in dieser Abhandlung nicht näher ein: Vgl. Edson/Savage-Smith/Von den Brincken, Der mittelalterliche Kosmos (wie Anm. 19), S. 73-76, Zitat 75; Campbell, Tony: Portolan Charts from the Late Thirteenth Century to 1500. In: The History of Cartography I (wie Anm. 17), S. 371-463; Mesenburg, Peter: Portolankarten. Die ,vermessene“ Welt des Mittelalters. In: Horst Wenzel (Hg.), Gutenberg und die Neue Welt. München 1994, S. 59-75.

76 Harvey, Medieval Maps (wie Anm. 23), S. 283; Harvey, P. D. A.: Local and Regional Cartography in Medieval Europe. In: The History of Cartography I (wie Anm. 17), S. 464-501; Edson/Savage-Smith/Von den Brincken, Der mittelalterliche Kosmos (wie Anm. 19), S. 78-88.

77 Ich setze mich hier nicht noch einmal kritisch auseinander mit der Thesenbildung von Englisch, Ordo orbis terrae (wie Anm. 23), passim, die von der Fachwissenmschaft einhellig (und zurecht) verworfen worden ist, vgl.die Besprechungen durch Johannes Fried, in: Historische Zeitschrift 277 (2003), S. 714-719, und Ingrid Baumgärtner, in: Deutsches Archiv für Erforschung des Mittelalters 60 (2004), S. 705-707. Zuletzt so auch Kugler (Hg.), Die Ebstorfer Weltkarte II (wie Anm. 37), S. 28.

78 Cosmas Indicopleustès : Topographie chrétienne. Ed. Wanda Wolska-Conus. (Sources Chrétiennes, 141,159,197.) Paris 1968/1970/1973; The Christian Topography of Cosmas, an Egyptian Monk. Translated from the Greek, and Edited, with Notes and Introduction by J. W. MC Crindle. New York o. J. [1897]. Zum Folgenden bes. Baldwin, Barry/Cutler, Anthony: Art. Kosmas Indikopleustes. In: The Oxford Dictionary of Byzantium, Vol. 2. New York/Oxford 1991, S. 1151f.; Wolska, Wanda: La topographie chrétienne de Cosmas Indicopleustès. Théologie et Science au $\mathrm{VI}^{\mathrm{e}}$ siècle. (Bibliothèque Byzantine, Études 3.) 


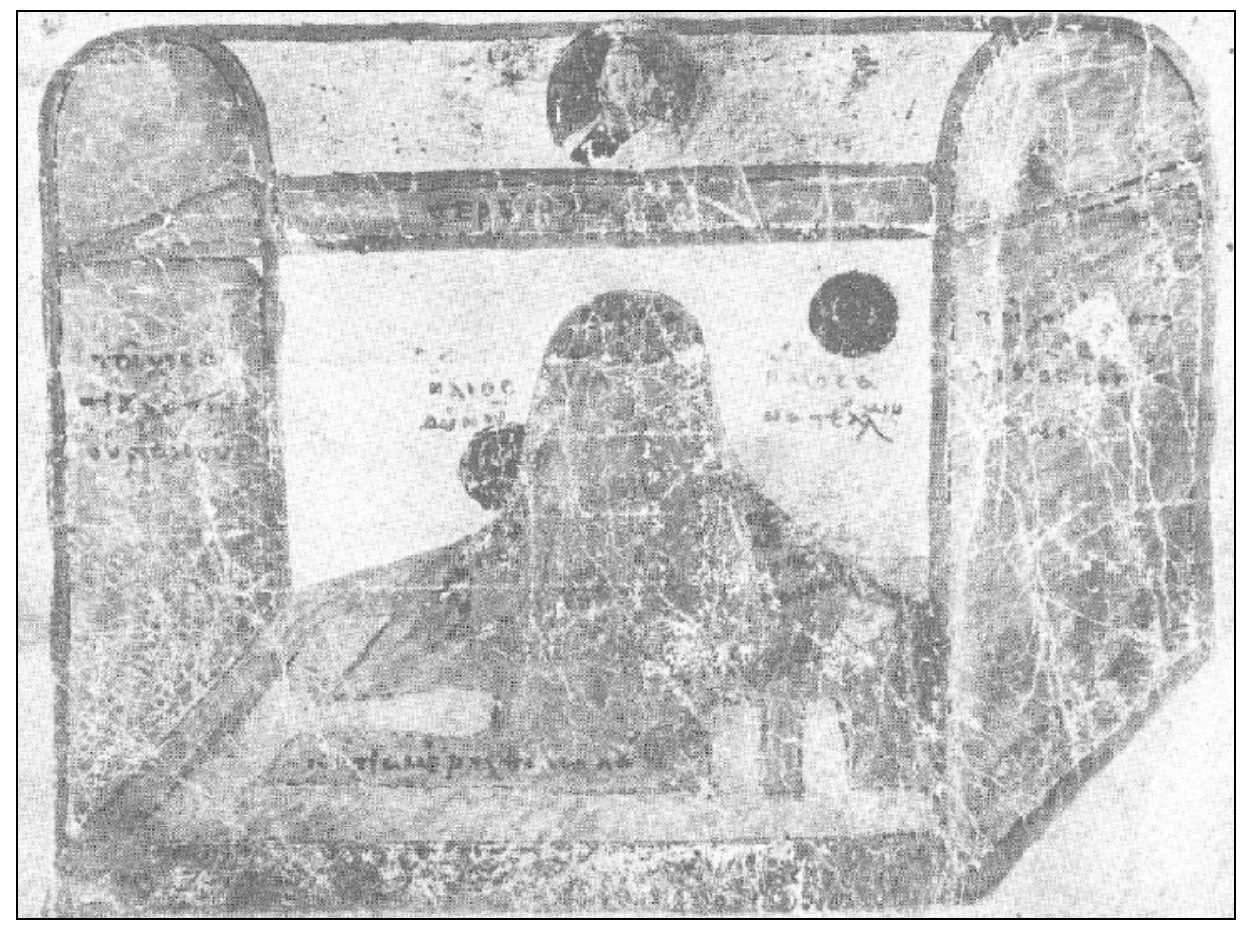

Abbildung 8

Kosmas Indikopleustes, Kosmos als Stiftshütte des Moses, 10./11. Jh. n. Chr., Florenz, Biblioteca Medicea Laurenziana, Plut. 9.28, fol. 95v (Repro nach Harley, J. B./Woodward, David (Eds.): The History of Cartography. Vol. 1: Cartography in Prehistoric, Ancient, and Medieval Europe and the Mediterranean. Chicago/London 1987, S. 262, Fig. 15.1)

und entwickelte eine „umfassende Kosmologie in Übereinstimmung mit der Bibel.““79 Die „Philosophen draußen“, also die Nichtchristen, attackierte Kosmas scharf, weil sie daran glaubten, dass die Welt eine Kugel sei. ${ }^{80}$ Seine Repräsentationen der Welt orientierten sich an der Stiftshütte des Moses gemäß dem Buch Exodus (2 Mose 25). Der Kosmos erhebt sich über einem rechteckigen Grundriss als gewölbte Schachtel, in der sich unten die Menschen und die Engel, im oberen, unsichtbaren Teil aber das Reich Gottes befinden (Abb. 8). Seine rechteckigen Karten folgten dem Vorbild

Paris 1962; Arentzen, Imago Mundi Cartographia (wie Anm. 23), S. 37-45; Chekin, Northern Eurasia in Medieval Cartography (wie Anm. 18), S. 87-91; Dilke, Cartography in the Byzantine Empire (wie Anm. 25), S. 261-263; Markschies, Chrisoph: Antike ohne Ende. Berlin 2008, S. 116-127.

79 Arentzen, Imago Mundi Cartographia (wie Anm. 23), S. 44.

80 Dilke, Cartography in the Byzantine Empire (wie Anm. 25), S. 261; Markschies, Antike ohne Ende (wie Anm. 78), S. 120. 


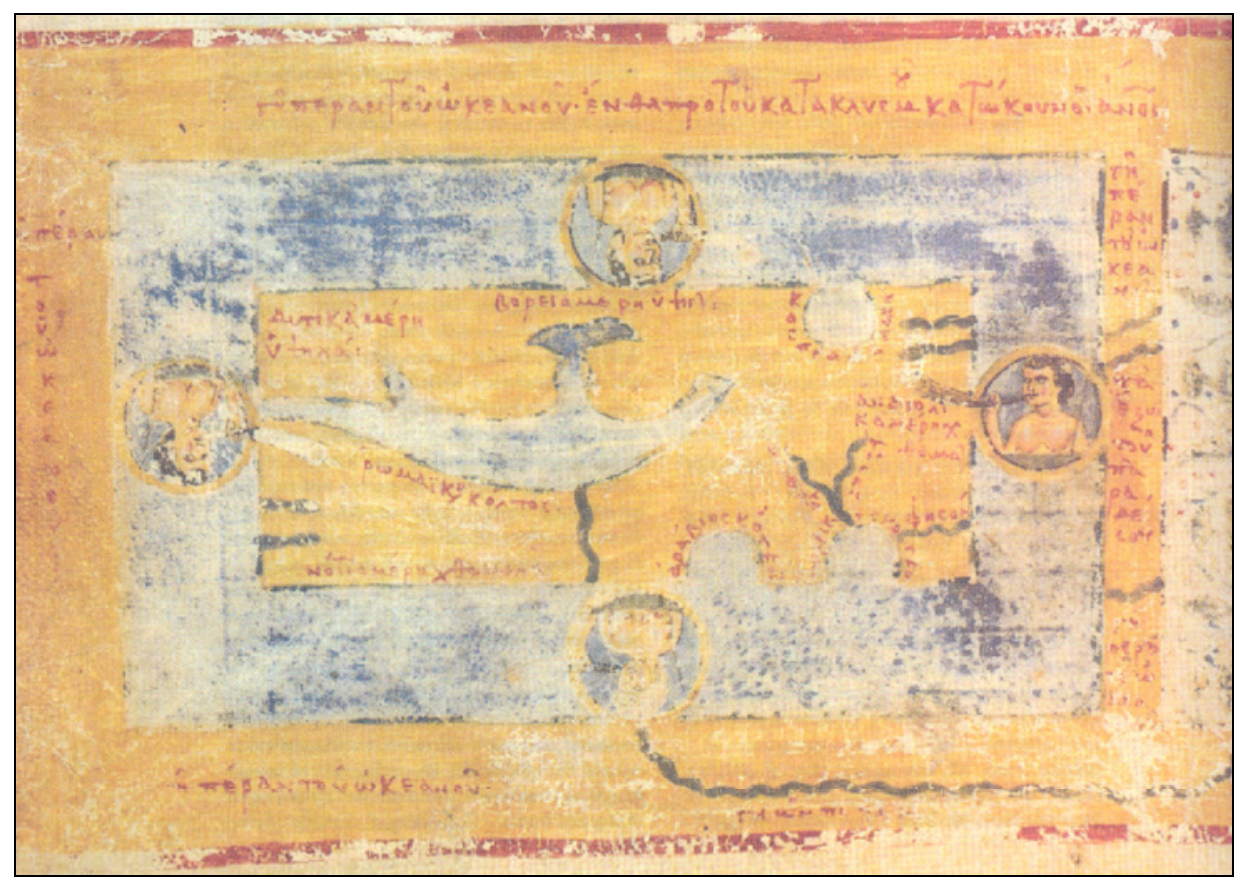

Abbildung 9

Kosmas Indikopleustes, Welt als Rechteck nach dem Vorbild der Schaubbrot-Tische (2 Mose 25,23 und 37,10), 10./11. Jh. n. Chr., Florenz, Biblioteca Medicea Laurenziana, Plut. 9.28, fol. 92v (Repro [Ausschnitt] nach: Terrarum Orbis. Histoire des représentations de l'espace: textes, images. History of the Representations of Space in Text and Image. Collection dirigée par General Editor of the Series Patrick Gautier Dalché. Vol. 4: Chekin, Leonid S.: Northern Eurasia in Medieval Cartography. Inventory, Text, Translation, and Commentary. Turnhout 2006, S. 393, VI.2.2)

der Schaubrot-Tische (2 Mose 25,23 und 37,10); die bewohnte Welt ist hier vom Ozean umgeben, der im Osten die Grenze zum Paradies markiert (Abb. 9). ${ }^{81}$ Das originelle Werk des - angeblichen - „Indienseefahrers“ blieb im Mittelalter zwar nicht unbeachtet, wurde aber nicht nachgeahmt und weiterentwickelt. Die Christenheit in Ost und West hielt im übrigen an der antiken Vorstellung von der Welt als Kugel fest. ${ }^{82}$

81 Aus der Hs. der Biblioteca Apostolica Vaticana, Rom, Vat. Gr. 699, ist fol. 40v abgebildet in Dilke, Cartography in the Byzantine Empire (wie Anm. 25), S. 263 Fig. 15.2, sowie bei Arentzen, Imago Mundi Cartographia (wie Anm. 23), Abb. 1 mit Umzeichnung Abb. 1a, vgl. ebd., S. 352 Nr. 1: 9. Jh.; ferner Chekin, Northern Eurasia in Medieval Cartography (wie Anm. 18), S. 90 zu VI.2.1.

82 Dilke, Cartography in the Byzantine Empire (wie Anm. 25), S. 263; Woodward, Medieval Mappaemundi (wie Anm. 23), bes. S. 318-323; Edson/Savage-Smith/Von den Brincken, 
Im lateinischen Mittelalter sind Weltkarten seit dem achten Jahrhundert kontinuierlich überliefert. ${ }^{83}$ Eine sicher nicht vollständige Erfassung brachte vor einiger Zeit den Nachweis von rund eintausend mappaemundi. ${ }^{84}$ Diese sollten nach dem Sprachgebrauch der Zeit formae, „Abbilder“ oder „Repräsentationen“, der Welt sein. ${ }^{85}$ Unter ihnen dominieren die dreigeteilten Diagramme, die die Ökumene, also die besiedelte Welt, darstellen. ${ }^{86}$ Im orbis terrae tripartitus nimmt Asien im Osten die obere Hälfte eines Kreises ein, während Europa im Norden das linke untere und Afrika im Süden das rechte untere Viertel zugeteilt wird (Abb. 10) ${ }^{87}$ Diese kartographische Ordnung der bewohnten Welt ist vorchristlichen Ursprungs; schon Texte der antiken Autoren Sallust und Lucan mögen von tripartiten Ökumenekarten begleitet worden sein. ${ }^{88}$ Durch Beschreibungen des Kirchenvaters Augustinus, seines Zeitgenossen Orosius und des Bischofs Isidor von Sevilla wurde das Schema zum

Der mittelalterliche Kosmos (wie Anm. 19), S. 58-64; Von den Brincken, Anna-Dorothee: Die Kugelgestalt der Erde in der Kartographie des Mittelalters. In: Archiv für Kulturgeschichte 58, 1976, S. 77-95; ND in: Dies., Studien zur Universalkartographie (wie Anm. 17), S. 186-205.

83 Harvey, Medieval Maps (wie Anm. 23), S. 283.

84 Mappemondes A.D. 1200-1500. Catalogue préparé par la Commission des Cartes Anciennes de l'Union Géographique Internationale. Rédacteur en chef Marcel Destombes. (Monumenta Cartographica Vetustioris Aevi A.D. 1200-1500, Vol. I.) Amsterdam 1964.

85 Ein Eintrag der Ebstorfer Weltkarte lautet: Mappa dicitur forma. Inde mappa mundi id est forma mundi. Kugler, in: Die Ebstorfer Weltkarte, (wie Anm. 37), Bd. I: Atlas, S. 42f. 7 A 2, übersetzt: „Mappa heißt Abbild, daher Mappa mundi soviel wie Abbild der Welt“; Woodward, Medieval Mappaemundi (wie Anm. 23), S. 287: „A map is called a figure, whence a mappa mundi is a figure of the world."

86 Zusammenfassend Edson/Savage-Smith/Von den Brincken, Der mittelalterliche Kosmos (wie Anm. 19), S. 44; Woodward, Medieval Mappaemundi (wie Anm. 23), S. 296 und passim.

87 Vgl. Woodward, Medieval Mappaemundi (wie Anm. 23), S. 346 Fig. 18.52: ApokalypsenKommentar des Beatus von Liébana, Handschrift des 11. Jh. (Paris, Bibliothèque Nationale, MS. Lat. 8878, fol. 7r), Umschrift einer T-O-Karte. Hier ist Asien zugunsten Europas und Libias (Afrikas) verkleinert.

88 Erhalten sind nur mittelalterliche Karten in Sallust- („De Bello Jugurthino“) oder Lucan(,Pharsalia“) Handschriften. Vgl. Chekin, Northern Eurasia in Medieval Cartography (wie Anm. 18), S. 28-31: „T Maps with Lucanian Nomenclature“, S. 33-58: „T Maps with Sallustian Nomenclature“; Ruberg, Mappae Mundi (wie Anm. 24), S. 556f., mit 586 Abb. 1; Arentzen, Imago Mundi Cartographia (wie Anm. 23), bes. S. 96-104 bzw. 104-107 mit Abb. 24, 27, 31-34 bzw. 21. - Die meisten der Lucan- und Sallustkarten sind geostet (Chekin S. 28 und S. 33-58 passim); das haben sie mit denen der westlichen Christenheit gemein (s. Edson/Savage-Smith/Von den Brincken, Der mittelalterliche Kosmos [wie Anm. 19], S. 54f.). Deshalb sollte man vorsichtig mit der Behauptung sein, die 


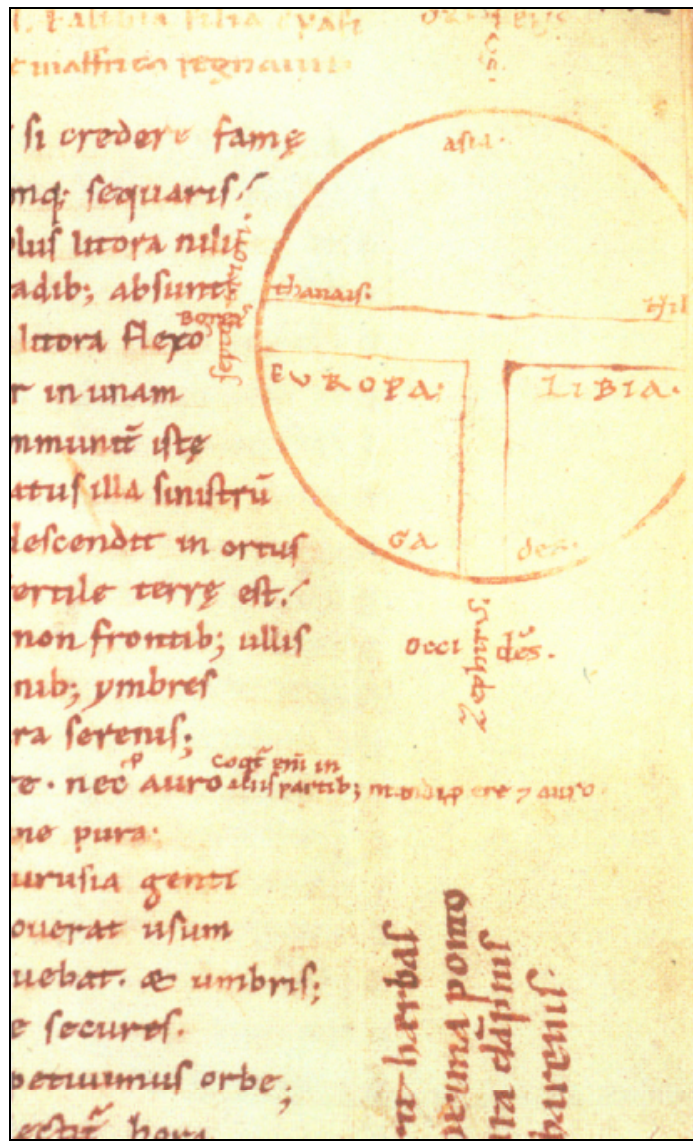

\section{Abbildung 10}

Münchener Lucan-Handschrift, T-O-Karte, 11./12. Jh. n. Chr., München, Bayerische Staatsbibliothek, CLM 14781, fol. 142r (Repro nach Terrarum Orbis. Histoire des représentations de l'espace: textes, images. History of the Representations of Space in Text and Image. Collection dirigée par General Editor of the Series Patrick Gautier Dalché. Vol. 4: Chekin, Leonid S.: Northern Eurasia in Medieval Cartography. Inventory, Text, Translation, and Commentary. Turnhout 2006; S. 328, I.1.4)

festen Wissensbestand des lateinischen Europa ${ }^{89}$ Ein entscheidender Schritt zur Verchristlichung des Kartenbildes wurde offenbar um das Jahr 600 vollzogen, als die Kontinente mit den Namen der Söhne Noahs verbunden wurden, Asien mit Sem, Europa mit Japhet und Afrika mit Cham. ${ }^{90}$ Kartographisch dürften zuerst Isidor

Ostausrichtung sei eine christliche Besonderheit. Die Karten des byzantinischen Gelehrten Kosmas sind genordet (s. oben Anm. 78).

89 Vgl. Arentzen, Imago Mundi Cartographia (wie Anm. 23), bes. S. 107f. (zu Augustinus, De civitate Dei 16,17), S. 46-48 (zu Orosius, Historiarum adversum paganos libri VII, 1,2), S. 108-114 (zu Isidor, Etymologiae 14,2); Von den Brincken, Fines Terrae (wie Anm. 17), S. 28-33, 45-49; Woodward, Medieval Mappaemundi (wie Anm. 23), S. 300-302.

90 Vgl. Borst, Arno: Der Turmbau zu Babel. Geschichte der Meinungen über Ursprung und Vielfalt der Sprachen und Völker. Bd. II.1. Stuttgart 1958. ND München 1995, S. 434f. 
(gest. 636) oder seine Illustratoren die Identifikation vollzogen haben. ${ }^{91}$ Im Mittelalter sind jedenfalls die sogenannten T-O-Karten mit den Noachidenkontinenten viele hunderte Mal überliefert (Abb. 11). ${ }^{92}$

Die bescheiden anmutende Erfindung der biblischen tripartiten Karte kann in ihrer Aussagekraft kaum überschätzt werden. Die Darstellung setzt einerseits durchaus reale räumliche Erfahrungen um, denn sie trennt drei große Landmassen an unterschiedlich dimensionierten und mit Namen bezeichneten Wasserscheiden voneinander, dem Mittelmeer (Afrika/Europa) und den Flüssen Don beziehungsweise Nil (Europa und Afrika/Asien). Im übrigen will sie aber die gesamte bewohnte Welt erfassen. Durch die Verbindung von Ortsnamen (der Kontinente) und Personennamen (der Söhne Noahs) verzeitlicht sie das Kartenbild. ${ }^{93}$ Sie unterstellt beim Betrachter die Kenntnis von Noah, seinem Geschlecht und seiner Geschichte. Nach biblischer Überlieferung hat Gott mit Noah einen Bund geschlossen, der dem Menschengeschlecht das Überleben der Sintflut ermöglichte (Gen 9,25-27); von den drei Söhnen des Erzvaters sollen die (70 oder 72) Völker der Erde abstammen, die in der Genesis (Gen 10) im einzelnen genannt werden. Durch die Namen der Söhne Noahs werden die Kontinente also auf einen gemeinsamen Urvater der Menschheit und die Völker auf jeweils besondere Väter bezogen. Das Ganze der bewohnten Welt ist auch das Ganze der Menschheit und ihrer Geschichte.

Die Noachiden-Karten bieten eine heilsgeschichtliche Botschaft, sie sind also zutiefst religiös. Sie gründen in einem epochalen Wandel des Geschichtsdenkens überhaupt, nämlich Israels Erfindung der Geschichtstheologie. Nach der Genesiserzählung bil-

91 Vgl. Arentzen, Imago Mundi Cartographia (wie Anm. 23), S. 113f.; Von den Brincken, Fines Terrae (wie Anm. 17), S. 48f.

92 Woodward, Medieval Mappaemundi (wie Anm. 23), S. 301f.; Von den Brincken, Fines Terrae (wie Anm. 17), S. 49-54. - Vgl. z. B. die Karte in der Handschrift 236 der Stiftsbibliothek von St. Gallen, pag. 89, aus dem 10. Jh. (Abb. IV.1.7 in Chekin, Northern Eurasia in Medieval Cartography [wie Anm. 18], S. 378, vgl. 77). Sie zeigt unmittelbar vor dem Kapitel De Asia in Isidors Etymologiae $(14,3,1)$ eine Karte, die zu ASIA die Beischrift SEM enthält, zu EUROPA IAFET, zu AFRICA CHAM. Das T ist mit TANAI FLUUIUS, NILUS FLUUIUS und MARE MAGNUM bezeichnet, eingebaut sind aber auch die maiotidischen Sümpfe (MEOTIDES PALUDES). Erläuternd steht daneben: Ecce diuiserunt terram filii Noe post diluuium.Vgl. Chekin S. 354 Abb. zu II.7.2 und Arentzen, Imago Mundi Cartographia (wie Anm. 23), Abb. 28f.

93 Vgl. Von den Brincken, Mappa mundi und Chronographia (wie Anm. 17), S. 119, ND 18: „Weltgeschichte vom Anfang der Zeiten auf eine Kartenfläche gebannt, also ein Geschichtsgemälde, so kann man die mittelalterliche Weltkarte zu verstehen suchen.“- Zum Folgenden Borst, Der Turmbau zu Babel (wie Anm. 90), Bd. I. Stuttgart 1957, ND München 1995, S. 113-128. 


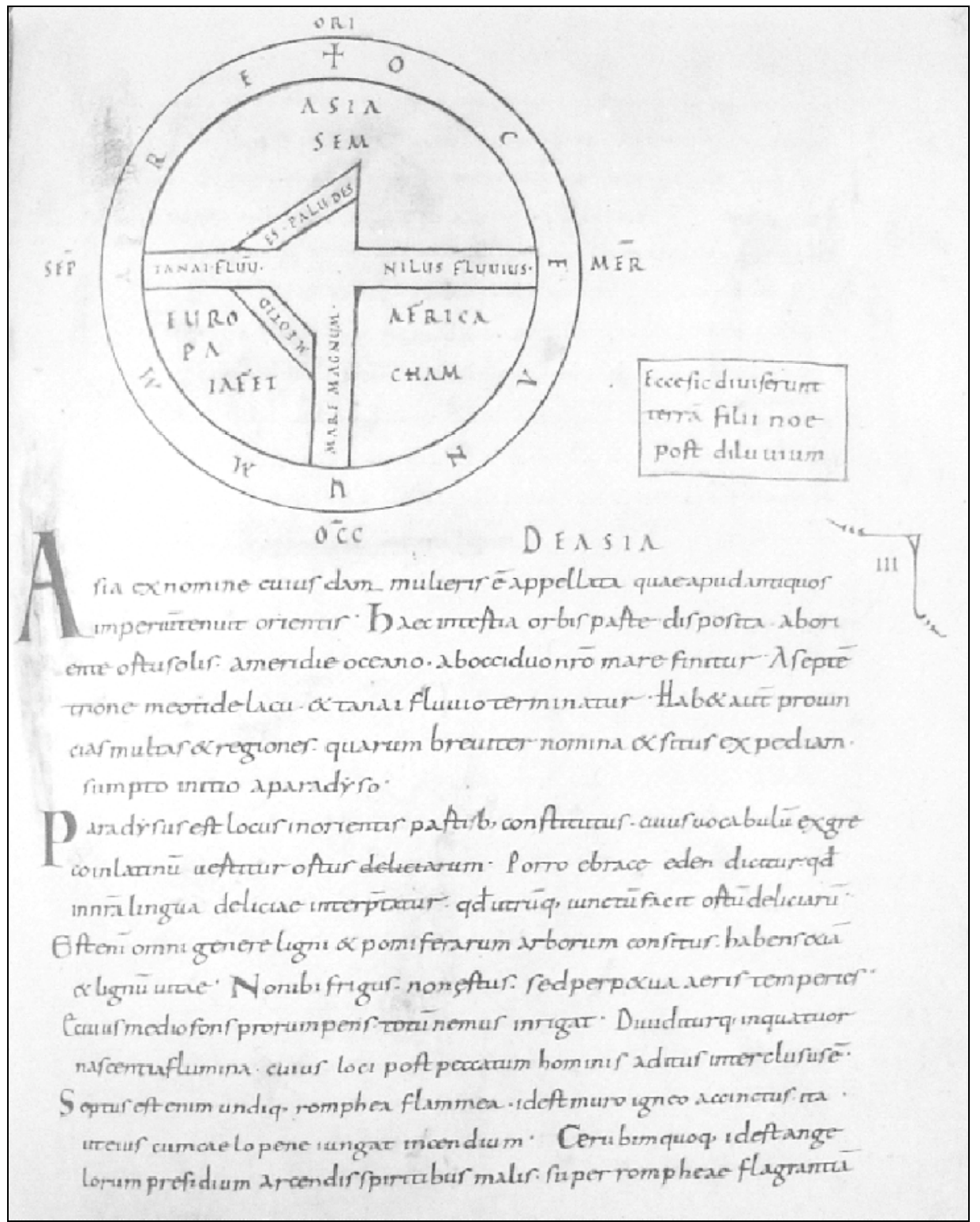

Abbildung 11

St. Galler Isidorhandschrift, Noachiden-Karte, 10. Jh. n. Chr., St. Gallen, Stiftsbibliothek, Ms. 236, fol. 89r (Repro nach Terrarum Orbis. Histoire des représentations de l'espace: textes, images. History of the Representations of Space in Text and Image. Collection dirigée par General Editor of the Series Patrick Gautier Dalché. Vol. 4: Chekin, Leonid S.: Northern Eurasia in Medieval Cartography. Inventory, Text, Translation, and Commentary. Turnhout 2006; S. 378, IV.1.7) 


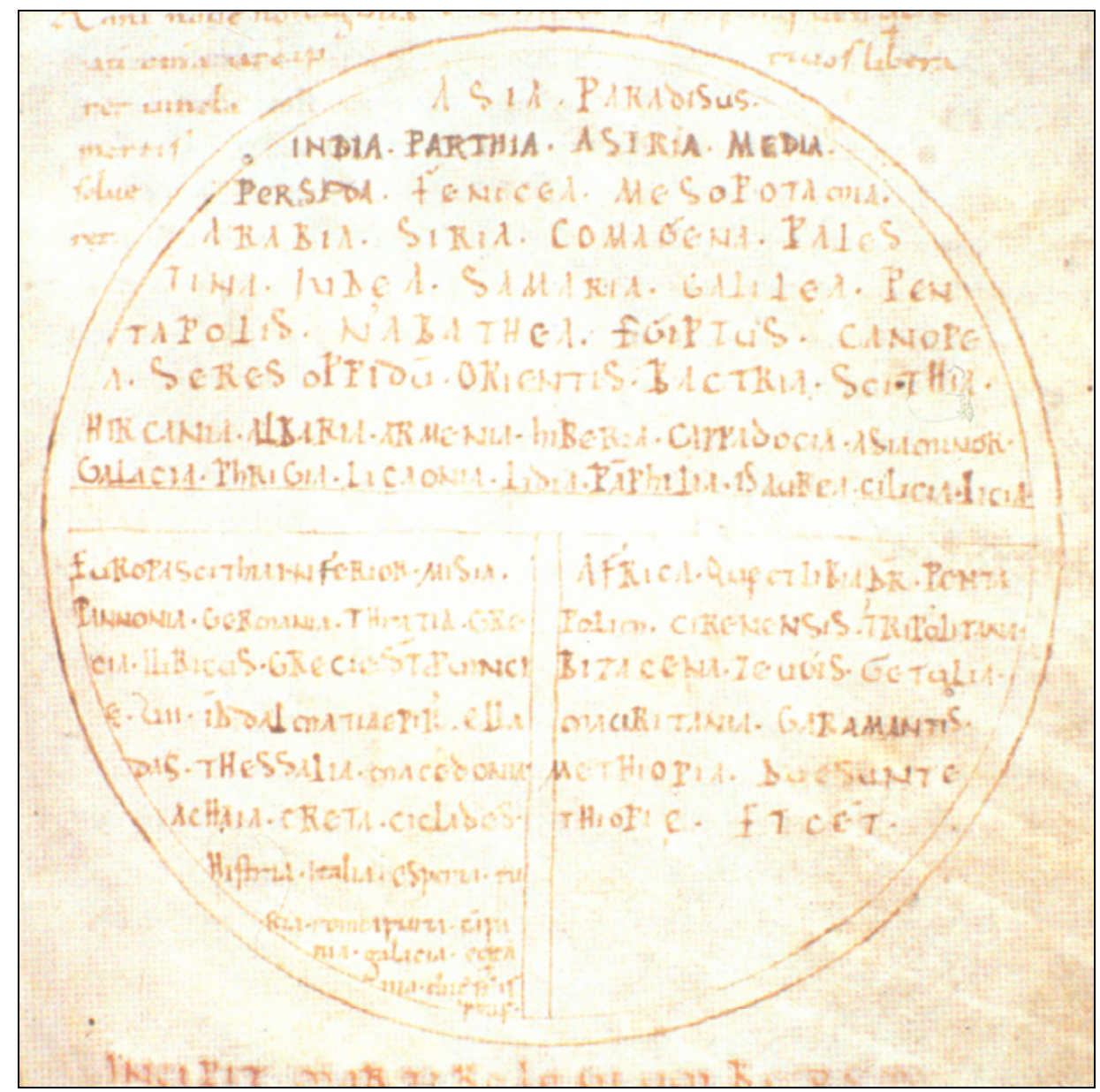

Abbildung 12

Oxforder Beda-Handschrift. T-O-Karte mit „Inventar" der drei Kontinente der Ökumene, 11. Jh. n. Chr., Oxford, Bodleian Library, MS Canon. Misc. 560, fol. 3r (Repro nach Terrarum Orbis. Histoire des représentations de l'espace: textes, images. History of the Representations of Space in Text and Image. Collection dirigée par General Editor of the Series Patrick Gautier Dalché. Vol. 4: Chekin, Leonid S.: Northern Eurasia in Medieval Cartography. Inventory, Text, Translation, and Commentary. Turnhout 2006; S. 364, III.1.3)

den alle Völker der Welt eine genealogisch bestimmte Einheit und sind über Noah und seine Söhne gleichberechtigt in das Heilsversprechen Gottes einbezogen. Diese T-O-Karten beruhen ihrer Anlage nach nicht auf der Unterscheidung von „Wir und die Anderen", sie formulieren ihre Weltsicht also nicht aus der partikularen Perspektive eines bestimmten Volkes, Raumes oder Ortes, sondern wollen das Gesamte der Welt - „Wir alle“ - gewissermaßen aus dem Blickwinkel Gottes selbst erfassen. 
Schon vor Jahrzehnten hat Arno Borst die „Völkertafel“ der Genesis in diesem Sinne hellsichtig gewürdigt: ,Was Moses, der Jahwist und wer immer sonst (...) hier aussagen, ist grundstürzend neu. In keinem Kulturkreis der Erde war bis dahin die Einheit des Menschengeschlechts und die einheitliche Lenkung der Geschichte durch einen Gott verkündet worden. “94 Dem ist hinzuzufügen, dass die Noachiden-Karten eben dieses Bild der Weltgeschichte im Diagramm fixierten und damit, wie ihre große Verbreitung zeigt, eine nachhaltige Wirkung erzielten. Entsprechend der biblischen Erzählung wurden die drei Kontinente oft noch mit den Namen vieler Länder und Völker angefüllt (Abb. 12). ${ }^{95}$

Im engeren Sinne ist der Kartentyp freilich biblisch, nicht exklusiv christlich geprägt.

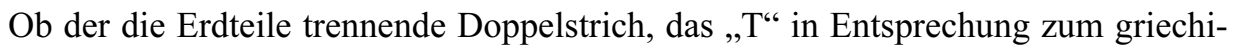
schen „tau“, unter Bezug auf Isidor als ein Abbild des Kreuzes Christi verstanden worden ist, wird sich kaum beweisen lassen. ${ }^{96}$ Schon in den ältesten Karten der La-

94 Ebd., S. 126.

95 Z. B. in der Beda-Handschrift Oxford, Bodleian Library, MS Canon. Misc. 560, fol. 3r (11. Jh. n. Chr.), Abb. in Chekin, Northern Eurasia in Medieval Cartography (wie Anm. 18), S. 364, vgl. 62f. zu III.1.3, und in Edson/Savage-Smith/Von den Brincken, Der mittelalterliche Kosmos (wie Anm. 19), S. 46 Abb. 31; oder: Biblioteca Apostolica Vaticana, Vat. Lat. 3328, fol. 13v (10./11. Jh. n. Chr.) in Chekin, Northern Eurasia in Medieval Cartography, S. 347, vgl. S. 41 II.2.1. Mit arabischen Inscriptionen: Madrid, Biblioteca Nacional, Vitr. 14.3, fol. 117v (8./9. Jh. n. Chr.), in Chekin, Northern Eurasia in Medieval Cartography, S. 362, vgl. 58-60 zu III.1.1.

96 Zu Isidor, Etymologiae 1,3,9 vgl. Edson/Savage-Smith/Von den Brincken, Der mittelalterliche Kosmos (wie Anm. 19), S. 55; Kugler, Hartmut: Symbolische Weltkarten der Kosmos im Menschen. Symbolstrukturen in der Universalkartographie bis Kolumbus. In: Wenzel (Hg.), Gutenberg und die Neue Welt (wie Anm. 75), S. 33-58, hier 41f. Vgl. auch Münkler, Marina: Erfahrung des Fremden. Die Beschreibung Ostasiens in den Augenzeugenberichten des 13. und 14. Jahrhunderts. Berlin 2000, S. 164. - Die Isidorhandschrift aus St. Gallen, Stiftsbibliothek, Ms. 237 (vgl. bereits oben Anm. 23), bietet auf pag. 1 (mit Umzeichnung von Konrad Miller in: Arentzen, Imago Mundi Cartographia [wie Anm. 23], Abb. 15/15a; Hs. ferner u. a. in Von den Brincken, Fines Terrae [wie Anm. 17], Abb. 10; Chekin, Northern Eurasia in Medieval Cartography [wie Anm. 18], S. 372 IV.1.1), ,die wohl älteste Isidor-Karte überhaupt, vielleicht sogar die älteste erhaltene Karte des lateinischen Mittelalters“ (Von den Brincken, Fines Terrae, S. 52), und zwar mit der T-Form sowie der hemisphärisch im Süden abgeteilten Terra Inhabitabilis (Antichthonenkontinent). Der T-Schaft ist aber nach oben (Osten) hin verlängert und scheint in einen Kruzifixus zu münden, der das Weltrund überhöht. Allerdings handelt es sich um ein von späteren Händen überschriebenes Palimpsest, und die Datierung schwankt zwischen dem 7. und 9. Jh. Vgl. neben Kugler vor allem Von den Brincken, AnnaDorothee: Die Ebstorfer Weltkarte im Verhältnis zur spanischen und angelsächsischen 
teiner fanden der Bibel gemäß auch das Paradies im Osten und die Völker Gog und Magog, meist im Nord(-Osten), ihren Platz. ${ }^{97}$ Eine um 762 datierte vatikanische Handschrift, die noch kaum Spuren des T-Schemas aufweist, markiert erstmals Orte des Heiligen Landes, darunter Wirkungsstätten Jesu (Bethlehem, Jericho, Jerusalem). ${ }^{98} \mathrm{Im}$ frühen Mittelalter zeigten aber erst die Karten zum Apokalypsen-Kom-

Weltkartentradition. In: Kugler, Hartmut (Hg.), Ein Weltbild vor Columbus. Die Ebstorfer Weltkarte. Interdisziplinäres Colloquium 1988. Weinheim 1991, S. 129-145, hier 131f., ND in: Dies., Studien zur Universalkartographie (wie Anm. 17), S. 415-431, 417f; Woodward, Medieval Mappaemundi (wie Anm. 23), S. 303; Arentzen, Imago Mundi Cartographia (wie Anm. 23), S. 262; Englisch, Ordo orbis terrae (wie Anm. 23), S. 46f. - Massive Einwände gegen die Hochbewertung des Zeugnisses und die Interpretation der Gestalt als Christus am Kreuz (nicht eher eine Frauengestalt?) jetzt aber bei Gautier Dalché, De la glose à la contemplation (wie Anm. 23), S. 727f., denen sich Chekin, Northern Eurasia in Medieval Cartography (wie Anm. 18) S. 75 ad IV.1.1 anschließt.

97 Edson/Savage-Smith/Von den Brincken, Der mittelalterliche Kosmos (wie Anm. 19), S. 54, 48 (zu den Gog und Magog auf muslimischen Karten s. o. bei Anm. 45f.). In der oben Anm. 23 genannten T-O-Karte aus Madrid sind arabische Inschriften angebracht, darunter unter den Nachkommen Japhets (Europa) neben den „Adjam“ (Barbaren) die Gog und Magog, während in Asien der Hejaz, Yathrib (Medina) und Mekka vermerkt sind: Chekin, Northern Eurasia in Medieval Cartography (wie Anm. 18), S. 59-61, 362. Auf Kartenbildern sind die Gog und Magog nach Von den Brincken, Ebstorfer Weltkarte (wie Anm. 97), S. 139 bzw. 426, erstmals auf der Cottoniana (von ca. 1030) eingeführt, um seit der Karte Heinrichs von Mainz (12. Jh.) eine eigene Bildtradition zu konstituieren; Dies., Gog und Magog (wie Anm. 46), S. 28; Dies., Fines Terrae (wie Anm. 17), S. 61f., 70.- Paradies im Osten mit den vier Paradiesesflüssen hat zum Beispiel eine Karte des 10. Jh. aus dem spanischen Millán de la Cogolla (zu Isidors Etymologiae 14,2,3): Von den Brincken, Fines Terrae, S. 51 mit Abb. 8; Chekin, Northern Eurasia in Medieval Cartography, S. 382 ad IV.2.1, vgl. ebd. S. 383-384 ad IV.2.2, IV.2.3.

98 Biblioteca Apostolica Vaticana, Ms. Vat. Lat. 6018, fol. 64v-65r; s/w Abb. u. a. bei Von den Brincken, Fines Terrae (wie Anm. 17), Abb. 16; farbig bei Chekin, Northern Eurasia in Medieval Cartography (wie Anm. 18), S. 447 ad X.1. Gewöhnlich wird die Handschrift um 775 datiert (etwa durch Von den Brincken, S. 50); da 93 der 135 Legenden der Karte sich auf Isidors Etymologien beziehen, wird der Codex meist als Isidor-Handschrift bezeichnet. Dagegen jetzt Chekin S. 126-128, der die Hs. auch auf 762-777 datiert. Nach Chekin ist die Karte gesüdet, nach Von den Brincken (S. 50) genordet, wenn man sie in Leserichtung des Gesamtcodex halte. Die Karte zeigt im Nordosten bzw. Osten noch innerhalb des asiatischen Festlandes eine Rosette, die das Paradies repräsentiert, umgeben von der terra eden. Zur Hervorhebung von Stätten des Heiligen Landes: Von den Brincken, Fines Terrae, S. 50; dagegen könne man nach Englisch, Ordo orbis terrae (wie Anm. 23), S. 129, „kaum von einem religiös dominierten Kartenbild sprechen, da all diese Elemente nicht primär mit der Struktur der Karte verwoben sind, sondern eher den Eindruck illustrativen [sic] Ergänzungen vermitteln, die in einem zweiten Arbeitsschritt hinzugefügt 


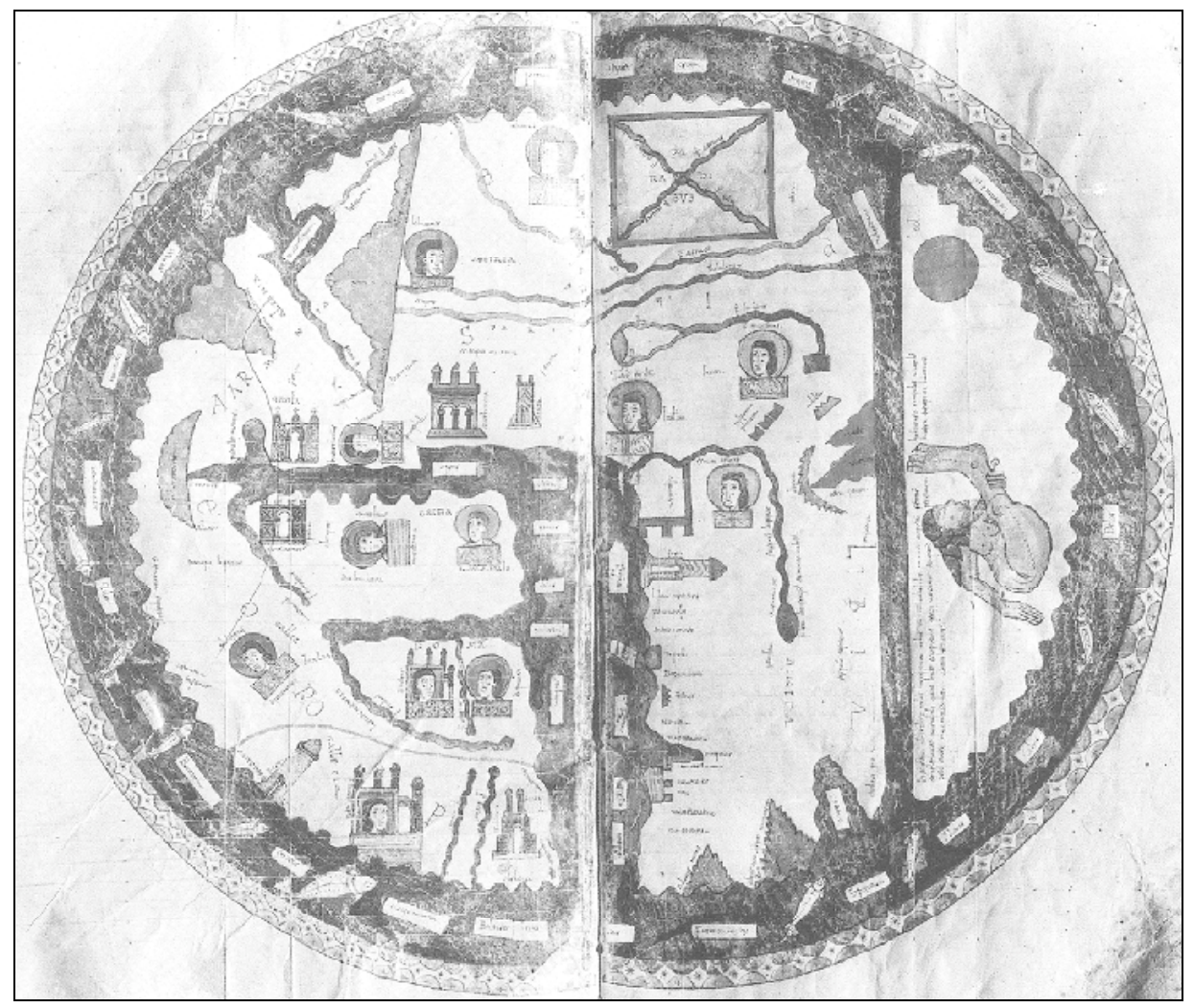

Abbildung 13

Osma-Karte zum Apokalypsenkommentar des Beatus von Liébana, um $1100 \mathrm{n}$. Chr., El Burgo de Osma, Archivo de la Catedral, fols. 35v-36r (Repro nach Terrarum Orbis. Histoire des représentations de l'espace: textes, images. History of the Representations of Space in Text and Image. Collection dirigée par General Editor of the Series Patrick Gautier Dalché. Vol. 4: Chekin, Leonid S.: Northern Eurasia in Medieval Cartography. Inventory, Text, Translation, and Commentary. Turnhout 2006; S. 477, XI.3.1)

mentar des Mönchs Beatus von Liébana (gest. ca. 798) ein betont christliches Kartenbild. ${ }^{99}$ Beatus selbst schloss eine pictura in seinen Text ein, um die Verbreitung des christlichen Glaubens durch die Apostel zu demonstrieren. Zum Beispiel sind in

wurden“. Zu der von der Mediävistik verworfenen Thesenbildung, die Englischs Urteil zugrundeliegt, s. aber oben Anm. 77.

99 Prelog, Jan/Klein, Peter K./Wawrik, Franz: Art. Beatus v. Liébana. In: Lexikon des Mittelalters, Bd. I.9. Zürich/München 1980, Sp. 1746f.; Wawrik, Franz: Art. Beatus-Karte. In: ebd., Sp. 1747; Von den Brincken, Fines Terrae (wie Anm. 17), S. 56-58; Chekin, Northern Eurasia in Medieval Cartography (wie Anm. 18), S. 171-179; Woodward, Medieval Mappaemundi (wie Anm. 23), S. $303 \mathrm{f}$. 
der Osmakarte von ca. 1100, die aber wohl auf die ursprüngliche Fassung zurückgeht, alle zwölf Apostel an den Stätten ihrer Glaubensverkündigung ,porträtiert“ (Abb. 13). ${ }^{100}$ Die Beatuskarten bieten im Süden auch den vierten Kontinent, den der Autor für bewohnt hielt, und zwar von Antipoden oder Monstren. ${ }^{101}$

Wie es scheint, wurde das Motiv der Apostelmission in den Karten des Beatus-Typs in der Epoche der Kreuzzüge wiederbelebt. ${ }^{102}$ Gleichzeitig rückte anderswo Jerusalem ins Zentrum der Karten. ${ }^{103}$ Ein Wort des Propheten Ezechiel hatte bereits der Kirchenvater Hieronymus mit den Thesen kommentiert, Jerusalem sei als Nabel der Erde inmitten der Welt und inmitten der Völker gelegen, so dass alle Nationen im Umkreis seinem Vorbild folgten. ${ }^{104}$ Die Weltkarte einer Handschrift aus Oxford

${ }^{100}$ Chekin, Northern Eurasia in Medieval Cartography (wie Anm. 18), S. 176 ad XI.3.1, Abb. 477: El Burgo de Osma, Archivio de la Catedral, fol. 35v-36r; auch bei Von den Brincken, Fines Terrae (wie Anm. 17), Abb. 17. - Der durch den Ozean abgetrennte, für die Beatuskarten typische Südkontinent zeigt einen Skiapoden, der sich mit den Füßen vor dem Sonnenlicht schützt.

101 Woodward, Medieval Mappaemundi (wie Anm. 23), S. 303f.; Von den Brincken, Fines Terrae (wie Anm. 17), S. 57f., 185-292; vgl. oben Anm. 100. - Ich muss in dieser Abhandlung nicht näher auf den zweiten Typ mittelalterlicher westlicher Weltkarten eingehen, der auf der Lehre des stoischen Philosophen Krates von Mallos (2. Jh. v. Chr.) bzw. dem Kommentar des Macrobius zu Ciceros „Somnium Scipionis“ beruht (um 400 n. Chr.); vgl. Woodward, Medieval Mappaemundi, S. 300; Edson/Savage-Smith/Von den Brincken, Der mittelalterliche Kosmos (wie Anm. 19), S. 45f., 57-60.

${ }^{102}$ Von den Brincken, Fines Terrae (wie Anm. 17), S. 58.

${ }^{103}$ Vgl. Edson/Savage-Smith/Von den Brincken, Der mittelalterliche Kosmos (wie Anm. 19), S. 57; Kugler, Symbolische Weltkarten (wie Anm. 96), S. 44-48; Von den Brincken, AnnaDorothee: Jerusalem on medieval mappaemundi: a site both historical and eschatological. In: Harvey, P. D. A. (Ed.), The Hereford World Map. Medieval World Maps and their Context. London 2006, S. 355-379; ND in: Dies., Studien zur Universalkartographie (wie Anm. 17), S. 683-703; Baumgärtner, Ingrid: Die Wahrnehmung Jerusalems auf mittelalterlichen Weltkarten. In: Bauer, Dieter/Herbers, Klaus/Jaspert, Nikolas (Hg.), Jerusalem im Hoch- und Spätmittelalter. Konflikte und Konfliktbewältigung - Vorstellungen und Vergegenwärtigungen. (Campus Historische Studien, Bd. 29.) Frankfurt/New York 2001, S. 271-334, hier 294-310; Elm, Kaspar: Die irdische und die himmlische, die verworfene und die heilige Stadt. In: Budde. Hendrik/Nachama, Andreas: (Hg.), Die Reise nach Jerusalem. Eine kulturhistorische Exkursion in die Stadt der Städte. 3000 Jahre Davidsstadt. Berlin 1995, S. 12-23, hier bes. 13f.

104 Ez 5,5: Ista est Jerusalem, in medio gentium posui eam, et in circuitu eius terras. Dazu S. Hieronymus presbyter, Commentarii in Hiezechielem. Ed. Franciscus Glorie. (Corpus Christianorum, Series Latina, 75.) Turnhout 1964, S. 55f.: Haec dicit Dominus Deus: (...). Hierusalem in medio mundi sitam, hic idem propheta testatur, umbilicum terrae eam esse demonstrans (...) a partibus enim orientis cingitur plaga quae appellatur Asia; 


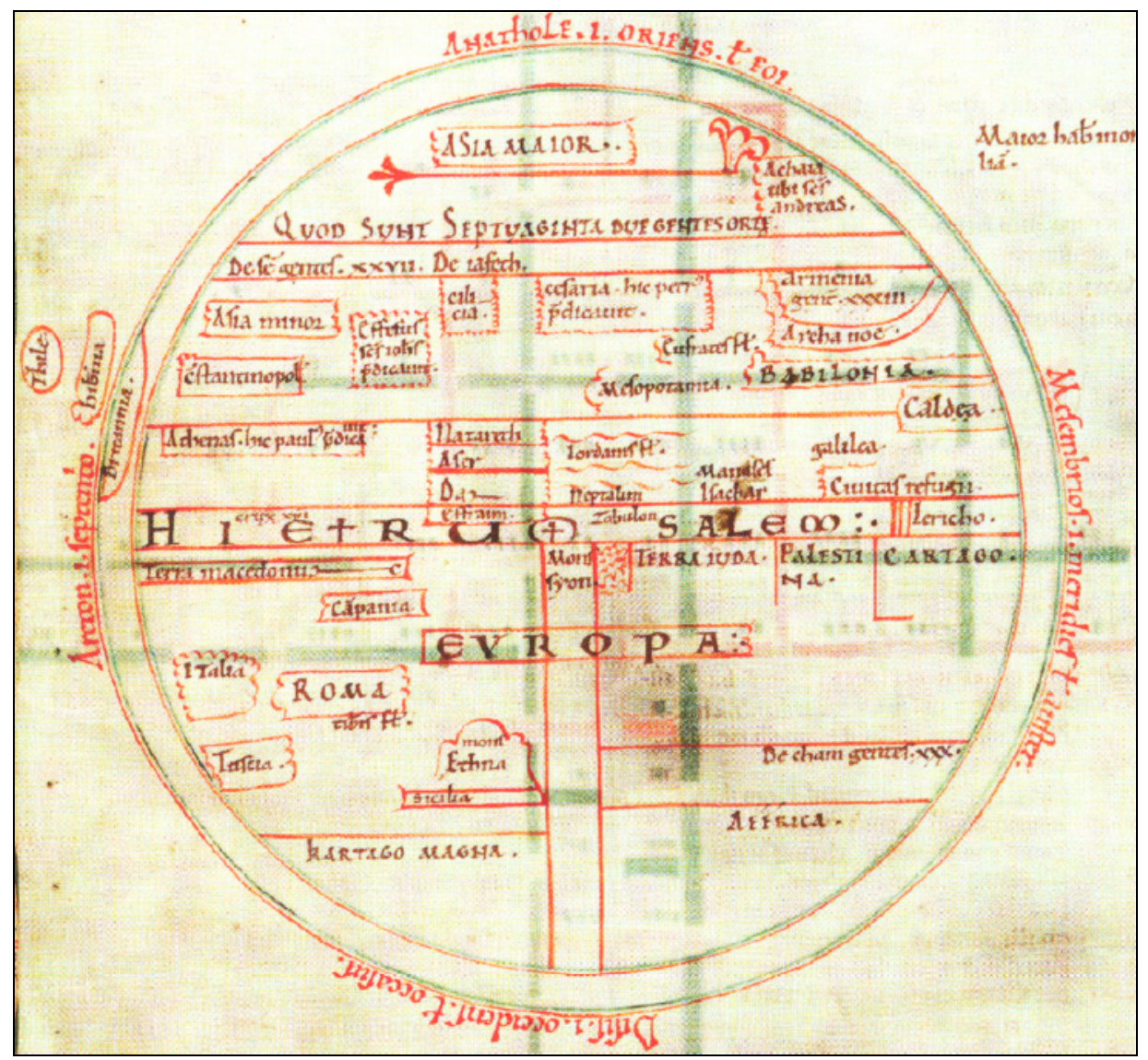

Abbildung 14

Komputistische Sammelhandschrift aus Oxford von 1110 n. Chr.? Oxford, St John's College, 17, fol. 6r (Repro [Ausschnitt] nach Edson, Evelyn/Savage-Smith, Emilie/Von den Brincken, Anna-Dorothee: Der mittelalterliche Kosmos. Karten der christlichen und islamischen Welt. Darmstadt 2005, S. 56, Abb. 39)

\footnotetext{
a partibus occidentis eius quae vocatur Europa; a meridie et austro Libya et Africa; a septemtrione Scythis, Armenia atque Perside et cunctis Ponti nationibus: in medio igitur gentium posita est ut, quia erat notus in Iudaea Deus et in Israel magnum nomen eius, omnes in circuitu nationes illius sequerentur exempla, quae, gentium circa se positarum impietatem secuta, vicit etiam ipsas in scelere suo. Vgl. Von den Brincken, Fines Terrae (wie Anm. 17), S. 24f.
} 
bringt dies geradezu ins Bild (Abb. 14): ${ }^{105}$ Im Querbalken des T, wo sonst Don und Nil genannt werden, ist hier HIERUSALEM eingeschrieben; zwei Kreuze markieren im Namen die crux Christi und - in der exakten Mitte des Weltrunds - den Mons Syon. Im Osten, dem Ort des Paradieses, erinnert der Schreiber an die Völker der Genesis, ${ }^{106}$ von denen er - nach Augustin - Sem in Asien 27 und Cham in Afrika 30 zuteilt. ${ }^{107}$ Neben der Archa Noe und BABILONIA sind Stätten des Wirkens Christi (Nazareth, Jericho, Galiläa, der Jordan) und besonders der apostolischen Verkündigung hervorgehoben: „Achaia, wo der heilige Andreas [war], Ephesus, [wo] der heilige Johannes predigte, Caesarea, hier predigte Petrus, Athen, wo Paulus predigte“" ${ }^{108}$ Mehrere In- und Beischriften deuten auf eine griechische Vorlage hin. ${ }^{109}$ Wenn die Karte mit dem Codex, wie meist angenommen wird, vom Jahr 1110 stammt, ${ }^{110}$

105 Edson/Savage-Smith/Von den Brincken, Der mittelalterliche Kosmos (wie Anm. 19), S. 55-57 mit Abb. 39 nach Oxford, St John's College, 17, fol. 6r, und Umzeichnung Abb. 40; Chekin, Northern Eurasia in Medieval Cartography (wie Anm. 18), S. 64-66 ad III.2.2 mit Abb. 365; Von den Brincken, Fines Terrae (wie Anm. 17), S. 66f.

106 Das Paradies ist hier selbst nicht eingezeichnet. Dafür steht unter ASIA MAIOR: QUOD SUNT SEPTUAGINTA DUE GENTES ORTE.

${ }^{107}$ Unter der in vorangehender Anm. zitierter Summenzeile, also im Asiensegment, sind vermerkt: De sem gentes xxvii; hierauf (also an falscher Stelle und nicht zu Europa) folgt: De iafeth, aber ohne Zahl. Im Afrikateil ist angegeben: De cham gentes xxx..Überdies sind zu armenia: gentes xxxiii vermerkt. Zur Zählung der 70 (Genesis) bzw. 72 Völker (Augustinus) s. Borst, Der Turmbau zu Babel I (wie Anm. 93), S. 126, 259.

108 Achaia ubi sanctus Andreas, Effesus sanctus Iohannes praedicauit, Cesaria, hic Petrus praedicavit, Athenas, hic Paulus praedicavit.

109 Vgl. Miller, Konrad: Mappae Mundi. Die ältesten Weltkarten. Bd. 3. Stuttgart 1895, S. 120. Neben den Himmelsrichtungen Anathole, Arcton, Mesembrios, Disis vgl. auch Achaia für das Wirkungsfeld des Apostels Andreas, zu diesem: Pesch, Rudolf: Art. Andreas, hl. Apostel. In: Lexikon für Theologie und Kirche, Bd. 1. Freiburg/Basel/Rom/ Wien ${ }^{3} 1993$, Sp. $625 f$.

110 Datierung der Hs. auf 1110 nach einer Zeitrechnungsnotiz (fol. 3v) bei Coxe, Henricus O.: Catalogus Codicum Mss. Qui in collegiis aulisque Oxoniensibus hodie adservantur. Pars II. Oxford 1852, S. 5. Danach jüngst Edson/Savage-Smith/Von den Brincken, Der mittelalterliche Kosmos (wie Anm. 19), S. 55; Von den Brincken, Fines Terrae (wie Anm. 17), S. 66; Baumgärtner, Die Wahrnehmung Jerusalems auf mittelalterlichen Weltkarten (wie Anm. 103), S. 294f. - Fol. 3 wird jedoch von C. W. Jones für eine spätere Beilage gehalten; außerdem stamme die Handschrift nach Cyril Hart nicht aus der Abtei Thorney, sondern aus dem nahegelegenen Ramsey, und zwar eher von 1080/90 n. Chr. als von ca. 1100, s. Kaufmann, C. M.: Romanesque Manuscripts 1066-1190. London 1975, S. 56f., der die Handschrift auf c. 1090 datiert. Chekin, Northern Eurasia in Medieval Cartography (wie Anm. 18), S. 64 gibt an: „About 1100, Thorney Abbey, East Anglia.“ 
dürfte sie die Aktualisierung der Heilsgeschichte nach der Eroberung Jerusalems durch die Ritter des Abendlandes belegen: Von Jerusalem aus sind alle Völker der Erde für die Botschaft des Evangeliums bestimmt. ${ }^{11}$

Seit der Wende zum zwölften Jahrhundert setzen immer mehr Kartenzeichner die Heilige Stadt in die Mitte der Welt, ${ }^{112}$ doch handelt es sich - im Unterschied zu den

${ }^{111}$ Die verlockende Idee, die Verdrängung Afrikas durch die Inschrift EVROPA im Kartenbild in den äußersten Südwesten könne dem erfolgreichen Vordringen der Kreuzfahrer Rechnung tragen, ginge in die Irre. Schon Sallust, Lucan und Orosius hielten Libyen (Afrika) für einen Teil Europas, s. Chekin, Northern Eurasia in Medieval Cartography (wie Anm. 18), S. 64; Arentzen, Imago Mundi Cartographia (wie Anm. 23), S. 97f. Vgl. Baumgärtner, Die Wahrnehmung Jerusalems auf mittelalterlichen Weltkarten (wie Anm. 103), S. 296f., in Auseinandersetzung mit F. Reichert. - Selbst wenn die Karte älter und vor dem ersten Kreuzzug (1096-1099 n. Chr.) entstanden sein sollte, hatten schon andere Ereignisse des 11. Jahrhunderts das Interesse der Christen in Ost und West für Jerusalem wiederbelebt: Die Zerstörung der Grabeskirche durch den fatimidischen Kalifen al-Hakim 1009 n. Chr. und der Verlust fast ganz Kleinasiens an die Seldschuken nach der unter Kaiser Romanos Diogenes verlorenen Schlacht bei Malazgirt 1071 n. Chr. Die Grabeskirche hatte Konstantin Monomachos 1048 n. Chr. wiederaufgebaut, während Papst Gregor VII. 1074 n. Chr. erwog, an der Spitze eines Ritterheeres in den Orient zu ziehen, um das Reich von Byzanz gegen die vordringenden „Heiden“, also die Seldschuken, zu verteidigen. Angeblich standen bereits 50.000 Mann bereit, um unter Führung des Papstes „bis zum Grab des Herrn“ zu ziehen (Das Register Gregors VII. Hrsg. v. Erich Caspar. Teil I. [Monumenta Germaniae Historica, Epistolae Selectae, T. II. Fasc. I.] Berlin/ Dublin/Zürich ${ }^{3} 1967$, S. 166 II.31). Vgl. Mayer, Hans Eberhard: Geschichte der Kreuzzüge. Stuttgart ${ }^{10} 2005$, S. 18-52, der auch darauf hinweist, dass „,der bloße Klang des Namens Jerusalem (...) für die Menschen des 11. Jh. einen magischen Glanz und Schimmer gehabt haben“" müsse (S. 21). Zum Millenium der Passion Christi 1033 sind umfangreiche Wallfahrten nach Jerusalem bezeugt (Mayer S. 23),1064/65 zog unter Leitung des Bischofs Gunther von Bamberg eine Gruppe von über 7.000 Menschen ins Heilige Land (ebd., S. 25). Trotzdem sei „nicht zu verkennen, dass seit Mitte des 11. Jh. n. Chr. die Schwierigkeiten für die Pilger zu wachsen begannen“ (ebd., S. 24). - Chekin, Northern Eurasia in Medieval Cartography 64, stellt neben die Oxford-Karte als eine der ältesten „maps with Jerusalem at the centre“ die Karte aus der Juvenal-Handschrift aus Neapel, Biblioteca Nazionale, IV F 45, fol. 33v, die er ins 11. Jh. datiert (Chekin S. 48 zu II.7.1). Tatsächlich ist Jerusalem hier exakt im Mittelpunkt eingetragen (vgl. ebd., Abb. 353). Die Karte befindet sich allerdings nach mehreren leeren Seiten verso auf dem letzten Blatt; ob ein Zusammenhang mit dem Juvenal-Text besteht, müsste geprüft werden, zumal am Codex mehrere Hände beteiligt waren.

112 Nicht zu halten ist die Behauptung von Edson/Savage-Smith/Von den Brincken, Der mittelalterliche Kosmos (wie Anm. 19), S. 65, dass nach der Oxford-Karte erst wieder die Wallingfordkarte aus der Mitte des 13. Jahrhunderts Jerusalem exakt im Mittelpunkt der Welt zeige (vgl. unten bei Anm. 139); korrekt dagegen Chekin, Northern Eurasia in Me- 
qibla-Karten der Muslime - nicht um einen Fokus, sondern um ein Zentrum, das auch nach außen strahlt. Die hier angelegte Expansion über die Grenzen der Christenheit hinaus tritt im nächsten Kartentyp lateinischer Weltrepräsentation noch klarer hervor. Jerusalem als Zentrum wird dabei in Bezug zu Christus beziehungsweise Gott als Heiland, Richter oder Herrscher gesetzt, der den Weltkreis überragt oder umschließt. Die Karten stammen aus dem 13., frühen 14. Jahrhundert. Einem Psalterium aus London ist eine Doppelkarte des T-O-Schemas vorgeschaltet. ${ }^{113}$ Auf der Recto-Seite des Blattes stützt sich der segnende Christus, in der Linken den Globus und umgeben von weihrauchspendenden Engeln, auf die Weltscheibe, unter der sich zwei Drachen beugen (Abb. 15). Die tripartite Mappamundi der Rückseite bietet ein Inventar von Länder-, Provinz- und Ortsnamen der drei Kontinente; Christus oder Gott umarmt hier die Welt, während seine Füße im Westen auf zwei Drachen treten (Abb. 16). ${ }^{114}$ Die Fülle der Orte und Berge, Gewässer und Gestalten bzw. der Namen auf beiden

dieval Cartography (wie Anm. 18), S. 34: „From the early twelfth century on, Jerusalem is often placed in the centre of maps, in accordance with Ezekiel 5.5." Chekins Nachweise im einzelnen sind allerdings oft ungenau, wie sich an seinen Abbildungen überprüfen lässt. Jerusalem im Mittelpunkt ist danach tatsächlich belegbar in der Münchener Handschrift, Bayerische Staatsbibliothek, CLM 14371, fol. 83v, datiert auf 1145/52 (Chekin S. 48f. II.7.2 mit Abb. 354), in den Pariser Handschriften Bibliothèque nationale, Latin 6813, fol. 2r, Ende des 12. Jh.s (Chekin S. 49 II.7.3, Abb. 355) und Latin 11334, fol. 1r (Chekin S. 57f. II.12, 13./14. Jh., mit Abb. 361), der Dubliner Handschrift Trinity College, 367, fol. 83v (Chekin S. 49f. II.7.4, erste Hälfte des 13. Jh., mit Abb. 356) und der Berliner Handschrift Staatsbibliothek, Theol. Lat. Fol. 149, fol. 27r (Chekin S. 51f. aus dem 12. Jh. mit Abb. 357). Mittelpunktslage trifft dagegen nicht zu (da Asien verkleinert ist) bei der (verlorenen) Görlitzer Handschrift, Oberlausitzische Gesellschaft, fol. 45v (Chekin S. 36 II.1.4, frühes 12. Jh., mit Abb. 335), der Pariser Handschrift Bibliothèque nationale, Latin 6089, fol. 26r (Chekin S. 37f. II.1.10, zweite Hälfte 12. Jh., mit Abb. 341), der Leidener Handschrift, Bibliotheek der Rijksuniversiteit, B.P.L. 193, fol. 1r (Chekin S. 39 II.1.13, 13. Jh., mit Abb. 344), der Leipziger Handschrift, Universitätsbibliothek, Fonds Stadtbibliothek, Rep. I.4‥14, fol. 46v (Chekin S. 39 II.1.14, 13. Jh., mit Abb. 345). Zur Hs. aus Neapel s. die vorige Anm.

113 Edson/Savage-Smith/Von den Brincken, Der mittelalterliche Kosmos (wie Anm. 19), S. 65-67 mit Abb. 48, nach London, British Library, Add. 28681, fol. 9r/9v; Chekin, Northern Eurasia in Medieval Cartography (wie Anm. 18), S. 140-142 X.9 mit Abb. 455f.; Von den Brincken, Fines Terrae (wie Anm. 17), S. 85-89; Englisch, Ordo orbis terrae (wie Anm. 23), S. 437-450; Barber, Peter: Medieval maps of the world. In: Harvey (Ed.), The Hereford World Map (wie Anm. 103), S. 1-44, hier 15-19; Reudenbach, Bruno: Die Londoner Psalterkarte und ihre Rückseite. Ökumenekarten als Psalterillustration. In: Frühmittelalterliche Studien 32, 1998, S. 164-181.

114 Edition des Nameninventars bei Von den Brincken, Fines Terrae (wie Anm. 17), S. 87f. 


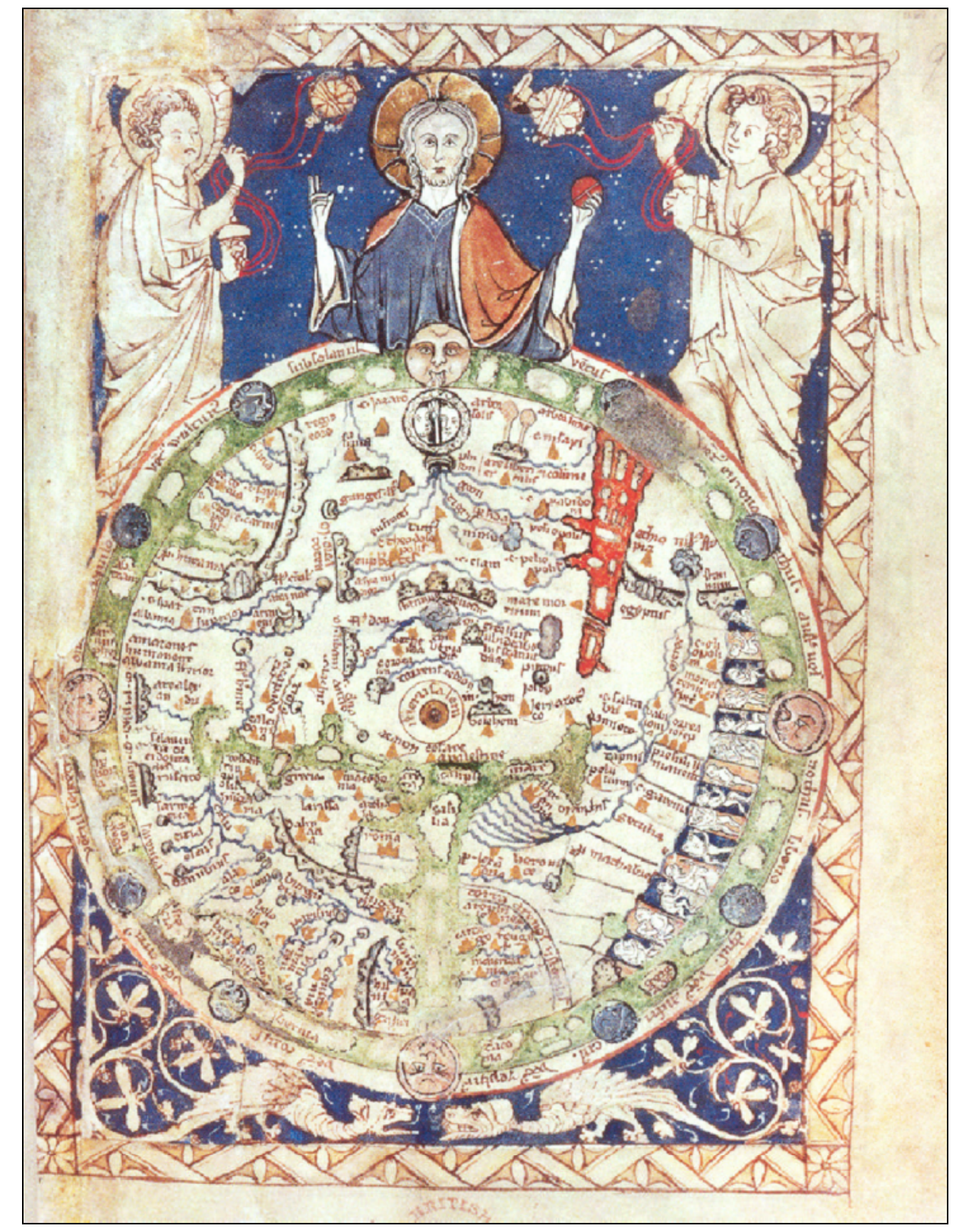

Abbildung 15

Londoner Psalter von 1262 n. Chr.? London, British Library, MS Add. 28681, fol. 9r (Repro nach Edson, Evelyn/Savage-Smith, Emilie/Von den Brincken, Anna-Dorothee: Der mittelalterliche Kosmos. Karten der christlichen und islamischen Welt. Darmstadt 2005, S. 66, Abb. 48) 


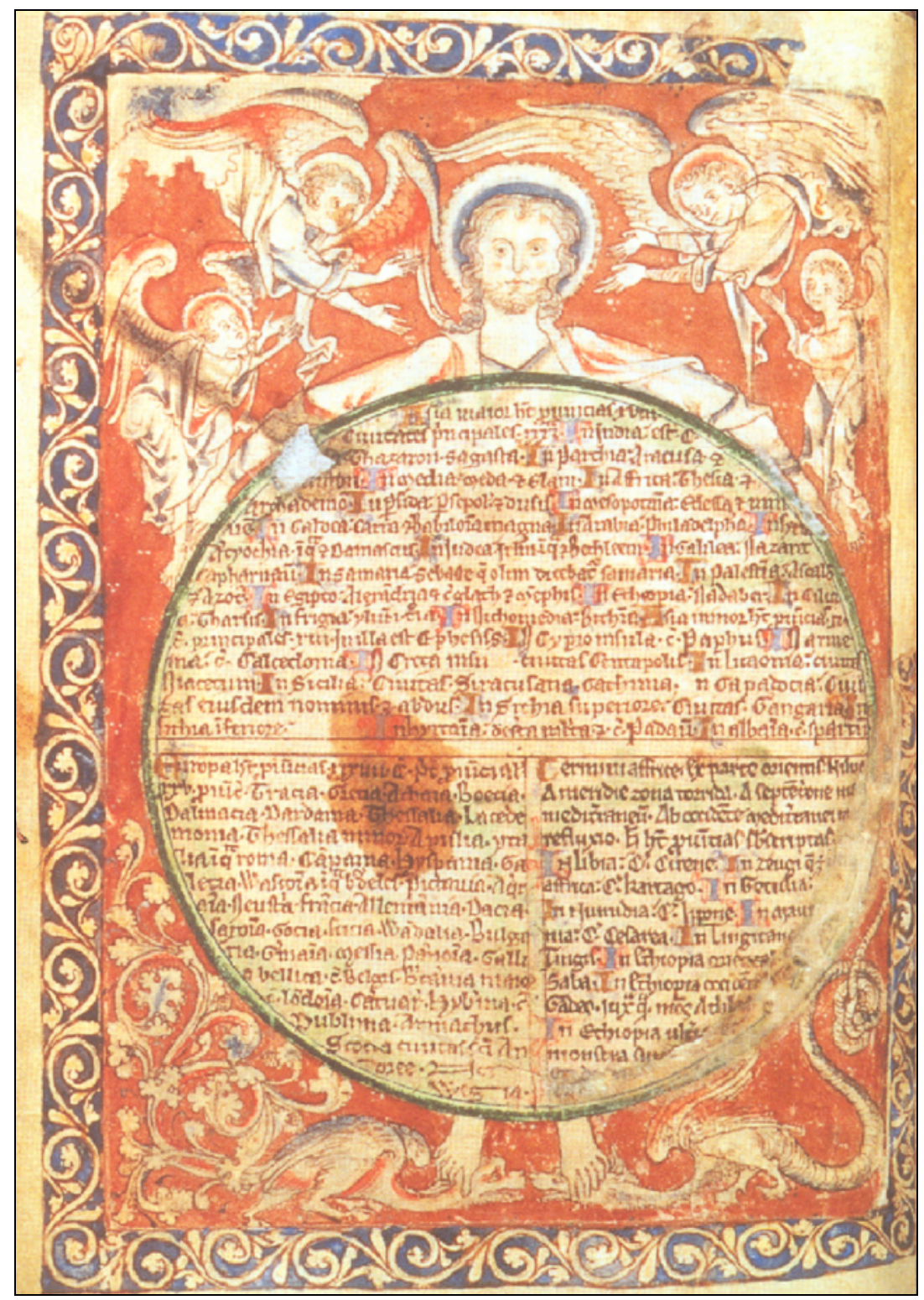

Abbildung 16

Londoner Psalter von 1262 n. Chr.? London, British Library, Add. 28681, fol. 9v (Repro nach Terrarum Orbis. Histoire des représentations de l'espace: textes, images. History of the Representations of Space in Text and Image. Collection dirigée par General Editor of the Series Patrick Gautier Dalché. Vol. 4: Chekin, Leonid S.: Northern Eurasia in Medieval Cartography. Inventory, Text, Translation, and Commentary. Turnhout 2006; S. 456) 
Seiten lassen sich mit bloßem Auge kaum erkennen, da die Karten nur einen Durchmesser von etwa neuneinhalb Zentimetern aufweisen. ${ }^{115}$ Die anderen Vertreter des Typs mussten sich nicht dem Format von Gebetsbüchern anpassen, sondern sind Einzelkarten und überdimensioniert. ${ }^{116}$ Die Hereford-Karte zeigt eine MajestasDarstellung des thronenden Weltenrichters zwischen dem pentagonalen Rahmen und dem Weltkreis (Abb. 17); die Mitte ist durch die Ciuitas Ierusalem als Befestigung hervorgehoben, über der sich der Kalvarienberg mit Christus am Kreuz erhebt (Abb. 18). ${ }^{117}$ Demgegenüber entsteigt der Auferstandene seinem Grab im Zentrum der Weltkarte von Ebstorf (Abb. 19), ${ }^{118}$ er wendet sich dabei nicht dem Betrachter zu, sondern nach Nord(-Osten) (Abb. 20). ${ }^{119}$ Dort hausen die durch Alexander ein-

115 Noch kleiner ist das Format eines anderen Londoner Psalters, in dem eine Welt von 66 Millimetern den Leib Christi zu bilden scheint. Die T-O-Karte enthält rund siebzig, meist separat eingekreiste geographische Namen. Allerdings befindet sich hier Jerusalem nicht exakt in der Mitte: London, Lambeth Palace Library, 371, fol. 9v, von ca. 1300, vgl. Chekin, Northern Eurasia in Medieval Cartography (wie Anm. 18), S. 72 III.2.8 mit Abb. 371.

116 Zur Gruppe dieser Karten werden in der Regel auch die im Folgenden genannten Fragmente gezählt, auch wenn Jerusalem nicht im Zentrum steht (Vercelli) oder Aussagen darüber nicht möglich sind (Cornwall-Fragment; Aslake). Duchy of Cornwall-Fragment (London, Duchy of Cornwall Office, Maps and Plans 1), s. Woodward, Medieval Mappaemundi (wie Anm. 23), S. 306. Danach habe eine Radiocarbonuntersuchung der Universität Oxford eine Datierung zwischen 1150 und 1220 ergeben. Abb. ebd. Tafel 14. Von den Brincken, Fines Terrae (wie Anm. 17), 95f., folgt indessen dem zuständigen Archivar mit dem Zeitansatz 1260-1283; Barber, Medieval maps of the world (wie Anm. 113), S. 19-23, mit 20 Fig. 7: ca. 1290 (?) - Karte im Archivio Capitolare von Vercelli, s. Chekin, Northern Eurasia in Medieval Cartography (wie Anm. 18), S. 142-146 X. 10 mit Abb. 457f.: Entstanden 13. Jh., unter Philipp III. von Frankreich (1270-1285)? Woodward, Medieval Mappaemundi, S. 306f., der die Datierung auf die Zeit Philipps I. (11801223) vorzieht. Von den Brincken, Fines Terrae, S. 90f.: Um 1270. - Aslake Map, London, British Library, Add. 63841 A, von ca. 1360: Barber, Medieval maps of the world, S. 35-38 mit 37 Fig. 12.

117 Westrem, The Hereford Map (wie Anm. 18), hier Section 2 und 6; Harvey (Ed.), The Hereford World Map (wie Anm. 103), passim; Von den Brincken, Fines Terrae (wie Anm. 17), S. 93-95; Chekin, Northern Eurasia in Medieval Cartography (wie Anm. 18), S. 161-168 X.12 mit Abb. 467.

118 Kugler (Hg.), Die Ebstorfer Weltkarte (wie Anm. 37), 2 Bde.; Wilke, Jürgen: Die Ebstorfer Weltkarte. 2 Bde. (Veröffentlichungen des Instituts für Historische Landesforschung der Universität Göttingen, Bd. 39.) Bielefeld 2001.

119 Vgl. Abb. bei Kugler (Hg.), Die Ebstorfer Weltkarte I (wie Anm. 37), S. 17, 92f. Vgl. Hengevoss-Dürkop, Kerstin: Jerusalem - Das Zentrum der Ebstorf-Karte. In: Kugler (Hg.), Ein Weltbild vor Columbus (wie Anm. 97), S. 205-222, bes. $216 \mathrm{f}$. 


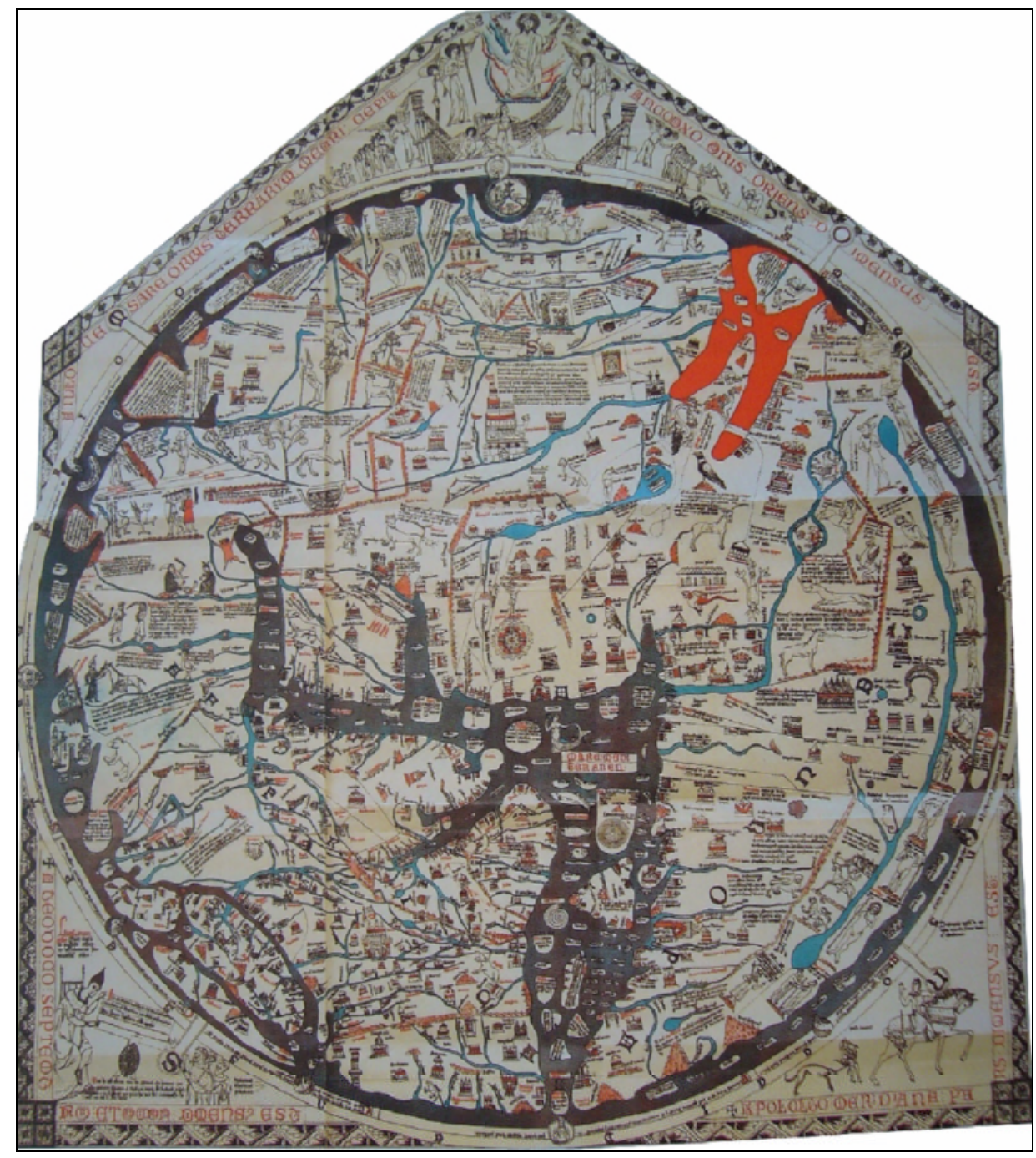

Abbildung 17

Weltkarte von Hereford um 1300 n. Chr., Umzeichnung durch Konrad Miller (1895/98) (Repro nach Arentzen, Jörg-Geerd: Imago Mundi Cartographica. Studien zur Bildlichkeit mittelalterlicher Weltund Ökumenekarten unter besonderer Berücksichtigung des Zusammenwirkens von Text und Bild. [Münstersche Mittelalter-Schriften, Bd. 53.] München 1984, Tafel 50)

geschlossenen „grausigen Völker Gog und Magog“, die „der Antichrist im Gefolge haben wird“ und die nach einer Beischrift Menschenfleisch essen und Blut trinken. ${ }^{120}$

${ }^{120}$ Kugler (Hg.), Die Ebstorfer Weltkarte I (wie Anm. 37), S. 58-61. 


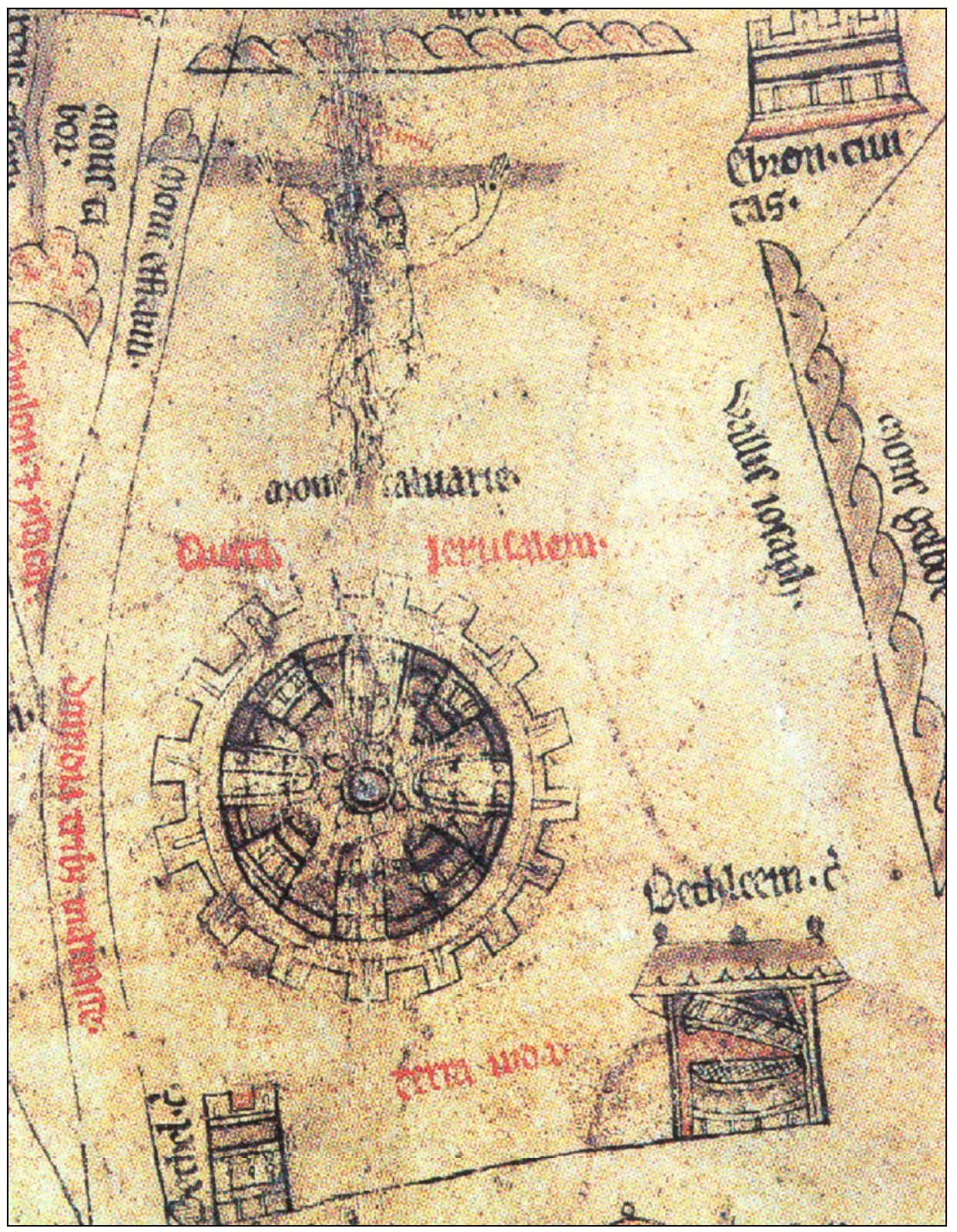

Abbildung 18

Weltkarte von Hereford um 1300 n. Chr., Ausschnitt: Jerusalem und Kalvarienberg (Repro nach Von den Brincken, Anna-Dorothee: Studien zur Universalkartographie des Mittelalters, hrsg. v. Thomas Szabó. [Veröffentlichungen des Max-Planck-Instituts für Geschichte, Bd. 229.] Göttingen 2008, Tafel 51b) 


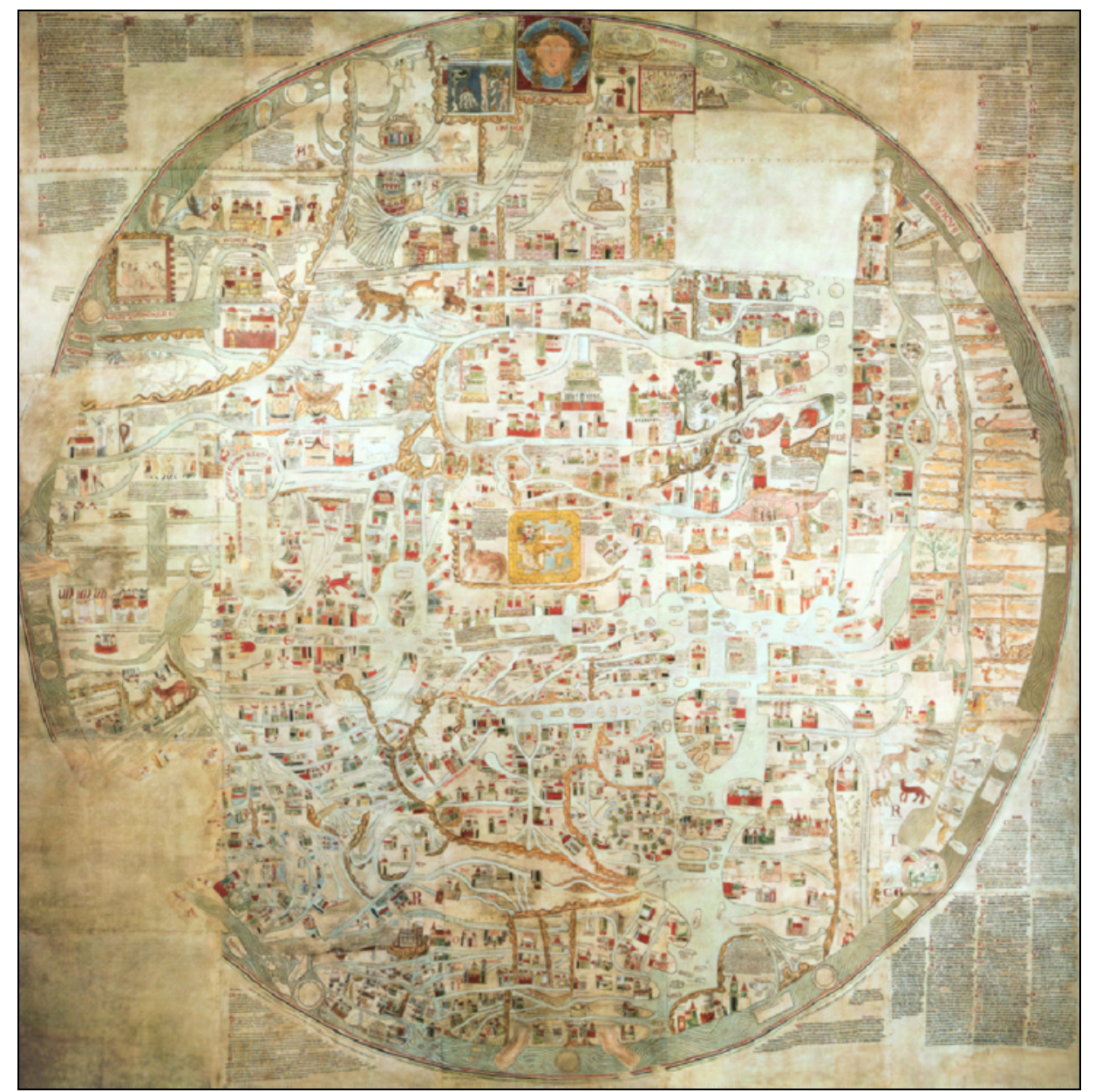

Abbildung 19

Ebstorfer Weltkarte um 1300 n. Chr. (Kopie) (Repro nach Edson, Evelyn/Savage-Smith, Emilie/Von den Brincken, Anna-Dorothee: Der mittelalterliche Kosmos. Karten der christlichen und islamischen Welt. Darmstadt 2005, S. 68, Abb. 49)

Im Unterschied zur Londoner Handschrift, wo Gott oder Christus hinter der Weltkarte zu stehen scheint oder diese seinen Leib repräsentiert, sind in Ebstorf das Haupt und die Extremitäten des Heilandes in allen vier Himmelsrichtungen in das Kartenrund einbezogen. ${ }^{121}$

121 Ebd., S. 19-21. 
Die drei Karten werden heute meist zwischen 1260 und 1330 datiert, ${ }^{122}$ könnten aber natürlich ältere, verlorene Vorläufer gehabt haben. ${ }^{123}$ Mit ihnen verwandt sind Darstellungen des Schöpfers, der den Kosmos bzw. das Sechstagewerk in den Händen hält, wie in einer Hildesheimer Handschrift von 1160 oder in einer Illustration zum Werk Hildegards von Bingen von ca. 1230. ${ }^{124}$ Der Theologe und Geschichtsdenker Hugo von St. Viktor hat schon im zwölften Jahrhundert ein Modell des Kosmos entworfen, in dem die Welt bzw. die Kirche als Arche Noah darzustellen war, die den Leib Christi repräsentiert. Über ihr, und zwar im Osten, sollte das Haupt

${ }^{122}$ Londoner Psalterkarte datiert auf ,the early part of the 1260s after 1262 “ Chekin, Northern Eurasia in Medieval Cartography (wie Anm. 18), S. 140; auf ca. 1265: Barber, Medieval maps of the world (wie Anm. 113), S. 15, auf ca. 1262: Edson/Savage-Smith/ Von den Brincken, Der mittelalterliche Kosmos (wie Anm. 19), S. 65. Diese Datierung geht offenbar zurück auf Morgan, Nigel: Early Gothic Manuscripts 2 (1250-1285). (Survey of Manuscripts Illuminated in the British Isles, 4.2.) London 1988, S. 82-85 Nr. 114 (von mir nicht eingesehen), dem auch Englisch, Ordo orbis terrae (wie Anm. 23), S. 437 Anm. 1, folgt; Kugler (Hg.), Die Ebstorfer Weltkarte II (wie Anm. 37), S. 37, gibt an „um 1270?“ - Hereford-Map um 1300: Barber, Medieval maps of the world, S. 27-30; vgl. Westrem, The Hereford Map (wie Anm. 18), S. xviii-xxv; Chekin, Northern Eurasia in Medieval Cartography, S. 161: spätes 13. Jh. - Ebstorfer Weltkarte um 1300, eher gegen 1330: Kugler (Hg.), Die Ebstorfer Weltkarte II, S. 69; Wilke, Die Ebstorfer Weltkarte 1 (wie Anm. 118), bes. S. 282-286: um 1300, so auch Edson/SavageSmith/Von den Brincken, Der mittelalterliche Kosmos (wie Anm. 19), S. 69; Chekin, Northern Eurasia in Medieval Cartography, S. 146: 13. Jh.

123 S. oben bei Anm. 36f.

124 Stammheim Missale, um 1160 in Hildesheim entstanden, jetzt The J. Paul Getty Museum, o. Sign., fol. 10v: Abb. bei Saurma-Jeltsch, Lieselotte E.: Die Miniaturen im „Liber Scivias“ der Hildegard von Bingen. Die Wucht der Vision und die Ordnung der Bilder. Wiesbaden 1998, S. 90 Abb. 49, vgl. 89. - Zweite Vision der Hildegard (gest. 1179) im „Buch der Göttlichen Operationen“ (Lucca, Biblioteca governativa, Ms 1942, fol. 6r): Kosmos bzw. Mensch in den Armen der feurigen Schöpferkraft, um 1230: Clausberg, Karl: Scheibe, Rad, Zifferblatt. Grenzübergänge zwischen Weltkarten und Weltbildern. In: Kugler (Hg.), Ein Weltbild vor Columbus (wie Anm. 96), S. 260-313. Vgl. ebd. auch Abb. aus Bern, Burgerbibliothek, Ms. 120, fol. 140r, die „Mappamundi als Wassergefäß mit Gebäudetapete" in einer Petrus de Ebulo-Hs. (Vision der Sapientia continens omnia), von ca. 1195. Kugler (Hg.), Die Ebstorfer Weltkarte II (wie Anm. 37), S. 19 bildet ferner die Machina mundi aus einer der Münchener Hs. des Thomas von Chantimpré (Clm lat. 2655, fol. 105r), Liber de natura rerum (vollendet um 1241) ab. - Vgl. auch Englisch, Ordo orbis terrae (wie Anm. 23), S. 25, 27, 215. - Ferner Wolf, Armin: Ikonologie der Ebstorfer Weltkarte und politische Situation des Jahres 1239. Zum Weltbild des Gervasius von Tilbury am welfischen Hofe, in: Kugler (Hg.), Ein Weltbild vor Columbus (wie Anm. 96), S. 54-116, hier 100f. 


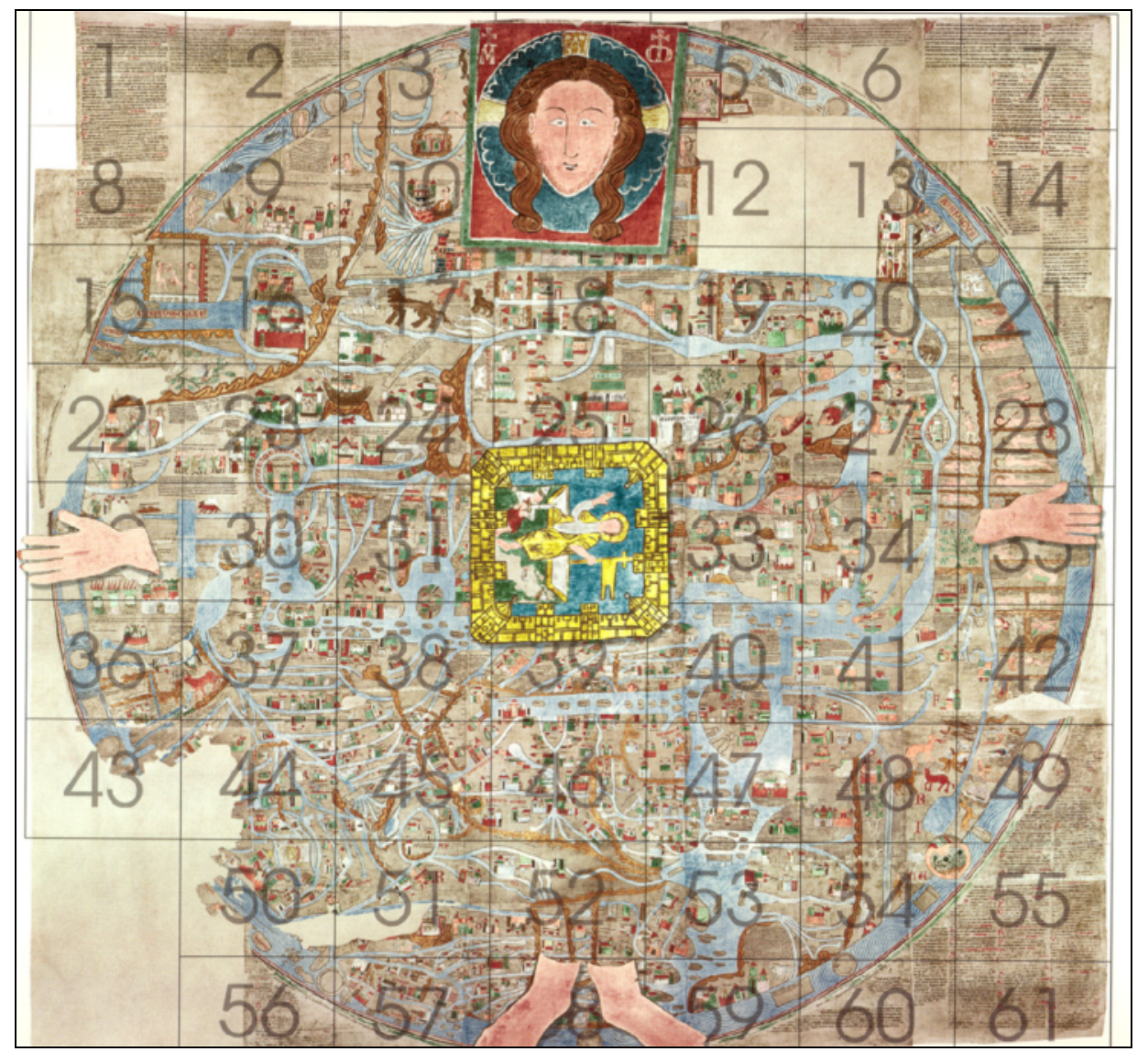

Abbildung 20

Ebstorfer Weltkarte um 1300 n. Chr., Christusbild (Repro nach Kugler, Hartmut [Hg.]: Die Ebstorfer Weltkarte. Kommentierte Neuausgabe in zwei Bänden. Bd. I: Atlas, Bd. II: Untersuchungen und Kommentar. Berlin 2007, Bd. I, S. 17)

Christi bis zu den Schultern sichtbar und von Engeln umgeben sein; am unteren, westlichen Bildrand dachte sich Hugo die Füße, während Christus rechts und links mit Armen und Händen das ganze Gebilde halte. ${ }^{125}$ Eng verwandt mit der Londoner

${ }^{125} \mathrm{Zu}$ Hugos Schrift(en) über die Arche als Abbild der menschlichen Seele, des gesamten Kosmos und der Heilsgeschichte (Migne PL 176, Sp. 681-794) vgl. Ehlers, Joachim: Hugo von St. Viktor. Studien zum Geschichtsdenken und zur Geschichtsschreibung des 12. Jahrhunderts. (Frankfurter Historische Abhandlungen, Bd. 7.) Wiesbaden 1973, S. 120 135; Ders., Arca significat ecclesiam. Ein theologisches Weltbild aus der ersten Hälfte des 12. Jahrhunderts, in: Frühmittelalterliche Studien 6, 1972, S. 173-187. Dieser mußte sich 
Psalter- und der Ebstorfer Weltkarte sind vor allem die Miniaturen des deus geometra, also Gottes als Schöpfer mit dem Zirkel, die in den Handschriften der Bible moralisée seit etwa 1220 begegnen (Abb. 21). ${ }^{126}$

Indessen geht es bei den Karten nicht nur um Weltschöpfung und Herrschaft Gottes. Den Kartographen kam es darauf an, die Vielfalt der Welt und ihre Geschichte bis zum Endgericht darzustellen, selbst wenn nur das Format einer Buchseite zur Verfügung stand. ${ }^{127}$ Einen Schlüssel zum historischen Verständnis der Londoner, Hereforder und Ebstorfer Karten bietet vielleicht ein Detail, das auf allen drei begegnet: Eine Galerie von Monstren. ${ }^{128}$ Diese menschlichen Mißgestalten oder halbmenschlichen, halbtierischen Phantasiewesen sind hier erstmals in Serie auf Karten über-

noch auf die Edition von „De arca Noe morali“ und „De arca Noe mystica“ in: Migne PL 176, Sp. 617-680 bzw. 681-704, stützen. Jetzt: Hvgonis de Sancto Victore De archa Noe. Libellvs de formatione arche. Cura et studio Patricii Sicard. (Corpus Christianorum. Continuatio Mediaevalis, T. CLXXVI.) Turnhout 2001.

${ }^{126}$ Vgl. Haussherr, Reiner: Art. Bible moralisée. In: Lexikon des Mittelalters II.1 Zürich/ München 1981, Sp. 108f.; Ders., Über die Auswahl des Bibeltextes in der Bible moralisée. In: Zeitschrift für Kunstgeschichte 1988, S. 126-146; Lowden, John: The Making of the Bibles moralisées. 2 vols., University Park (Pennsylvania) 2000. Vor allem Oxford, Bodleian Library, Ms. 270b, fol. 1v: Paris, um 1235/45, Abb. bei Edson/Savage-Smith/Von den Brincken, Der mittelalterliche Kosmos (wie Anm. 19) S. 8 Abb. 1; auch Borgolte, Christen, Juden, Muselmanen (wie Anm. 6), S. 41: Der thronende Schöpfer, der mit dem Zirkel den Globus umfährt. - Gott (mit dem Nimbus Christi), der sich mit dem Zirkel über den Kosmos beugt, in der Handschrift Wien, Österreichische Nationalbibliothek, Cod. 2554, fol. 1v, aus Paris, um 1220/1230, z. B. bei Englisch, Ordo orbis terrae (wie Anm. 23), S. 14 Abb. 1. - Vgl. Ohly, Friedrich: Deus Geometra. Skizzen zur Geschichte einer Vorstellung von Gott. In: Kamp, Norbert/Wollasch, Joachim (Hg.), Tradition als historische Kraft. Interdisziplinäre Forschungen zur Geschichte des früheren Mittelalters. Berlin/New York 1982, S. 1-42 (mit s/w-Abb. aus der Wiener Hs., Tafel 1). Ohly zitiert S. 6f. aus dem Gedicht des persischen Epikers Nizami („Chosrou und Schirin“) von 1180/81, nach dem Gott mit Hilfe von Punkten, Strichen und Buchstaben die Welt geometriert, und fügt als Kommentar an, dies habe im Westen keine Entsprechung. Ohly wirft die Frage auf, ob Nizamis Konzept einer geometrischen Weltentstehung im Islam alleinstehe (S. 8).

127 S. Anm. 93

128 Als Zeichen für ,eine Auseinandersetzung mit dem Fremden, in der das Fremde dazu diente, die Grenze des Eigenen zu bestimmen“, deutet die Monstren am Kartenrand (nicht nur in den „Galerien“) Marina Münkler, Monstra und mappae mundi: die monströsen Völker des Erdrands auf mittelalterlichen Weltkarten. In: Glauser/Kiening (Hg.), Text Bild - Karte (wie Anm. 15), S. 149-173, Zitat 173; Dies., Experiencing Strangeness: Monstrous Peoples on the Edge of the Earth as Depicted on Medieval Mappae Mundi. In: Medieval History Journal 5/2 (2002), S. 195-222. Vgl. auch die folgende Anm. 


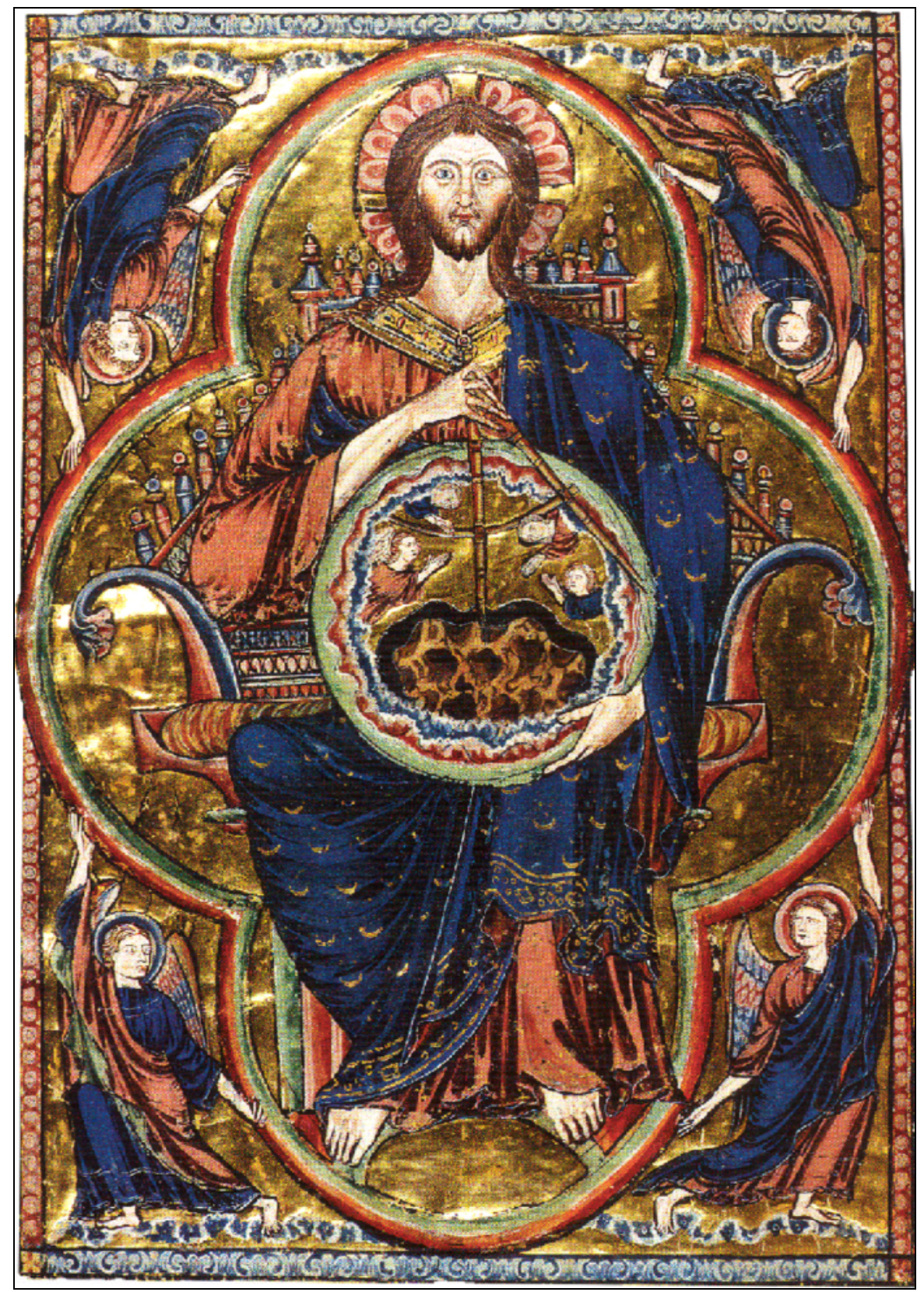

Abbildung 21

Bible moralisée aus Oxford um 1235/45, Oxford, Bodleian Library, Ms 270b, fol. 1v. Paris: Thronender Deus Geometra (Repro nach Edson, Evelyn/Savage-Smith, Emilie/Von den Brincken, Anna-Dorothee: Der mittelalterliche Kosmos. Karten der christlichen und islamischen Welt. Darmstadt 2005, S. 8 Abb. 1)

Christliche und muslimische Repräsentationen der Welt | 133 
liefert, ${ }^{129}$ auch wenn Hugo von St. Viktor eine solche schon ein Jahrhundert früher gesehen und beschrieben zu haben scheint (Abb. 15). ${ }^{130}$ Die Londoner und die Ebs-

${ }^{129}$ Edson/Savage-Smith/Von den Brincken, Der mittelalterliche Kosmos (wie Anm. 19), S. 67; Von den Brincken, Fines Terrae (wie Anm. 17), S. 89 (zur Londoner Psalterkarte); Dies., Die Ebstorfer Weltkarte (wie Anm. 96), S. 143 bzw. 429 (in Bezug auf alle drei Karten). - Zu Monstren allgemein: Block Friedman, John: The Monstrous Races in Medieval Art and Thought. Cambridge, Mass./London 1981; Wittkower, Rudolf: Marvels of the East. A Study in the History of Monsters. In: Journal of the Warburg and Courtauld Institutes 5, 1942, S. 159-197; Flint, Monsters and the Antipodes (wie Anm. 27); Münkler, Erfahrung des Fremden (wie Anm. 96), S. 206-221; Münkler, Marina/Röcke, Werner: Der ordo-Gedanke und die Hermeneutik der Fremde im Mittelalter. Die Auseinandersetzung mit den monströsen Völkern des Erdrandes. In: Herfried Münkler (Hg.), Die Herausforderung durch das Fremde. (Interdisziplinäre Arbeitsgruppen. Forschungsberichte. Hrsg. v. der Berlin-Brandenburgischen Akademie der Wissenschaften, Bd. 5.) Berlin 1998, S. 701-767; Münkler, Marina: Die monstra in Konrads von Megenberg Buch der Natur. In: Märtl, Claudia/Drossbach, Gisela/Kintzinger, Martin (Hg.), Konrad von Megenberg (1309-1374) und sein Werk. Das Wissen der Zeit. (Zeitschrift für Bayerische Landesgeschichte, Beiheft 31. Reihe B.) München 2006, S. 209-250; vgl. Anm. 27 und 128.

${ }^{130}$ Gautier Dalché, La „Descriptio Mappae Mundi“ de Hugues de Saint-Victor (wie Anm. 32), S. 147f. cap. XV: De monstris Ethiopie. (...) Hic igitur fluuius magna et mira monstra in Ethiopia gignit. Sunt enim illic homines, si tamen homines dicendi sunt, qui nunquam igne utuntur. Alii carent auribus, alii naribus, alii ore, et ideo calamo pascuntur. Alii linguis carentes signis loquuntur. Alii sunt bicipites, duo capita in uno corpore habentes, alii quatuor oculos in uno capite, quidam etiam sine capite in pectore oculos habentes. Sunt ibi serpentes et scorpiones multi generis et diuerse figure. Est ibi serpens quidam, prester appellatus, alas habens et caput cornutum et barbatum quasi capra, habens caudam multis nodis et flexuris tortuosam. Ibi habitant aspides et cerastes, quatuor cornua habentes, et iaculus serpens uolans. Hec omnia sunt in Ethiopia inter Nilum et australem occeanum. Zur Datierung ebd., S. 57. - Ebd., S. 81-85 (mit vereinfachter Karte 83), wird die Münchener Isidorkarte CLM 10058, fol. 154v, mit der Beschreibung Hugos in Verbindung gebracht (vgl. Von den Brincken, Fines Terrae [wie Anm. 17], S. 51; Chekin, Northern Eurasia in Medieval Cartography [wie Anm. 18], S. 132-134 X.4), doch sind hier zwischen Nil und Ozean im Süden nur Tiere (serpentes, prester, coluber mire longitudinis) eingezeichnet, keine Monster (ablehnend zur Ableitung der Karte von Hugo: Englisch, Ordo orbis terrae [wie Anm. 23], S. 90f.). Die Karte, die die Stadt Tyrus in den Mittelpunkt rückt, ähnelt im übrigen sehr der Londoner Psalterkarte, entbehrt aber des Gottesbildes, vgl. Abb. bei Chekin S. 450. - Vgl. zur Londoner Psalterkarte oben Anm. 113. Auch auf der Versoseite erscheinen im „Inventar“ von Afrika In Ethiopia ulter(iore) monstra, s. Von den Brincken, Fines Terrae (wie Anm. 17), S. 88, vgl. 85. Zur Monstrengalerie auf der Ebstorfer Karte vgl. die Abb. bei Kugler (Hg.), Die Ebstorfer Weltkarte I (wie Anm. 37), S. 85 Atlasbild 28. Zu den Monstren auf der Hereford-Karte s. Abb. bei Westrem, The Hereford Map (wie Anm. 18), Section 11. 
torfer Karten stimmen in Auswahl und Reihung der Gestalten mit Zeichnungen der „Mirabilia mundi“ überein, die eine französische Handschrift von etwa 1277 überliefert. ${ }^{131}$ In der Anordnung der Monstren im Süden (auch jenseits des Nils) hat man einen Niederschlag der Vorstellung vom vierten Kontinent südlich der Ökumene gesehen; dort hatte ja zum Beispiel auch Beatus von Liébana die Monstren angesiedelt (Abb. 13). ${ }^{132}$

Wenn die Monstrengalerien andererseits ,als Abschluss der bewohnten Welt" gegenüber einer terra incognita zu deuten sind, wie Anna-Dorothee von den Brincken überzeugend dargetan hat ${ }^{133}$, dann liegt es nahe, in ihnen eine Reaktion auf die Mongoleneinfälle nach Europa seit ca. $1220^{134}$ und die darauf folgenden Erkundungsund Missionsreisen der Westeuropäer nach Ostasien seit $1245 \mathrm{zu}$ sehen ${ }^{135}$. Dieser Schluss wurde bisher nicht gezogen, weil die Tataren sonst gern mit den Gog und Magog identifiziert wurden, die nach biblischer Tradition von Norden her die Chris-

${ }^{131}$ Willing, Antje: Orbis apertus. Zur Quellenkritik mittelalterlicher Kartographie. In: Archiv für Kulturgeschichte 86, 2004, S. 283-314. Enge Übereinstimmungen mit den Mirabilia weisen demnach auch das Cornwall- und das Aslake-Fragment auf (vgl. oben Anm. 116). Vgl. Kugler (Hg.), Die Ebstorfer Weltkarte II (wie Anm. 37), S. $37 \mathrm{f}$.

132 Von den Brincken, Fines Terrae (wie Anm. 17), S. 89, vgl. 85; Edson/Savage-Smith/ Von den Brincken, Der mittelalterliche Kosmos (wie Anm. 19), S. 67. Vgl. oben bei Anm. 102.

133 Edson/Savage-Smith/Von den Brincken, Der mittelalterliche Kosmos (wie Anm. 19), S. 67 (zur Autorschaft Von den Brinckens s. ebd., S. 4).

134 Borgolte, Michael: Europa entdeckt seine Vielfalt 1050-1250. (Handbuch der Geschichte Europas, Bd. 3.) Stuttgart 2002, S. 175; Ziegler, Gudrun/Hogh, Alexander (Hg.): Die Mongolen. Im Reich des Dschinghis Khan. Darmstadt 2005, S. 29 f.

135 Ziegler/Hogh (Hg.), Die Mongolen (wie Anm. 134), S. 95-113; Hamilton, Die christliche Welt des Mittelalters (wie Anm. 9), S. 260-270; Vauchez, André: Christen und Nichtchristen. In: Ders. (Hg.), Machtfülle des Papsttums (1054-1274). (Die Geschichte des Christentums, Bd. 5.) Freiburg/Basel/Wien 1994, S. 754-795, hier 791-794. - Mit der oben vorgeschlagenen Deutung sollen die erhaltenen Karten und -fragmente aus dem 13./14. Jahrhundert nicht verabsolutiert werden. Wenn man einbeziehen wollte, dass schon Hugo von St. Viktor (gest. 1141) eine solche Karte gesehen hat (oben bei Anm. 130), würde die Interpretation kaum zu modifizieren sein. Hugos Schrift ist jedenfalls nach Beginn der Kreuzzugszeit zu datieren, mit der die Auseinandersetzung der Lateiner mit dem Fremden (Orient) nach Jahrhunderten der weitgehenden europäischen Selbstreferentialität wieder eingesetzt hat. Eine Figur Gottes über dem Weltrund erwähnt Hugo in seiner „Descriptio“ übrigens nicht, Jerusalem ist nicht markant hervorgehoben, vgl. Gautier Dalché, La „Descriptio Mappae Mundi“ de Hugues de Saint-Victor (wie Anm. 32), S. $142 \mathrm{f} ., 177$. 
tenheit bedrohen sollten. ${ }^{136}$ Kein Geringerer als Friedrich II. hat aber mit dieser Vorstellung gebrochen und im Juli 1241 an den englischen König Heinrich III. geschrieben, schon vor langer Zeit sei „,von den entlegensten südlichen Ländern der Erde ein Volk barbarischer Abkunft und Lebensweise, dessen Ursprung und erste Wohnsitze Wir nicht kennen und das man Tataren nennt, ausgezogen, nachdem es lange unter einer brennenden Sonne gelebt und sich dann nach Norden gewendet" habe. ${ }^{137}$ Der Staufer suchte den Ursprung der Mongolen im Tartarus, in den sie die Christenheit auch wieder hinabstürzen müsse. ${ }^{138}$ Zwar werde das „mächtige, kaiserliche Europa“ von den „Tartaren“ mit Unterstützung Satans bedroht, doch fürchteten ,sogar feindliche Dämonen“ Deutschland, Frankreich und die anderen Länder „,unter dem westlichen Himmel“ und „unter dem Banner des lebenspendenden Kreuzes““ ${ }^{139}$ Mit seiner Lokalisierung der „Tartaren“ stieß der Kaiser auf Widerspruch bei dem gelehrten Chronisten Matthaeus Parisiensis, ${ }^{140}$ doch ging die Suche nach der Herkunft der Mongolen weiter. ${ }^{141}$ Ein Schüler des Matthaeus ließ sich von der Frage offenbar zu

${ }^{136}$ Vgl. Von den Brincken, Ebstorfer Weltkarte (wie Anm. 96), S. 139 bzw. 426. Vgl. oben Anm. 97.

137 Matthæi Parisiensis, monachi Sancti Albani, Chronica Majora. Ed. by Henry Richards Luard. Vol. IV. (Rerum Britannicarum Medii Aevi Scriptores, [57].) London 1877, S. 112: Egressa enim dudum ex ultimis mundi finibus de regione Australi, qua diu sole sub torrida zona tosta latuerat, quce postea versus partes Boreales occupatis violenter regionibus diu manens ut brucus multiplicatur, gens barbarce nationis et vitce, quo nescimus a loco vel origine, Tartari nuncupata (...). Übers. nach Heinisch, Klaus J. (Hg.): Kaiser Friedrich II. in Briefen seiner Zeit. Darmstadt 1978, S. 513, der aber australis mit „südöstlich““ übersetzt.

${ }^{138}$ Friedrich befragte auch Michael Scotus, wo die Hölle sei, wo das Fegefeuer und das himmlische Paradies? Auf eine Karte in seinem „Liber introductorius“ platzierte der Hofgelehrte des Staufers den locus inferni ,im Buch der Erde“: „Dort unten liege ein dunkles Gehäuse“, schrieb Michael, ,rund wie ein Backofen, umgeben von Felsen und Gebirg, durch einen einzigen Eingang erreichbar, aber mit Öffnungen nach Sizilien, Indien und irgendwo im hohen Norden, aus denen Schwefel, Rauch und Flammen hervorträten und das Wehklagen der verdammten Seelen nach oben dringe": Reichert, Folker: Geographie und Weltbild am Hofe Friedrichs II.. In: Deutsches Archiv für Erforschung des Mittelalters 51, 1995, S. 433-491, hier 455, mit Abb.1: München, Bayerische Staatsbibliothek, CLM 10268, fol. 45ra.

139 Matthæi Parisiensis Chronica Majora IV (wie Anm. 137), S. 113, 118f.; Heinisch (Hg.), Kaiser Friedrich II. in Briefen (wie Anm. 137), S. 513, $518 f$.

140 Matthæi Parisiensis Chronica Majora IV (wie Anm. 137), S. 119f.; Heinisch (Hg.), Kaiser Friedrich II. in Briefen (wie Anm. 137), S. 520.

141 Vgl. auch Reichert, Geographie und Weltbild am Hofe Friedrichs II. (wie Anm. 138), S. 475f.: ,Die jüngste interpolierte Fassung der Historia de preliis $\left(\mathrm{I}^{3}\right)$ enthält einen Ein- 
einer der sehr seltenen Klimatenkarten des Westens inspirieren, bei der er sich an islamischem Vorbild orientierte (vor 1258) (Abb. 22). ${ }^{142}$ Auf der nördlichen Hemisphäre hob er im vierten Klima Jerusalem hervor, wo sich sonst Arabien befindet, ${ }^{143}$ im Südwesten trug er monstruosi homines ein. ${ }^{144}$ Im Mittelpunkt von Ost und West, Nord und Süd, hart an der Ozeangrenze zur unbesiedelten südlichen Erdkugel vermerkte er Aren ciuitas. Diese Stadt Aren oder Arym, ursprünglich indischer Herkunft, galt nach arabischer Sage als Zufluchtsort der Dämonen und Thron des Iblīs, des Teufels, ${ }^{145}$ im Westen hatte sie zuerst der zum Christentum bekehrte Jude Petrus

schub, der die von Alexander dem Großen eingeschlossenen unreinen Völker, an ihrer Spitze Gog und Magog, als Tataren identifiziert. Sie entstand vor 1236 (...). Ein fingierter Brief an den kaiserlichen Hofastrologen seit 1239, Magister Theodor aus Antiochia, bezeichnet ebenfalls Gog und Magog als Tataren; seine Entstehung in der Umgebung Friedrichs II. ist allerdings keineswegs gesichert.“

${ }^{142}$ Von den Brincken, Die Klimatenkarte in der Chronik des Johann von Wallingford (wie Anm. 30); Edson/Savage-Smith/Von den Brincken, Der mittelalterliche Kosmos (wie Anm. 19), S. 64f.; Von den Brincken, Fines Terrae (wie Anm. 17), S. 109-112; Chekin, Northern Eurasia in Medieval Cartography (wie Anm. 18), S. 202f. XV.1: London, British Library, Coll. Julius D. VII, fol. 46r, Abb. 495. - Matthæi Parisiensis Chronica Majora IV (wie Anm. 137), 120: Et cum sint in totius mundi capacitate septem climata, videlicet Indorum, Ethiopum vel Maurorum, Egiptiorum, Jerosolitanorum, Gracorum, Romanorum, et Francorum, nec sint tam remoti in tota nostra habitabili, quod mercatores navigando non rimentur, unde poeta Oratius, ,Impiger extremos curris mercator ad Indos, 'ubi tot et tales hactenus latuerunt? Vgl. dazu die Beischriften der Wallingford-Karte, nach Von den Brincken, Fines Terrae 111: Clima Indorum quod est ultimum versus austrum; clima Ethiopum sive Maurorum; clima Egiptiorum; clima Jerosolimitarum, quod est medium septem climatum; clima Grecorum; clima Romanorum; clima Francorum.

143 S. oben bei Anm. 43 und bei Anm. 112. - Jerusalem ist also gleichzeitig Mittelpunkt der Ökumene.

${ }^{144}$ Und zwar im zweiten Klima, s. Von den Brincken, Fines Terrae (wie Anm. 17), S. 111.

145 Miller, Mappae Mundi 3 (wie Anm. 109), S. 127; „Aryn mit grossem Schloss ist nach arabischer Sage Zufluchtsort der Dämonen und Thron des Iblys. Dieser Ort ist bei den Arabern schon im 9. Jahrhundert nachweisbar; auf einer persischen Karte des 12. Jahrhunderts sei er als Mittelpunkt der Erde zu finden (...), im Abendland wird er erst im 13. Jahrhundert öfters genannt“; hinduistischer Ursprung nach Edson/Savage-Smith/Von den Brincken, Der mittelalterliche Kosmos (wie Anm. 19), S. 47. - Vgl. ferner Miller, Konrad (Hg.): Mappae Arabicae. Arabische Welt- und Länderkarten, Bd. 5: Weltkarten. Stuttgart 1931, S. 133. - Die Stadt wird nicht erwähnt bei Wensinck, A. J./Gardet, L.: Art. Iblīs. In: The Encyclopaedia of Islam. New Edition, Vol. III. Leiden/London 1971, S. 668f., und auch nicht bei MacDonald, D. B./Massé, H.: Art. Djinn. In: ebd., Vol. II. Leiden/London 1965, S. 546-548. Neue Forschungen der Islamwissenschaftler wären hier erwünscht (s. auch unten Anm. 147). - Man beachte, dass Aren auf der Wallingford- 


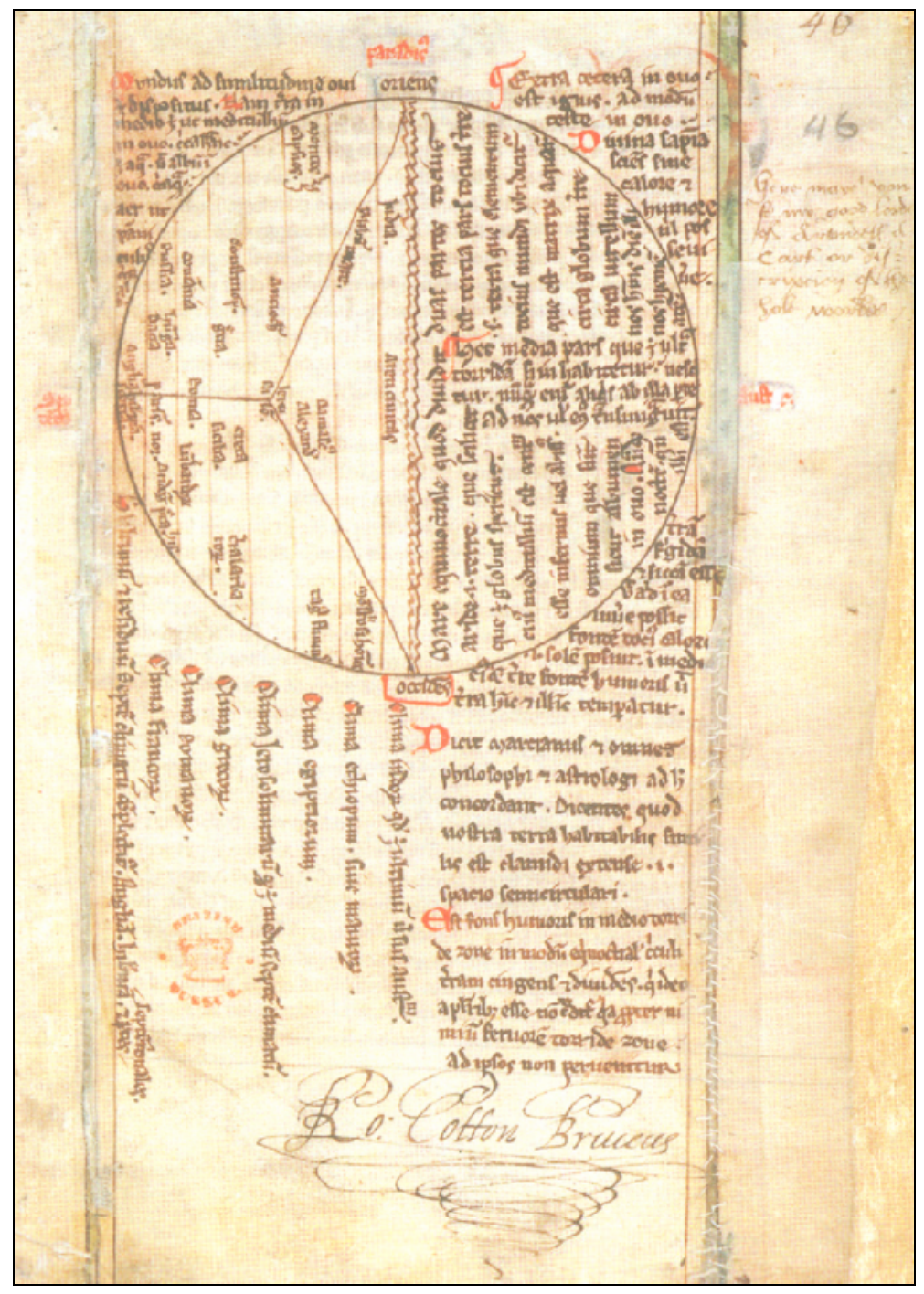

Abbildung 22

Wallingford-Karte, vor 1258, London, British Library, Cotton MSS Julius D.VII, fol. 46r (Rerpo nach Terrarum Orbis. Histoire des représentations de l'espace: textes, images. History of the Representations of Space in Text and Image. Collection dirigée par General Editor of the Series Patrick Gautier Dalché. Vol. 4: Chekin, Leonid S.: Northern Eurasia in Medieval Cartography. Inventory, Text, Translation, and Commentary. Turnhout 2006; S. 495 XV.1)

Karte nicht eigentlich das Zentrum, sondern am Übergang von Ökumene zu Antökumene eine Randposition der Welt bildet. Als Mittelpunkt der bewohnten Welt ist Jerusalem eindeutig, auch durch die Verbindungslinien zu Oriens und Occidens, hervorgehoben. 
Alfonsi an entsprechender Stelle in seiner Karte verzeichnet, ${ }^{146}$ und später sollte sie noch wiederholt bei anderen Gelehrten der lateinischen Welt erscheinen. ${ }^{147}$ Die Nachbarschaft der Stadt Aren und der monströsen Menschen auf der Karte kommt den Darlegungen Friedrichs II. über die Mongolen sehr nahe. Wollte der Kartograph also für die Herkunft der „Tartaren“ den islamischen Dämonensitz im Süden der bewohnten Welt zu Hilfe nehmen?

Schon seit der antiken Ethnographie wurden fremde Völker als monstra bezeichnet und beschrieben und am Rand der Ökumene angesiedelt. ${ }^{148}$ Trotzdem will ich nicht behaupten, die Monstrengalerien seien geradezu Repräsentationen der Mongolen,

${ }^{146}$ Edson/Savage-Smith/Von den Brincken, Der mittelalterliche Kosmos (wie Anm. 19), S. 47 mit Abb. 3 (nach franz. Hs. des frühen 14. Jh.); Von den Brincken, Fines Terrae (wie Anm. 17), S. 76f. mit Abb. 25: Paris, Bibliothèque Nationale, Ms. Lat. 10722, fol. 77r; Chekin, Northern Eurasia in Medieval Cartography (wie Anm. 18), S. 201. Der „Dialogus contra Iudaeos" des Petrus Alfonsi, dem die Karte beigefügt ist, wird auf ca. $1110 \mathrm{n}$. Chr. datiert, zuletzt Tischler, Matthias M.: Der iberische Grenzraum. Drei frühe Entwürfe zum Islam aus Exegese und Theologie. In: Borgolte/Schiel/Seitz/Schneidmüller (Hg.), Mittelalter im Labor (wie Anm. 3), S. 95-116, hier 97.

147 Zur Bestimmung der Längen- und Breitengrade wird die Stadt genannt und verwandt bei Roger Bacon (gest. um 1292): The 'Opus Majus' of Roger Bacon. Ed. by John Henry Bridges. Vol. I. Oxford 1897, S. 300: Et similiter ducatur una linea ab Arym civitate in medio mundi usque ad polum arcticum, et ab ea ducatur linea recta usque civitatem, quae notabit distantiam civitatis a medio mundi. Ebd. S. 310: Meridianum vero latus Indiae descendit a tropico Capricorni, et secat aequinoctialem circulum apud montem Malcum et regiones ei conterminas et transit per Syenem, quae nunc Arym vocatur (...). Et ideo Arym non distat ab oriente per nonaginta gradus tantum. Sed mathematici ponunt eam in medio habitationis sub aequinoctiali distans aequaliter ab occidente et oriente, septentrione et meridie. Nec est contradictio, quia mathematici loquuntur de habitatione eis nota secundum veras comprehensiones longitudinum et latitudinum regionem: et hoc non est tantum quantum notum est per experientiam itineris et navigationis apud Plinium et alios naturales. - Sodann Pierre d'Ailly: Ymago Mundi de Pierre d'Ailly. Cardinal de Cambrai et Chancelier de l'Université de Paris (1350-1420). Ed. Edmond Buron, T. II. Paris 1930, S. 524: De locis autem extra climata habitabilibus sciendum est, quod ante climata versus meridiem habitatio est magna. Nam etiam secundum quosdam Astrologos vsque ad equinoctialem habitatur. Et sub eo est Arym ciuitas eque distans ab oriente et occidente septentrione et meridie ymmo secundum Hali vltra equinoctialem per tres gradus sunt ciuitates due. Vgl. auch die Karte ebd., T. I, S. 140f. - Vgl. Von den Brincken, Mappa mundi und Chronographia (wie Anm. 17), S. 136 bzw. 34. - Vgl. oben Anm. 145.

148 Münkler, Erfahrung des Fremden (wie Anm. 96), S. 214; Münkler/Röcke, Der ordoGedanke und die Hermeneutik der Fremde (wie Anm. 129); Münkler, Monstra und mappae mundi (wie Anm. 128). 
die explizit nirgends genannt werden. ${ }^{149}$ Wohl aber können sie die überwältigende Erfahrung des fremden Volkes widerspiegeln, das Europa in den Grundfesten erschütterte und neben den Christen auch den Muslimen als tödliche Gefahr erschienen war. ${ }^{150}$

Allerdings scheinen die Karten, die ja nicht vor 1260 entstanden sein dürften, schon einer späteren Stufe der Auseinandersetzung Rechnung zu tragen. Damals hatte zwar Großkhan Kublai erst begonnen, das mongolische Reich auf seine größte Ausdehnung zu führen, ${ }^{151}$ aber im Westen war die Expansionskraft der Teilstaaten gebrochen. Das Ilkhanat in Persien scheiterte bei dem Versuch, die Mamlūken aus Palästina zu vertreiben, und konsolidierte sich ebenso wie die Goldene Horde im osteuropäischen Russland. ${ }^{152}$ Umgekehrt hatten die Gesandtschaften des Papstes schon bis 1253 dazu geführt, dass sich die „Tartaren“ aus ,einem apokalyptischen Volk in ein Missionsvolk" verwandelten ${ }^{153}$ Innozenz IV. nahm sie in die Liste der Völker auf, denen das Wort Gottes verkündet werden sollte. ${ }^{154} \mathrm{Da}$ in christlicher Sicht niemand vom Heil ausgeschlossen werden kann, hatte bereits Hugo von St. Viktor argumentiert, jeder Mensch habe seiner Natur entsprechend seinen Platz im Haus Gottes, und zwar auch Heiden und Ungläubige, ,weil alles von ihr Geschaffene durch die göttliche Macht gehalten und regiert“ werde. ${ }^{155}$ Auch die monströsen Völker wurden als Missions-

${ }^{149}$ Von den Brincken, Ebstorfer Weltkarte (wie Anm. 96), S. 139 bzw. 426.

${ }^{150} \mathrm{Vgl}$. Borgolte, Europa entdeckt seine Vielfalt (wie Anm. 134), S. 230.

151 Ziegler/Hogh (Hg.), Die Mongolen (wie Anm. 134), S. 69-75, 108-113; Weiers, Michael: Geschichte der Mongolen. Stuttgart 2004, S. 137ff.

152 Ebd., S. 70-73; Jackson, Peter: The Mongols and Europe. In: The New Cambridge Medieval History, Vol. V: ca. 1198-1300. Ed. by David Abulafia. Cambridge 1999, S. 703719. - Krawulsky, Dorothea: Mongolen und Ilkhâne, Ideologie und Geschichte. 5 Studien. Beirut 1989, datiert S. 131f. die Gründung des iranischen Mongolenstaates mit der Niederlage gegen die Mamlūken bei Ain Dschalut 1260 (damit sei dem Mongolischen Imperium zum ersten Mal in seiner Geschichte eine Grenze gesetzt worden) bzw. mit der Anerkennung Hülägüs durch Großkhan Kublai 1264 (s. auch ebd., S. 21).

153 Münkler, Erfahrung des Fremden (wie Anm. 96), S. 73.

154 Ebd., S. 72.

155 Ehlers, Hugo von St. Viktor (wie Anm. 125), S. 121, unter Bezug auf Hugos (jetzt so genannte) Schrift „De archa Noe pro archa sapientie cvm archa ecclesie et archa matris gratie“, in: Hvgonis de Sancto Victore De archa Noe. Libellvs de formatione arche (wie Anm. 125), S. 1-117, hier 7f. c. I,2: Domus Dei totus est mundus, domus Dei Ecclesia catholica est, domus Dei etiam est quelibet fidelis anima. Sed aliter mundum inhabitat, aliter Ecclesiam, aliter unamquamque fidelem animam. In mundo est ut imperator in regno, in Ecclesia est ut paterfamilias in domo, in anima est ut sponsus in thalamo. Pagani et infideles quique in domo eius sunt (id est in regno), quia ipse omne quod condidit, per diuinitatis sue potentiam tenet et regit. Falsi fideles in domo eius sunt (id est in Ecclesia), 
völker betrachtet, ${ }^{156}$ wenngleich ihr Genus als menschliche Wesen nicht sicher erschien. ${ }^{157}$ So gesehen kann Christus als Erlöser auf dem Londoner Psalterbild die Ökumene einschließlich der Monstren umgreifen ${ }^{158}$ und sich seine Linke auf der Ebstorfer Weltkarte schützend über die Galerie legen. Terram palmo concludit „mit der flachen Hand schließt er die Erde ein“ - erläutert der Kartograph die Geste auf einer Beischrift (Abb. 23). ${ }^{159}$

Der Beitrag sollte zu Antworten auf die Frage führen, wie stark Religion die Kulturen des Mittelalters geprägt hat. Der durchgeführte Vergleich von Karten aus der monotheistischen Weltzone zwischen Island und Indus hat ergeben, dass wohl von christlichen, weniger aber von muslimischen Kulturen des Mittelalters die Rede sein

quia ipse omnibus quos ad fidem uocauit sacramentorum suorum participationem credit. Fideles uero in domo eius sunt, et ut uerius dicam ipsi domus eius sunt, quia eos per dilectionem inhabitans possidet et regit. Omnes in domo eius sumus per conditionem qua creauit nos; in domo eius sumus per fidem qua uocauit nos; in domo eius sumus per dilectionem qua iustifiauit nos. Si in domo Dei es per conditionem, et diabolus tecum es. Si in domo Dei es per fidem, et palea cum granis in arca est. Si autem in domo Dei fueris per caritatem, beatus es, quia non solum tu in domo Dei sed tu domus Dei esse cepisti, ut ipse tecum habitet in te qui fecit te.

156 Münkler, Erfahrung des Fremden (wie Anm. 96), S. 218; Münkler/Röcke, Der ordo-Gedanke und die Hermeneutik der Fremde (wie Anm. 129), S. 744f. - In ähnlicher Weise wie oben im Hinblick auf Monstrengalerien und Missionsgedanke argumentiert wird, hat dies bereits Block Friedman, The Monstrous Races in Medieval Art and Thought (wie Anm. 129), S. 59-86, bes. 82-86, im Hinblick auf die hundsköpfigen Monster (Cynocephali) in den Karten von Hereford und Ebstorf getan

157 Münkler, Erfahrung des Fremden (wie Anm. 96), S. 214f.

158 Von den Brincken, Fines Terrae (wie Anm. 17), S. 88f.

159 Kugler (Hg.), Die Ebstorfer Weltkarte I (wie Anm. 37), S. 98f. Atlasbild 35. Vgl. Woodward, Medieval Mappaemundi (wie Anm. 23), S. 334: "When the body of Christ is superimposed on the map of the earth in an all-embracing dying gesture, as in the Ebstorf map, the map itself becomes a clear symbol of the salvation of the world. Even the twentyfour monstrous races are embraced by the arms of Christ, although symbolically they are by his left hand at the very extremity of the world." - Kugler II S. 19-21, 66f. deutet das Christusbild (Haupt, Hände, Füße und Auferstehungsstätte) als „Andachtsbild“, auf das die Weltkarte den Betrachter verweisen solle. Daraus ergibt sich auch eine andere Deutung der Hand Christi über der Monstrengalerie: „Bei der Linken liest man die Worte: terram palmo concludit. Da die Hand über der menschenfeindlichen heißen Zone am afrikanischen Ozeanrand steht, läßt sich diese Aussage gut mit der Aufgabe der scientia verbinden, den Menschen zum Verzicht auf unzuträgliche Grenzüberschreitungen zu bewegen“ (S. 22). Die Beischrift spielt aber unverkennbar auf das Motiv des Schutzes für die ganze Welt an, wie dies sonst bei dem den Erdkreis umgreifenden Schöpfergott zum Ausdruck kommt. 


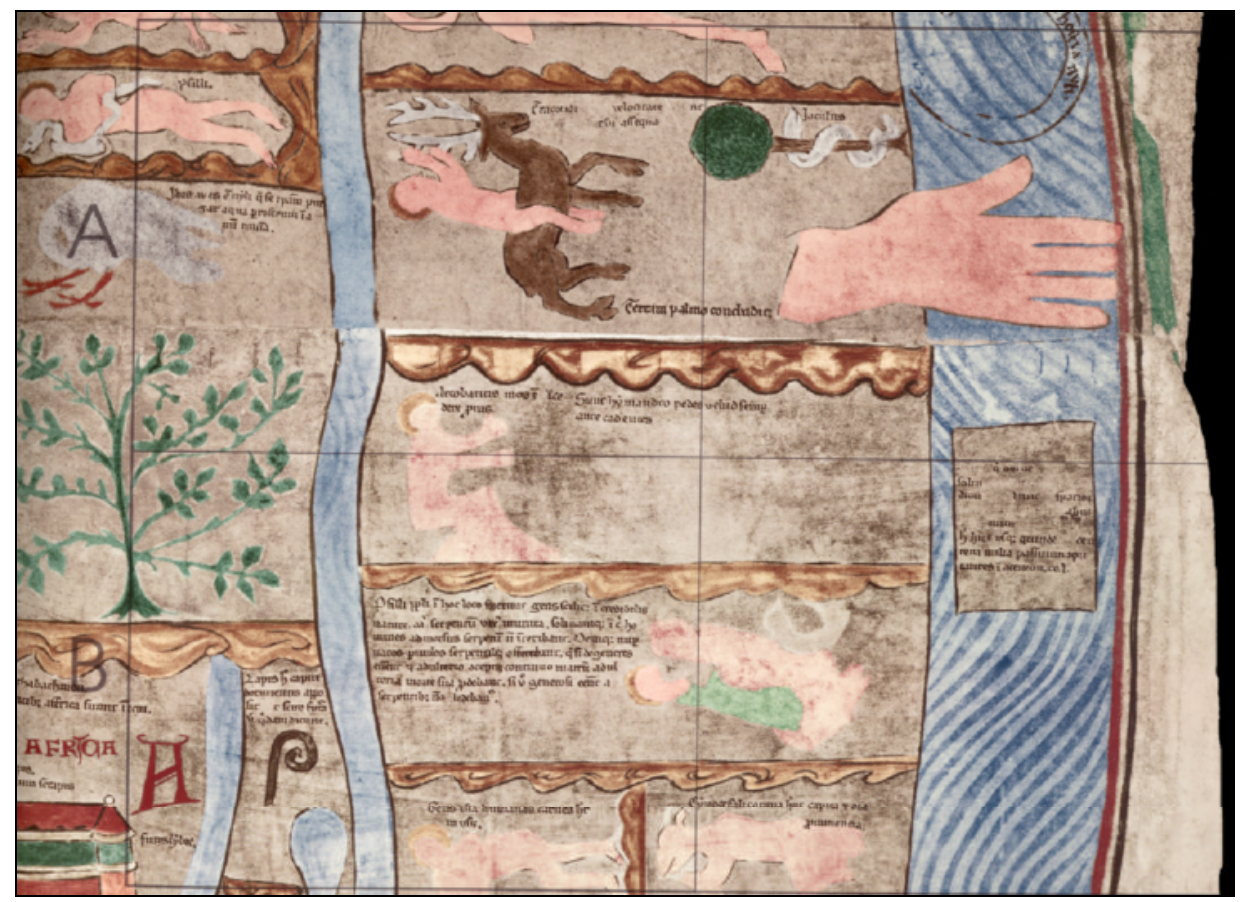

Abbildung 23

Ebstorfer Weltkarte um 1300, Ausschnitt mit der linken Hand des Erlösers über der Monstrengalerie (Repro nach Kugler, Hartmut [Hg.]: Die Ebstorfer Weltkarte. Kommentierte Neuausgabe in zwei Bänden. Bd. I: Untersuchungen und Kommentar. Berlin 2007, Bd. I, S. 99)

kann. Wo nämlich Christen die Welt auf Karten dargestellt haben, wurde diese, abgesehen vom Niederschlag heidnisch-antiker Werke, stets christlich oder jedenfalls biblisch repräsentiert. Dabei wurde die ganze Ökumene, ja sogar die „Gegenwelt“ der Monstren und mit ihnen die ganze Schöpfung einbezogen. Die Muslime traten das Erbe der antiken griechischen Naturwissenschaften an; sie isolierten diese aber als „fremde“ von den ,islamischen“ Wissenschaften, so dass zwei kartographische Traditionen entstanden. ${ }^{160}$ Um ihrer religiösen Praxis willen pflegten sie neben Mathematik und Astronomie auch die Geographie und fertigten Himmelskarten an, ihre Weltkarten in Atlaswerken traten religiös jedoch indifferent in Erscheinung. Nur die Devotion gegenüber Mekka scheint eine, allerdings sehr reiche und bis heute andauernde Produktion von Weltkarten hervorgebracht zu haben, die Gebete und Pilgerschaften nach der Ka'ba ermöglichen sollten. ${ }^{161}$

${ }^{160}$ Vgl. oben Anm. 48.

${ }^{161}$ Vgl. die aktuelle Karte der Wallfahrt nach Mekka (hağğ) in: Ruthven/Nanji, Historical Atlas of the Islamic World (wie Anm. 10), S. 140f. 
Wo die Christen dazu neigten, die ganze Welt in ihrer Einheit zu erfassen, tendierten die Muslime zur Beschränkung auf ihre weltweite Gemeinde, und dies trotz des gemeinsamen Kosmosdenkens in beiden Religionen. ${ }^{162}$ Auch die Serien ihrer Regionalkarten scheint über dar al-islam nicht hinausgegangen zu sein, wenn man von al-Idrīsī, einem Sonderfall christlichen Mäzenatentums, absieht. Zugespitzt gesagt, war die kartographische Weltrepräsentation der Christen expansiv, die der Muslime selbstbezüglich angelegt. Im einen Fall sind die fremden Völker Objekte der Verheißung, weil allen das Evangelium verkündet werden soll, im anderen sind sie als „Gebiet des Krieges“ (dar al-harb) zur Unterwerfung bestimmt. ${ }^{163}$

Was diese Befunde für die Erkenntnis der Geschichte überhaupt und für die künftige Forschung bedeuten können, ist hier nur anzusprechen. Ohne einer einfachen Linearität historischer „Entwicklung“ zu huldigen, fragt man sich, ob der Einbezug der ganzen Welt in die Religion bei den mittelalterlichen Christen, der im Missionsbefehl Jesu gründete, nicht als Ausgangspunkt der modernen Globalisierung verstanden werden muss. Andererseits scheint die Wissenschaftlichkeit der Araber im Mittelalter, die diese uns doch besonders nahebringt, in neuerer Zeit geradezu ein Hindernis für ihre Modernisierung dargestellt zu haben. Jedenfalls benötigten wohl nur die Christen mit ihrer vergleichsweise homogenen Kultur jene „Entzauberung der Welt", von der Max Weber sprach, oder die Erfindung des „Trennungsdenkens“ in der Moderne. ${ }^{164}$ Unverkennbar ist auch, dass die Dissoziation der Wissenschaften seit dem Kalifat des neunten Jahrhunderts zu allgemeineren Differenzerfahrungen der muslimischen Welt gehört, die im Christentum nur schwer vorstellbar wären. Man denke nur daran, dass muslimische Unterwerfung keineswegs zwingend zur Konversion der Christen und Juden geführt hat, sondern die Angehörigen der Schriftreligion unter muslimischen Herren jahrhundertelang geduldet werden konnten. ${ }^{165}$ Vielleicht wird die Neugier, die sich heute in westlichen Ländern auf den Islam richtet, nicht nur durch die täglichen Konflikte mit ethnischen oder religiösen Minderhei-

\footnotetext{
162 Vgl. oben bei Anm. 19.

163 Dabei darf natürlich nicht übersehen werden, dass die christliche Mission oft gewaltsam durchgesetzt wurde, während die Muslime auf Glaubenszwang verzichten sollten (s. a. unten bei Anm. 165).

${ }^{164}$ Vgl. Weber, Max: Wirtschaft und Gesellschaft. Grundriss einer verstehenden Soziologie. Fünfte, revidierte Auflage, besorgt von Johannes Winckelmann. Tübingen 1972, S. 308; zum „liberalen Trennungsdenken“ (E. R. Huber) s. Borgolte, Michael: Das soziale Ganze als Thema deutscher Mittelalterforschung vor und nach der Wende. In: Francia 22/1 (1995), S. 155-171, hier 161.

165 Vgl. Borgolte, Christen, Juden, Muselmanen (wie Anm. 6), S. 242-302.
} 
ten, sondern von der postmodernen Vorliebe für kulturelle Differenzen gespeist, ${ }^{166}$ die schon in der Geschichte der Muslime deutlicher zutagetreten als in dem auf Einheit und Ganzheit fixierten Christentum.

Viele neue Forschungsfragen drängen sich auf. So sind, wie ich glaube, die mittelalterlichen Berichte von christlichen und muslimischen Reisenden vergleichend neu $\mathrm{zu}$ untersuchen. ${ }^{167}$ Denn es muss doch einen Unterschied machen, ob die einen auf Pilgerfahrt gehen müssen und auf ein überragendes Ziel fixiert sind, während die anderen, übrigens nicht unangefochten, ${ }^{168}$ pilgern dürfen, dabei aber die freie Wahl zwischen verschiedenen Destinationen haben. Es musste sich auch auswirken, dass die einen unter fremdgläubiger Herrschaft eigentlich nicht leben durften, ${ }^{169}$ die anderen aber die Fremde gerade aus religiösen Gründen suchen sollten. Wie wirkten sich so verschiedenartige Dispositionen auf die Wahrnehmung unbekannter Völker und Länder aus? Berücksichtigt werden muss zweifellos auch, ob eine Reise, nicht nur eine Pilgerschaft, im Rahmen kirchlicher Strukturen, also einer hierarchischen Ordnung mit systematischer Raumerfassung unternommen wird, oder ob sie als Teil eines sich selbst organisierenden Netzwerkes aufzufassen ist. ${ }^{170}$

Ebenso eng wie bei den Reiseberichten bieten sich auch bei den Weltchroniken interkulturell-vergleichende Studien an. ${ }^{171}$ In Analogie zu den Karten ginge es dabei zuerst um die Repräsentation der Welt, hier in ihrer Geschichte, aber auch um die Frage der Integration des Abweichenden durch den jeweiligen Erzähler. ${ }^{172}$ Zwar

${ }^{166}$ Vgl. Borgolte, Michael: Mittelalterforschung und Postmoderne. Aspekte einer Herausforderung. In: Zeitschrift für Geschichtswissenschaft 43 (1995), S. 615-627; Ders., Kulturelle Einheit und religiöse Differenz (wie Anm. 14).

${ }^{167}$ Für dieses viel beackerte Forschungsfeld seien nur genannt: Reichert, Folker: Erfahrung der Welt. Reisen und Kulturbegegnung im späten Mittelalter. Stuttgart/Berlin/Köln 2001; Eickelman, Dale F./Piscatori, James (Eds.): Muslim Travellers. Pilgrimage, migration, and the religious imagination. London 1990; Block Friedman, John/Mossler Figg, Kristen (Eds.): Trade, Travel, and Exploration in the Middle Ages. An Encyclopedia. London 2001.

${ }^{168}$ Vgl. Herbers, Klaus: Jakobsweg. Geschichte und Kultur einer Pilgerfahrt. München 2006, S. 78-81.

169 Vgl. Borgolte, Europa entdeckt seine Vielfalt (wie Anm. 134), S. 261.

${ }^{170}$ Vgl. Böhme, Hartmut: Einführung. Netzwerke. Zur Theorie und Geschichte einer Konstruktion. In: Barkhoff, Jürgen/Böhme, Hartmut/Riou, Jeanne (Hg.), Netzwerke. Eine Kulturtechnik der Moderne. Köln/Weimar/Wien 2004, S. 17-36, bes. 32f.: „Heterarchie von Netzen".

171 Zum engen (auch überlieferungsgeschichtlichen) Zusammenhang von Weltkarte und Universalchronik vgl. Von den Brincken, Mappa mundi und Chronographia (wie Anm. 17).

${ }^{172}$ Vgl. zur Exklusion fremder Reiche, der Juden und Heiden aus seiner Chronik etwa Otto von Freising (1143/46), bes. im Kontext der Christianisierung des Römischen Reiches 
stehen solchen Untersuchungen Disproportionen der Editions- und Forschungslage entgegen, ${ }^{173}$ aber ein Vergleich der „Geschichte der Propheten und Könige“ von alTabarī (839-923) ${ }^{174}$ mit einem gleichzeitigen oder späteren Chronisten des lateinischen Mittelalters dürfte sich rasch als lohnend erweisen. Erst recht können die Mediävisten zu der oft wiederholten Behauptung der Iranisten Stellung nehmen, dass um 1300 im persischen Täbris ein vom Judentum konvertierter Muslim im Dienst des mongolischen Ilkhans die erste „echte“ Weltchronik verfasst habe. ${ }^{175}$ Dieses in der Tat eindrucksvolle Werk des Rašĩduddīn soll sich nämlich dadurch ausgezeichnet haben, dass es die Geschichte fremder Völker, der Inder und Chinesen, der türkischen Oguzen, der „Franken“ und der Juden, ohne diese abzuwerten der „eigenen“ Geschichte beigefügt habe. ${ }^{176}$ Allerdings hat die bisherige Forschung wohl überse-

seit Theodosius: „Noch freilich besteht der nichtchristliche Staat der ungläubigen Juden und Heiden; da aber unsere Glaubensgenossen alle bedeutenderen Staaten innehaben, während jene nicht nur vor Gott, sondern auch vor der Welt bedeutungslos sind, so lassen sich kaum irgendwelche von ihnen ausgeführte Taten finden, die der Erwähnung wert und der Nachwelt zu überliefern wären“ (Otto Bischof von Freising, Chronik oder die Geschichte der zwei Staaten. Übers. v. Adolf Schmidt, hrsg. v. Walther Lammers. [Ausgewählte Quellen zur deutschen Geschichte des Mittelalters. Freiherr vom Stein-Gedächtnisausgabe, Bd. XVI.], Darmstadt 1972, S. 375 Vorwort zum 5. Buch; vgl. ebd. S. 9, 71, 151, 397 [Mohammed], 499, 511 [Muslime]).

173 Zur muslimischen Geschichtsschreibung vgl.: Hirschler, Konrad: Art. Historical Writing. In: Encyclopedia of Islam and the Muslim World (wie Anm. 40), S. 306-309; Rosenthal, Franz: A History of Muslim Historiography. Leiden ${ }^{2}$ 1968; Lewis. Bernard/Holt, P. M. (Eds.), Historians of the Middle East. London 1962; Scott Meisami, Julie: Persian Historiography to the End of the Twelfth Century. Edinburgh 1999. Vgl. auch Morgan, D. O. (Ed.): Medieval Historical Writing in the Christian and Islamic Worlds. London 1982; Khalidi, Tarif: Arabic Historical Thought in the Classical Period. Cambridge 1994.

174 The History of al-Tabarī (Ta'rīkh al-rusul wa'l-mulūk), Vol. I. General Introduction and From the Creation to the Flood, translated and annotated by Franz Rosenthal. New York 1989. Sieben weitere Bände in englischer Übersetzung bis 1997.

175 Jahn, Karl: Die Erweiterung unseres Geschichtsbildes durch Rašīd al-Dīn. In: Anzeiger der Österreichischen Akademie der Wissenschaften. Philosophisch-Historische Klasse 107/15, 1970, S. 139-149; Ders., Rashīd al-Dīn as World Historian, in: Yádnáme-ye Jan Rypka. Collection of Articles and Tajik Literature. Prague 1967, S. 79-87; Boyle, John Andrew: Rashīd al-Dīn: The first World Historian. In: Iran. Journal of the British Institute of Persian Studies 9 (1971), S. 19-26; Rosenthal, A History of Muslim Historiography (wie Anm. 173), S. 7; Hirschler, Art. Historical Writing (wie Anm. 173), S. 308; Hoffmann, Birgitt:Waqf im mongolischen Iran. Rašīduddīns Sorge um Nachruhm und Seelenheil. (Freiburger Islamstudien, Bd. XX.) Stuttgart 2000, S. 53.

176 Die Teileditionen und Übersetzungen sind jetzt nachgewiesen bei Hoffmann, Waqf im mongolischen Iran (wie Anm. 175), S. 384f. Für die Geschichte der „Franken“, also der 
hen, dass Rašīduddīns Kompilation in ihrer Anlage dem Kartentyp der „Kishvars“ entspricht, in dem um Iran als Zentrum die gleichen Länder dargestellt wurden (Abb. 2) ${ }^{177}$ Der Mediävist darf in transdisziplinärer Absicht den Fachleuten die Frage stellen, ob sich Rašīduddīns vielgelobtes ${ }^{178}$ Werk so nicht doch im Kern als traditionell ethnozentrische Historiographie um die Mongolenherrschaft in Persien darstellt. ${ }^{179}$

lateinischen Christen des Westens, stützten sich der Autor oder seine Helfer auf die Papst- und Kaiserchronik des Martin von Troppau. Vgl. die deutsche Übersetzung durch Karl Jahn, Die Frankengeschichte des Rašīd ad-Dīn. Einleitung, vollständige Übersetzung, Kommentar und 58 Texttafeln. (Österreichische Akademie der Wissenschaften. Philosophisch-Historische Klasse. Denkschriften, 129. Bd. = Veröffentlichungen der iranischen Kommission, Bd. IV.) Wien 1977; vgl. Ders., Das christliche Abendland in der islamischen Geschichtsschreibung des Mittelalters. In: Anzeiger der Österreichischen Akademie der Wissenschaften. Philosophisch-Historische Klasse 113/1, 1976, S. 1-19; Von den Brincken, Anna-Dorothee: Zu Herkunft und Gestalt der Martins-Chroniken. In: Deutsches Archiv für Erforschung des Mittelalters 37, 1981, S. 694-735, hier bes. 695f., 730-735.

${ }^{177}$ S. oben bei Anm. 44. Das Schema hat zuerst der Universalgelehrte al-Bīrūnī (gest. 1048 in Ġazna, Afghanistan) gezeichnet und es folgendermaßen erläutert: „Diese Aufteilung hat nichts mit den natürlichen klimatischen Bedingungen zu tun und auch nichts mit astronomischen Erscheinungen. Es wurde vielmehr den Reichen folgend erstellt, die sich voneinander aus verschiedenen Gründen unterscheiden, und zwar verschiedenen Eigenheiten ihrer Völker und verschiedener Regeln ihrer Ethik und ihrer Gebräuche“, s. Karamustafa, Cosmographical Diagrams (wie Anm. 22), S. 77/80. Die Umzeichnung durch Karamustafa (80) zeigt in der Mitte „Fourth Kishvar: Iran“ und im Uhrzeigersinn oben beginnend: „First Kishvar: India; Second Kishvar: Arabia and Abyssinia; Third Kishvar: Egypt and Syria; Fifth Kishvar: Asia Minor and Land of Slavs; Sixth Kishvar: Land of Turks and Gog and Magog; Seventh Kishvar: China“" Zum Autor s. Kennedy, Edward St.: Art. alBīrūnī. In: Lexikon des Mittelalters II.2, Zürich/München 1981, S. 226f.

${ }^{178}$ Vgl. auch Morgan, David: Rašĩd al-Dīn and Gazan Khan. In: L'Iran face à la domination Mongole. Études réunies et présentées per Denise Aigle. Téhéran 1977, S. 179-188; Hoffmann, Waqf im mongolischen Iran (wie Anm. 175), S. 73f.

${ }^{179}$ Es wäre dann im europäischen Westen am ehesten mit der Weltchronik des Sigebert von Gembloux (gest. 1112) vergleichbar (Sigeberti Gemblacensis Chronographia, Ed. Ludowicus Conradus Bethmann, in: Monumenta Germaniae Historica, Scriptorvm Tomvs VI. Hannover 1844, S. 268-374), s. Von den Brincken, Anna-Dorothee: Contemporalitas Regnorum. Beoabachtungen zum Versuch des Sigebert von Gembloux, die Chronik des Hieronymus fortzusetzen. In: Berg, Dieter/Goetz, Hans-Werner (Hg.), Historiographia Mediaevalis. Studien zur Geschichtsschreibung und Quellenkunde des Mittelalters. Festschrift für Franz-Josef Schmale. Darmstadt 1988, S. 199-211. Während Sigebert bis zu neun Herrscherstränge bietet, stellt Paulinus Minorita aus Venedig in seiner "Chronographia Magna“" von 1331 sogar bis zu 26 Spalten nebeneinander (darunter Turkestan 
als die mongolischen Stammlande, China, Kumanien, das Reich der Ilkhane in Persien, Ägypten, Armenien, Zypern usw.), s. Von den Brincken, Zu Herkunft und Gestalt der Martins-Chroniken (wie Anm. 176), S. 729f. - Wenn man in Rašīduddīns Werk aber nur eine Kompilation verschiedener Völkerchroniken zu sehen hätte, wäre es sogar Sigeberts Chronik (von 381 bis 1105, als Fortsetzung der Chronik des Hieronymus konzipiert) mit ihrem heilsgeschichtlichen Sinn konzeptionell unterlegen, vgl. Von den Brincken, $\mathrm{Zu}$ Herkunft und Gestalt der Martins-Chroniken, S. 731. 
